Uma abordagem orientada a sistemas para otimização de escalonamento de processos em grades computacionais 
SERVIÇO DE PÓS-GRADUAÇÃO DO ICMC-USP

Data de Depósito:

Assinatura:

\title{
Uma abordagem orientada a sistemas para otimização de escalonamento de processos em grades computacionais
}

\author{
Paulo Henrique Ribeiro Gabriel
}

Orientador: Prof. Dr. Rodrigo Fernandes de Mello

Tese apresentada ao Instituto de Ciências Matemáticas e de Computação - ICMC-USP, como parte dos requisitos para obtenção do título de Doutor em Ciências - Ciências de Computação e Matemática Computacional. VERSÃO REVISADA 
Ficha catalográfica elaborada pela Biblioteca Prof. Achille Bassi e Seção Técnica de Informática, ICMC/USP, com os dados fornecidos pelo(a) autor(a)

\begin{tabular}{|c|c|}
\hline \multirow[t]{3}{*}{ G118a } & $\begin{array}{l}\text { Gabriel, Paulo Henrique Ribeiro } \\
\text { Uma abordagem orientada a sistemas para } \\
\text { otimização de escalonamento de processos em grades } \\
\text { computacionais / Paulo Henrique Ribeiro Gabriel; } \\
\text { orientador Rodrigo Fernandes de Mello. -- São } \\
\text { Carlos, } 2013 \text {. } \\
\quad 98 \text { p. }\end{array}$ \\
\hline & $\begin{array}{l}\text { Tese (Doutorado - Programa de Pós-Graduação em } \\
\text { Ciências de Computação e Matemática Computacional) -- } \\
\text { Instituto de Ciências Matemáticas e de Computação, } \\
\text { Universidade de São Paulo, } 2013 .\end{array}$ \\
\hline & $\begin{array}{l}\text { 1. Escalonamento de processos. 2. Grades } \\
\text { computacionais. 3. Escalonamento orientado a } \\
\text { sistemas. 4. Modelo de otimização matemática. } 5 . \\
\text { Algortimos de aproximação. I. de Mello, Rodrigo } \\
\text { a }\end{array}$ \\
\hline
\end{tabular}




\section{Agradecimentos}

Ao chegar ao fim de mais uma etapa de minha vida, quero expressar minha sincera gratidão a todos aqueles que, direta ou indiretamente, contribuíram para a realização deste trabalho.

Ao meu orientador, Prof. Dr. Rodrigo Fernandes de Mello, pela orientação, pelo incentivo e apoio durante toda a realização deste projeto. Agradeço a confiança em mim depositada, sua amizade e a atenção com a qual se dedicou no desenvolvimento desta tese.

Ao Programa de Pós-graduação de Ciências de Computação e Matemática Computacional (PGCCMC) do Instituto de Ciências Matemáticas e de Computação (ICMC), pela oportunidade e estrutura oferecida para a realização deste doutorado. Aos funcionários e professores dispostos na prestação de serviços e colaboração. Agradeço especialmente ao Prof. Dr. Antonio Castelo Filho, por sua imprescindível colaboração no desenvolvimento das diversas equações presentes nesta tese. Quero agradecer, também, às coordenadoras do PG-CCMC, Profa. Dra. Agma Juci Machado Traina e Profa. Dra. Maria da Graça Campos Pimentel, por um importante auxílio nas últimas semanas deste projeto.

À Profa. Angela Cristina Pregnolato Giampedro, do Centro Cultural da USP de São Carlos, pela ajuda com as revisões de textos em inglês, resultantes deste trabalho, e a Regina Célia Vidal Medeiros, da Seção de Atendimento ao Usuário da Biblioteca do ICMC, por dicas e auxílio na normatização deste documento. Qualquer desrespeito às normas e eventuais erros são, no entanto, de minha responsabilidade.

Aos meus colegas e amigos do laboratório BIOCOM que, se não colaboraram diretamente com este projeto, ao menos ajudaram a transformar esses anos em um período muito mais agradável. Destaco aqui o apoio de Marcelo Keese Albertini, colaborador em várias etapas deste trabalho. Agradeço também a Cássio Martini Martins Pereira, Fausto Guzzo da Costa, José Augusto Andrade Filho e Ricardo Araújo Rios, cujas críticas e sugestões contribuíram significativamente para a melhoria da qualidade desta tese.

Aos meus amigos Daniel Rodrigo Ferraz Bonetti, Debora Maria Rossi de Medeiros, Eduardo Alves da Silva Ticianelli, Evelise Roman Corbalan Góis Freire, Marcio Kassouf Crocomo, Renato Rodrigues Oliveira da Silva, Rosane Maria Maffei Vallim e Thiago Ferreira Covões, sempre presentes em minha vida ao longo de todos esses anos. Não destacarei outros nomes aqui, porém sei que estarei sempre em débito com várias pessoas com as quais me relacionei nesses últimos anos.

À Fundação de Amparo à Pesquisa do Estado de São Paulo (FAPESP) pela concessão da bolsa de doutorado e pelo apoio financeiro para a realização desta pesquisa (processo número 2009/15338-1).

Finalmente, não poderia deixar de agradecer à minha família (José Lázaro, Ana Maria, Juliana e Mariana), pelo carinho e pelo apoio oferecido durante toda minha formação. 
"It is sometimes a mistake to climb; it is always a mistake never even to make the attempt. If you do not climb, you will not fall. This is true. But is it that bad to fail, that hard to fall? (...) Sometimes you wake, and sometimes, yes, you die. But there is a third alternative (...) [S]ometimes, when you fall, you learn to fly."

NeIl Gaiman, The Sandman, Vol. 6 :

Fables \& Reflections (1993) 
Um dos maiores desafios envolvidos no projeto de grades computacionais é o escalonamento de processos, o qual consiste no mapeamento de processos sobre os computadores disponíveis, a fim de reduzir o tempo de execução de aplicações ou maximizar a utilização de recursos. A literatura na área de Sistemas Distribuídos trata, geralmente, esses dois objetivos separadamente, dando origem às abordagens de escalonamento orientado a aplicações e orientado a recursos, respectivamente. Mais recentemente, uma nova abordagem, denominada escalonamento orientado a sistemas, tem recebido destaque, buscando otimizar ambos objetivos simultaneamente. Seguindo essas abordagens, algoritmos heurísticos e de aproximação têm sido propostos. Os heurísticos buscam por soluções de maneira eficiente sem, contudo, apresentar garantias quanto à qualidade das soluções obtidas. Em contrapartida, os algoritmos de aproximação provêm tais garantias, contudo são mais difíceis de serem projetados, o que justifica o fato de haver apenas versões simplificadas desses algoritmos para cenários de escalonamento de processos. A falta de algoritmos de aproximação adequados para abordar o problema de escalonamento de processos e a necessidade de soluções que atendam o escalonamento orientado a sistemas motivaram esta tese de doutorado que apresenta a proposta do Min Heap-based Scheduling Algorithm (MHSA), um algoritmo de aproximação para o problema de escalonamento de processos orientado a sistemas. Esse algoritmo foi baseado em um modelo de otimização matemática proposto no contexto desta tese. Esse modelo considera os comportamentos de processos e recursos a fim de quantificar a qualidade de soluções de escalonamento. O funcionamento do MHSA envolve a construção de uma árvore min-heap, em que os nós representam computadores e as chaves de ordenação correspondem aos tempos de fila, i.e., ocupação dos computadores. Apesar de esse algoritmo primordialmente reduzir o tempo de execução (ou makespan) de aplicações, essa estrutura em árvore permite que qualquer computador que ocupe o nó raiz receba cargas, o que favorece a ocupação de recursos e, portanto, sua orientação a sistemas. Esse algoritmo tem complexidade assintótica de pior caso igual a $\mathcal{O}\left(\log _{2} m\right)$, em que $m$ corresponde ao número de computadores do sistema. Sua razão de aproximação foi estudada para ambientes distribuídos heterogêneos com e sem a presença de comunicação entre processos, o que permite conhecer, a priori, o nível mínimo de qualidade alcançado por suas soluções. Experimentos foram conduzidos para avaliar o algoritmo proposto e compará-lo a outras propostas. Os resultados confirmam que o MHSA reduz o tempo dispendido na obtenção de boas soluções de escalonamento.

Palavras-chave: Escalonamento de processos, sistemas distribuídos, grades computacionais, escalonamento orientado a sistemas, modelo de otimização matemática, algoritmos de aproximação. 
One of the most important challenges involved in the design of grid computing systems is process scheduling, which maps applications into the available computers in attempt to reduce the application execution time, or maximize resource utilization. The literature of Distributed Systems usually deals with these two objectives separately, supporting the application-centric and the resourcecentric scheduling, respectively. More recently, a third approach referred to as system-centric scheduling has emerged which attempts to optimize both objectives in conjunction. Heuristic-based and approximation-based algorithms have been proposed to address this third type of scheduling. Heuristics aim to find good solutions at acceptable time constraints, without guaranteeing solution quality. On the other hand, approximation-based algorithms provide optimal solution bounds, however they are more difficult to design what makes them available only to simple scenarios. The need for approximation-based algorithms to support system-centric scheduling has motivated this thesis which presents Min Heap-based Scheduling Algorithm (MHSA). This approximation algorithm is based on a mathematical optimization model, also proposed in this work, which considers process and resource behaviors to measure the quality of scheduling solutions. MHSA builds a min-heap data structure in which tree nodes represent computers and sorting keys correspond to queuing times, i.e., computer workloads. Besides this algorithm primarily reduces application execution times (also referred to as makespan), its data structure allows any computer assume the root node and, consequently, receive workloads, what favors resource utilization. This algorithm has the worst-case time complexity equals to $\mathcal{O}\left(\log _{2} m\right)$, in which $m$ represents the number of system computers. Its approximation ratio was analyzed to heterogeneous distributed systems considering bag-of-tasks and communication-intensive applications. Having this ratio, we know the minimum quality level provided by every scheduling solution. Experiments were performed to compare MHSA to others. Results confirm MHSA reduces the time spent to obtain good quality scheduling solutions.

Keywords: Process scheduling, distributed systems, grid computing, system-centric scheduling, mathematical optimization model, approximation-based algorithms. 
2.1 Classificação hierárquica para algoritmos de escalonamento. . . . . . . . . 9

2.2 Classificação hierárquica para métricas de escalonamento de processos. . . 13

2.3 Exemplo de escalonamento utilizando o algoritmo LS. . . . . . . . . . . . . 17

2.4 Exemplo de escalonamento utilizando o algoritmo LPT. . . . . . . . . . . . . . 18

2.5 Exemplo de DAG para uma aplicação composta por 10 processos. . . . . . . 20

3.1 Exemplo de rede de interconexão. . . . . . . . . . . . . . . . . . . . . 30

3.2 Vetor de computadores ordenado, de maneira decrescente, por capacidade de processamento. . . . . . . . . . . . . . . . . 43

3.3 Vetor de computadores da Figura 3.2 organizado como uma árvore min-heap. 43

3.4 Exemplo de escalonamento. . . . . . . . . . . . . . . . . . . . 45

3.5 Árvore min-heap formada por três computadores ociosos. . . . . . . . . . . 47

3.6 Exemplo de escalonamento de seis processos sobre a min-heap ilustrada na Figura 3.5. . . . . . . . . . . . . . . . . . . . . . . . . . 48 48

3.7 Árvore min-heap após a atribuição do processo $p_{7}$ ao computador $v_{1} \ldots \ldots \quad 48$

3.8 Árvore min-heap após a atribuição do processo $p_{\mathrm{mc}}$ ao computador $v_{3}$. . . . 48

4.1 Exemplo de aplicação da função de aptidão. . . . . . . . . . . . . . . . . 57

4.2 Exemplo de codificação de uma solução na forma de um cromossomo. . . . 58

4.3 Exemplo de operadores de reprodução. . . . . . . . . . . . . . . . . . . . 59

4.4 Resultados de simulações em que o número de processos é constante $|P|=$ 6 e o número de computadores varia na forma $|V|=\{2, \ldots, 9\} \ldots 66$

4.5 Resultados de simulações em que o número de computadores é constante $|V|=6$ e o número de processos varia na forma $|P|=\{2, \ldots, 9\} . \quad \ldots \quad \ldots 6$

4.6 Resultados de simulações em que o número de processos é constante $|P|=$ 32 e o número de computadores varia na forma $|V|=\{2,4,8,16,32,64\}$. .

4.7 Resultados de simulações em que o número de computadores é constante $|V|=32$ e o número de processos varia na forma $|P|=\{2,4,8,16,32,64\}$.

4.8 Resultados de simulações em que o número de computadores constante $|V|=1024$ e o número de processos varia na forma $|P|=\{512,1024,2048,4096\}$. 75

A.1 Limitantes inferiores para um ponto dual factível. . . . . . . . . . . . . . 97 


\section{Lista de Tabelas}

3.1 Comportamento dos processos das aplicações paralelas. . . . . . . . . . . 29

3.2 Características dos computadores. . . . . . . . . . . . . . . . . . . . . 30

4.1 Classificações dos algoritmos de escalonamento. . . . . . . . . . . . . . . 60

4.2 Tempo médio de execução (em segundos) apresentado pelos algoritmos força-bruta, linp, GA e MHSA quando $|P|=6$ e quando $|V|=6$. É apresentado, também, o desvio-padrão (em segundos). . . . . . . . . . . . . . . .

4.3 Tempo médio de execução (em segundos) apresentado pelos algoritmos linp, Random, RR, LS, GA e MHSA quando $|P|=6$ e quando $|V|=6$. É apresentado, também, o desvio-padrão (em segundos). . . . . . . . . . . . . Random, RR, LS e MHSA quando $|V|=1024$ computadores. É apresentado, também, o desvio-padrão (em segundos) . . . . . . . . . . . . . . . . . . 73 


\section{Lista de Siglas}

\begin{tabular}{|c|c|}
\hline ACO & Ant Colony Optimization (Otimização por Colônia de Formigas) \\
\hline CP & Critical Path (Caminho Crítico) \\
\hline CPOP & Critical Path On a Processor \\
\hline CPU & Central Processing Unit (Unidade Central de Processamento) \\
\hline DAG & Directed Acyclic Graph (Grafo Acíclico Não-dirigido) \\
\hline ELS & Extended List Scheduling \\
\hline EP & Elemento de Processamento \\
\hline FF & First Fit \\
\hline FFD & First Fit Decreasing \\
\hline GA & Genetic Algorithm (Algoritmo Genético) \\
\hline HEFT & Heterogeneous Earliest Finish Time \\
\hline I-KS & Integer Knapsack Problem (Problema da Mochila Inteira) \\
\hline LPT & Longest Processing Time \\
\hline LS & List Scheduling \\
\hline MCT & Minimum Completion Time \\
\hline MET & Minimum Execution Time \\
\hline MHSA & Min Heap-based Scheduling Algorithm \\
\hline MI & Milhões de Instruções \\
\hline MIPS & Milhões de Instruções por Segundo \\
\hline MWCTS & Minimum Weighted Completion Time Scheduling \\
\hline OLB & Opportunistic Load Balancing \\
\hline $\mathbf{R R}$ & Round-Robin \\
\hline
\end{tabular}




\section{Lista de Símbolos}

$\alpha \quad$ Razão de aproximação

$\Gamma \quad$ Capacidade dos canais de comunicação entre computadores

$\delta(\mathbf{S})$ Atraso ou custo total de execução para uma determinada solução de escalonamento

$\delta^{c o m m}(\mathbf{S})$ Atraso ou custo total de execução para uma determinada solução de escalonamento em termos de comunicação

$\delta^{c p u}(\mathbf{S})$ Atraso ou custo total de execução para uma determinada solução de escalonamento em termos de processamento

$\ell_{i, j} \quad$ Total de dados enviados pelo processo $p_{i}$ ao processo $p_{j}$

$\gamma_{i, j} \quad$ Capacidade do canal de comunicação entre os computadores $v_{i}$ e $v_{j}$

$\lambda \quad$ Multiplicador de Lagrange

$\mathbb{R} \quad$ Conjunto dos números reais

$\mathbb{R}^{+} \quad$ Conjunto dos números reais positivos

$\mathbb{R}_{0}^{+} \quad$ Conjunto dos números reais não-negativos $\left(\mathbb{R}_{0}^{+}=\mathbb{R}^{+} \cup\{0\}\right)$

$\mathbb{Z} \quad$ Conjunto dos números inteiros

$\mathbb{Z}^{+} \quad$ Conjunto dos números inteiros positivos

$\mathbb{Z}_{0}^{+} \quad$ Conjunto dos números inteiros não-negativos $\left(\mathbb{Z}_{0}^{+}=\mathbb{Z}^{+} \cup\{0\}\right)$

c Vetor com capacidades de computadores em termos de CPU

L Matriz com total de comunicação entre processos

S Matriz que representa uma solução de escalonamento

w Vetor com cargas de trabalho de processos

$\mathcal{A} \quad$ Algoritmo de otimização

$\mathcal{G} \quad$ Grafo que representa um sistema distribuído, $\mathcal{G}=(V, E)$ 
$\mathcal{G}_{D A G}$ Grafo acíclico não-dirigido que representa uma aplicação, $\mathcal{G}_{D A G}=(P, L)$

OPT Valor ótimo para uma dada instância de um problema de otimização

$\tau\left(p_{i}, v_{j}\right)$ Completion time de um processo $p_{i}$ quando escalonado sobre $v_{j}$

VAL Valor numérico relacionado à solução de um algoritmo

$\varrho \quad$ Função que indica o escalonamento de um processo em $P$ sobre um computador em $V$

A Conjunto de aplicações paralelas

$a_{k} \in A$ Aplicação (elemento) do conjunto $A$

$c_{j} \quad$ Capacidade de processamento do computador $v_{j}$

E Conjunto de canais de comunicação

$M_{\max }$ Makespan de uma aplicação

$M_{\max }^{*}$ Makespan ótimo

$P \quad$ Conjunto de processos

$p_{i} \in P$ Processo (elemento) do conjunto $P$

$p_{\mathrm{mc}} \in P$ Processo de maior carga

$q\left(v_{j}\right) \quad$ Tempo de fila do computador $v_{j} \in V$

$s_{i, j} \quad$ Elemento da matriz $\mathbf{S}$ que indica a existência de um escalonamento de $p_{i}$ sobre $v_{j}$

$V \quad$ Conjunto de computadores

$v_{j} \in V$ Computador (elemento) do conjunto $V$

$v_{\text {melhor }} \in V$ Computador com maior velocidade de processamento

$v_{\text {pior }} \in V$ Computador com menor velocidade de processamento

$w_{i} \quad$ Número de instruções do processo $p_{i}$ 
1 Introdução 1

1.1 Contextualização e Motivação . . . . . . . . . . . . . . . . . . . . . . 1

1.2 Hipótese e Objetivo . . . . . . . . . . . . . . . . . . 3

1.3 Organização da Tese . . . . . . . . . . . . . . . . . 6

2 Escalonamento de Processos 7

2.1 Considerações Iniciais . . . . . . . . . . . . . . . . . . . 7

2.2 Taxonomia de Algoritmos de Escalonamento de Processos . . . . . . . . . 8

2.2.1 Classificação Hierárquica . . . . . . . . . . . . . . . . . . . 8

2.2 .2 Classificação Plana . . . . . . . . . . . . . . . . . . . . . . 11

2.3 Classificação das Metas de Escalonamento de Processos . . . . . . . . . . 12

2.3.1 Escalonamento Orientado a Aplicações . . . . . . . . . . . . . . . . 12

2.3.2 Escalonamento Orientado a Recursos . . . . . . . . . . . . . . . . . . . 14

2.3.3 Escalonamento Orientado a Sistemas . . . . . . . . . . . . . . . . . 15

2.4 Projeto de Algoritmos de Escalonamento de Processos . . . . . . . . . . . 16

2.4.1 Abordagens Envolvendo Algoritmos de Aproximação . . . . . . . . . . 16

2.4.2 Abordagens Envolvendo Algoritmos Heurísticos . . . . . . . . . . . . 21

2.5 Considerações Finais . . . . . . . . . . . . . . . . . . . . . . . 24

3 Abordagem para Escalonamento Orientado a Sistemas... 27

3.1 Considerações Iniciais . . . . . . . . . . . . . . . . . . . . . 27

3.2 Formalização do Problema de Escalonamento de Processos . . . . . . . . 28

3.3 Modelo de Otimização Matemática para Escalonamento de Processos . . . 32

3.3.1 Modelo de Otimização Matemática . . . . . . . . . . . . . . . . . . . 32

3.3.2 Método de Otimização . . . . . . . . . . . . . . . . . . . . . . . . . . . . . . . . . . . .

3.3 .3 Discussão . . . . . . . . . . . . . . . . . . . . . . . . . 42

3.4 O Algoritmo MHSA . . . . . . . . . . . . . . . . . . . . . . . . . . 42

3.4.1 Funcionamento . . . . . . . . . . . . . . . . . . 43

3.4.2 Razão de Aproximação Considerando Aplicações Bag-of-tasks . . . 46

3.4.3 Razão de Aproximação Considerando Comunicação entre Processos 50

3.5 Considerações Finais . . . . . . . . . . . . . . . . . . . . . . . . 52

4 Experimentos 53

4.1 Considerações Iniciais . . . . . . . . . . . . . . . . . . . . 53

4.2 Algoritmos Considerados . . . . . . . . . . . . . . . . . . . 54 
4.2 .1 Algoritmo de Força-bruta . . . . . . . . . . . . . . . . . . . . . . . 54

4.2.2 Método de Resolução de Sistemas Lineares . . . . . . . . . . . . . 54

4.2 .3 Algoritmo Genético . . . . . . . . . . . . . . . . . . . . . 56

4.2 .4 Algoritmo Random . . . . . . . . . . . . . . . . . . . . . . . . 58

4.2 .5 Algoritmo Round-Robin . . . . . . . . . . . . . . . . . . . . . . 59

4.3 Classificação dos Algoritmos . . . . . . . . . . . . . . . . . . . 59

4.4 Planejamento dos Experimentos . . . . . . . . . . . . . . . . . 60

4.5 Primeiro Cenário: Instâncias Pequenas . . . . . . . . . . . . . . . . . 62

4.6 Segundo Cenário: Instâncias Grandes . . . . . . . . . . . . . . . . . . . . 68

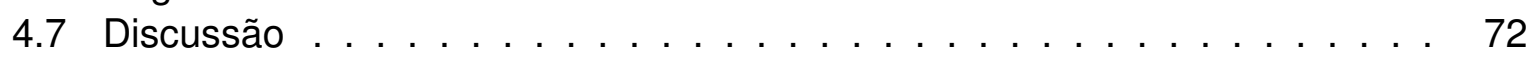

4.8 Considerações Finais . . . . . . . . . . . . . . . . . . . . . . 73

5 Conclusões $\quad 77$

5.1 Contribuições . . . . . . . . . . . . . . . . . . . . . . 77

5.2 Trabalhos Futuros . . . . . . . . . . . . . . . . . . . . . 79

5.3 Publicações . . . . . . . . . . . . . . . . . . . . . . 79

$\begin{array}{ll}\text { Referências } & 81\end{array}$

$\begin{array}{ll}\text { Glossário } & 89\end{array}$

A Método dos Multiplicadores de Lagrange 95

A.1 Conceitos . . . . . . . . . . . . . . . . . . . . . . . . . . 95

A.2 Exemplo Numérico $\ldots \ldots \ldots$. . . . . . . . . . . . . . . . . . 97 


\subsection{Contextualização e Motivação}

Aplicações de alta demanda computacional e consequente necessidade de escalabilidade motivaram a construção de computadores de alto desempenho. Empresas envolvidas nessa frente, como a IBM (GARA et al., 2005) e a Cray (GUTIERREZ et al., 2012), projetaram máquinas compostas por diversos processadores e módulos de memória integrados por barramentos internos. Esses computadores apresentavam limites previamente definidos de escalabilidade e executavam apenas uma imagem do sistema operacional, a qual era responsável por gerenciar recursos e aplicações.

Essa abordagem, denominada scale-up (MICHAEL et al., 2007) passou a ser adotada por nichos específicos de mercado, devido a seu alto custo financeiro e seus limites de escalabilidade. Esses fatores, aliados à redução de preços de microcomputadores e à evolução das tecnologias de interconexão em rede, motivaram a construção de aglomerados de computadores (do inglês, clusters), os quais foram rapidamente adotados pela comunidade científica (FOSTER et al., 2008).

Aglomerados utilizam uma abordagem distinta para prover escalabilidade, interconectando computadores via redes, os quais se comunicam por meio de passagem de mensagens. Essa abordagem, denominada scale-out (MICHAEL et al., 2007) provê, a priori, escalabilidade sem limites definidos, por meio da integração de computadores que executam diversas cópias de um sistema operacional. Contudo, a adoção dessa abordagem acarretou novas questões ou problemas, como, por exemplo (FOSTER; KESSELMAN, 1998): i) a necessidade de adaptação a um novo paradigma de desenvolvimento de software, uma 
vez que a comunicação entre processos ocorre via rede; ii) o escalonamento de processos em função da capacidade de computadores e demandas das aplicações; iii) a inconsistência de dados e o aumento da complexidade envolvida no gerenciamento do ambiente distribuído devido à presença de múltiplas cópias de um mesmo ou de vários sistemas operacionais, etc.

Com a disponibilidade de aglomerados de computadores em diferentes centros de pesquisa, observou-se a possibilidade de interconectá-los a fim de construir sistemas de maior porte. Ao mesmo tempo, alguns pesquisadores contemplaram a interconexão de outros recursos, como instrumentos de laboratório, dispositivos de visualização e demais equipamentos de alto custo, a tais sistemas com o objetivo de compartilhá-los remotamente. Esses ambientes deram origem às grades computacionais (do inglês, grids), as quais interconectam recursos heterogêneos, geograficamente distribuídos, para que cooperem a fim de resolver o mesmo problema computacional (FOSTER; KESSELMAN, 1998; STOCKINGER, 2007; FOSTER et al., 2008).

Novos desafios foram observados a partir do projeto e utilização de grades computacionais, como, por exemplo, a presença de alta latência de comunicação, a inviabilidade de execução de determinados tipos de aplicações (devido ao custo de sincronização via rede de comunicação), a demanda por alta disponibilidade e segurança, a dificuldade proveniente do gerenciamento de recursos geograficamente distribuídos e o escalonamento de processos e dados (DONG; AKL, 2006).

Dentre esses desafios, destaca-se o tema de escalonamento de processos, o qual consiste na alocação eficiente de aplicações paralelas sobre os recursos disponíveis em um sistema distribuído (CASAVANT; KUHL, 1988; DONG; AKL, 2006). O desempenho de um sistema distribuído é diretamente influenciado pelas soluções de escalonamento tomadas. Em geral, algoritmos de escalonamento são projetados de modo a satisfazer objetivos específicos, como a redução do tempo de execução (ou makespan) de aplicações ou a diminuição da ociosidade dos elementos de processamento (EPs) envolvidos (FEITELSON et al., 1997; DONG; AKL, 2006).

A fim de atingir tais objetivos, dois aspectos principais devem ser considerados (DONG; AKL, 2006): i) os consumidores de recursos, ou seja, usuários e suas aplicações; e ii) os provedores de recursos, i.e., recursos compartilhados, como processadores, memória, disco rígido, canais de comunicação, etc. Os consumidores buscam por maior desempenho para suas aplicações, ou seja, buscam reduzir tempos de execução, enquanto que os provedores tentam aumentar sua utilização por um dado período de tempo, justificando sua aquisição e reduzindo sua depreciação. Esses dois objetivos têm motivado duas principais classes de escalonamento de processos: i) o escalonamento orientado a aplicações e o escalonamento orientado a recursos (DONG; AKL, 2006; CHUNLIN; LAYUAN, 2009), respectivamente. Recentemente, uma terceira classe denominada escalonamento orientado a sistemas, que considera ambos objetivos em conjunto, tem recebido particular atenção, 
uma vez que possui como meta a redução do makespan sem, contudo, subutilizar recursos (CHUNLIN; LAYUAN, 2009).

Essas classes de escalonamento têm sido abordadas levando-se em consideração os requisitos individuais de processos, como o número de instruções e o volume de dados transferido, e recursos, como velocidade de CPU e largura de banda. Mais recentemente, pesquisadores têm dado especial atenção à heterogeneidade dos recursos, devido ao crescimento no número de sistemas distribuídos que mantêm parte de seus recursos legados (STOCKINGER, 2007; FOSTER et al., 2008). Todas essas variáveis influenciam na complexidade do escalonamento de processos. De fato, pode-se demonstrar que o problema de encontrar um escalonamento ótimo é $\mathcal{N} \mathcal{P}$-Completo para dois ou mais computadores idênticos mesmo na ausência de comunicação entre processos (LUEKER, 1975; LENSTRA; KAN; BRUCKER, 1977; GAREY; JOHNSON, 1979).

Devido à sua complexidade, esse problema tem motivado diferentes frentes de pesquisa as quais buscam por melhores soluções de escalonamento respeitando restrições temporais. Logo, duas questões são muito relevantes nesse contexto: i) a qualidade da solução proposta e ii) a eficiência do algoritmo de escalonamento. Essas questões, em conjunto com a $\mathcal{N} \mathcal{P}$-Completude envolvida no problema de escalonamento de processos, motivaram o projeto de algoritmos aproximados e heurísticos. Os primeiros buscam soluções cuja qualidade está a um fator $\alpha$ da solução ótima (WILLIAMSON; SHMOYS, 2010). Os algoritmos heurísticos buscam por soluções satisfatórias sem, contudo, apresentar provas sobre sua qualidade em relação à solução ótima (BLUM; ROLI, 2003).

O projeto de algoritmos aproximados é mais complexo e envolve o desenvolvimento de formulações matemáticas que permitam concluir sobre a qualidade das soluções propostas. Mais especificamente, no cenário de escalonamento de processos, os algoritmos aproximados encontrados na literatura abordam, em sua maioria, cenários homogêneos com pouca ou nenhuma comunicação entre processos (HALL, 1997). Em contrapartida, a maior parte dos trabalhos recentes na área de escalonamento propõem algoritmos heurísticos (MA et al., 2011), pois são de projeto mais simples e podem empregar diversos conceitos e recursos disponíveis em áreas tais como Otimização Inteira e Computação Bioinspirada (BLUM; ROLI, 2003).

As questões relativas à redução do makespan e maior utilização dos recursos disponíveis em ambientes de grade computacional, em conjunto com os aspectos envolvidos no projeto de algoritmos aproximados para o escalonamento de processos, motivaram esta tese de doutorado, cujos detalhes são apresentados a seguir.

\subsection{Hipótese e Objetivo}

A importância em garantir a qualidade de soluções de escalonamento de processos e, simultaneamente, reduzir o tempo dispendido na busca por tais soluções e atender as 
demandas provenientes do escalonamento orientado a sistemas, motivou a hipótese desta tese de doutorado, a qual é apresentada a seguir:

Uma combinação adequada de comportamentos de processos e computadores de uma grade computacional, respeitando restrições temporais, possibilita reduzir o tempo de execução de aplicações e aumentar a ocupação de recursos.

O termo "combinação adequada" se refere à capacidade do algoritmo de escalonamento encontrar soluções respeitando questões relativas à qualidade, o que motiva a adoção de algoritmos aproximados. Entende-se por "comportamentos de processos e computadores", a utilização de conhecimento adquirido por meio de históricos ou de maneira online, i.e., durante a execução, sobre as operações executadas por processos e a ocupação de recursos. O termo "grade computacional" delimita o estudo desenvolvido neste trabalho no contexto de ambientes scale-out que contam com grande quantidade de recursos geograficamente distribuídos. O respeito quanto às "restrições temporais" se refere à busca por algoritmos eficientes, i.e., que produzam soluções em tempo hábil ${ }^{1}$. Além disso, a hipótese contempla a redução do "tempo de execução de aplicações" e aumento na "ocupação de recursos", ambos relativos à classe de escalonamento orientado a sistemas, em que o primeiro auxilia usuários obterem resultados de maneira mais veloz e o segundo justifica a aquisição de equipamentos.

A definição da hipótese deste trabalho permitiu delinear o objetivo desta tese de doutorado, que consiste no projeto de um algoritmo eficiente para o problema de escalonamento de processos orientado a sistemas. A fim de atingir esse objetivo e, assim, confirmar a hipótese, fez-se necessário o cumprimento das seguintes atividades. Primeiramente, observou-se a necessidade de formalizar o problema de escalonamento de processos segundo a classe orientada a sistemas, i.e., considerando a redução no tempo de execução de processos e o aumento na ocupação de recursos. A partir dessa formalização, projetouse um modelo de otimização matemática que permite avaliar a qualidade das soluções de escalonamento, assim tornou-se possível medir o desempenho do escalonador ótimo e compará-lo ao novo algoritmo projetado. Esse modelo leva em conta as seguintes variáveis: i) carga de trabalho de processos, i.e., operações que cada processo solicita a fim de executar instruções de processamento; ii) taxa de comunicação, i.e., o total de bytes transferidos durante a execução de processos; iii) capacidade de computadores, i.e., o número de instruções que cada computador pode executar durante certo intervalo de tempo (definido como um segundo); e iv) capacidade de rede, i.e., o número de bytes que cada canal de comunicação pode transferir durante certo intervalo de tempo (definido como um segundo).

\footnotetext{
${ }^{1}$ Esse termo, portanto, não se refere ao conceito de deadline, comumente utilizado para definir um limite estrito de tempo.
} 
Em seguida, demonstrou-se que o modelo de otimização matemática proposto é inteiro e convexo, o que permite a adoção de ferramentas empregadas na literatura para a resolução de problemas de otimização convexa (BOYD; VANDENBERGHE, 2004). A partir disso, considerou-se, primeiramente, a rotina linp, disponível no pacote LINPACK (DONGARRA; STEWART, 1984), para abordar esse problema de otimização. Essa rotina relaxa o problema inteiro de modo a tratá-lo como um problema de otimização linear. Os resultados produzidos por essa rotina foram comparados a um algoritmo de força-bruta, que permite encontrar a solução ótima para qualquer instância do problema.

Como esperado, o algoritmo de força-bruta apresentou custo computacional proibitivo. O mesmo foi observado em relação ao linp, mesmo considerando suas relaxações. Esses resultados reforçaram, ainda mais, o projeto de um novo algoritmo de escalonamento orientado a sistemas no contexto desta tese. Esse algoritmo, denominado Min Heap-based Scheduling Algorithm (MHSA), inicialmente constrói uma estrutura de dados no formato de árvore min-heap (CORMEN et al., 2001) com base no tempo de fila (KLEINROCK, 1975) dos computadores do sistema. Como consequência, o nó raiz da árvore contém o computador mais ocioso e as folhas os mais ocupados. Quando um processo chega ao sistema, esse é escalonado sobre a raiz da árvore e o tempo de fila do computador é atualizado. Assim, tal computador pode se mover em direção às folhas da min-heap.

O algoritmo MHSA foi projetado com o intuito de prover soluções com certo nível de aproximação em relação à solução ótima. Dessa maneira, o passo seguinte consistiu de um estudo sobre a qualidade das soluções propostas pelo MHSA em ambientes distribuídos heterogêneos considerando tanto aplicações do tipo bag-of-tasks quanto aplicações com diferentes taxas de comunicação. Como resultado, demonstrou-se que o MHSA é uma $\alpha$-aproximação, i.e., esse algoritmo garante uma solução que, no pior caso, tem custo $\alpha$ vezes o custo da solução ótima.

Em seguida, avaliou-se a complexidade do algoritmo MHSA em relação ao força-bruta e ao linp. MHSA apresenta complexidade de tempo $\mathcal{O}(1)$ para o escalonamento de cada processo individual e $\mathcal{O}\left(\log _{2} m\right)$ para a atualização da árvore min-heap, em que $m$ é o número de computadores do sistema. O algoritmo de força-bruta tem complexidade de tempo exponencial e, finalmente, dado o fato da rotina linp adaptar suas relaxações e execuções de versões de algoritmos para a resolução de problemas de otimização linear, torna-se muito difícil definir com precisão sua complexidade. No entanto, pode-se comprovar, experimentalmente, que o MHSA executa algumas ordens de magnitude mais rápido que ambos.

Experimentos foram realizados a fim de comparar o MHSA, ao força-bruta e ao linp, além de uma meta-heurística de escalonamento baseada em algoritmos genéticos (GAs, do inglês Genetic Algorithm ) projetada com base no modelo proposto. Também foram considerados outros algoritmos de escalonamento disponíveis na literatura: Random, que atribui processos de maneira aleatória, Round-Robin (RR), que atribui processos sequen- 
cialmente aos computadores, e List Scheduling (LS) um dos algoritmos de aproximação mais estudados para o problema de escalonamento de processos. Os resultados permitiram confirmar que o MHSA provê soluções de boa qualidade. Em contrapartida, o MHSA executa muito mais rápido que o força-bruta e o linp. Em cenários com instâncias pequenas, o MHSA não encontra, necessariamente, as melhores soluções. Porém, para cenários grandes, o MHSA sempre vence os demais algoritmos. Vale ressaltar que o MHSA é um algoritmo aproximado, o que permite conhecer, a priori, seus limites mínimos de qualidade. Para complementar, o MHSA executa algumas ordens de magnitude mais rápido que o GA em todos os cenários avaliados, além de manter-se próximo aos algoritmos mais eficientes considerados nesta tese.

A estrutura de dados no formato de uma árvore min-heap permite, ainda, que o MHSA distribua processos sobre todos os computadores do ambiente, enquanto busca pela redução em seus tempos de execução. Tais características permitem definí-lo como um algoritmo orientado a sistemas. As etapas envolvidas e os resultados de simulação permitiram, portanto, comprovar a hipótese desta tese.

\subsection{Organização da Tese}

Esta tese está organizada conforme segue: No Capítulo 2, apresenta-se uma revisão da literatura sobre escalonamento de processos em sistemas distribuídos. Em seguida, aborda-se trabalhos relacionados, mais precisamente aqueles que consideram algoritmos de aproximação e heurísticos para atingir metas de escalonamento. No Capítulo 3 são detalhadas as atividades desenvolvidas durante o doutorado, bem como suas contribuições, as quais compreendem: i) a formalização do problema de escalonamento de processos segundo a classe orientada a sistemas; ii) o modelo de otimização matemática proposto; e iii) o algoritmo de escalonamento de processos MHSA. Além disso, são apresentadas demonstrações matemáticas sobre a aproximação desse algoritmo. O Capítulo 4 apresenta os experimentos conduzidos, os quais comparam o MHSA ao método de força-bruta, que sempre encontra soluções ótimas, ao método de resolução de sistemas lineares linp, à meta-heurística GA e aos algoritmos Random, RR e LS. Finalmente, o Capítulo 5 apresenta as considerações e conclusões finais deste trabalho. Em seguida são listadas as referências e o glossário de termos adotados ao longo desta tese. O Apêndice A finaliza este trabalho com a descrição do método de multiplicadores de Lagrange (BERTSEKAS, 1996), adotado no Capítulo 3. 


\section{Escalonamento de Processos}

\subsection{Considerações Iniciais}

O problema de escalonamento de processos compreende a atribuição de um conjunto de processos $P$ sobre um conjunto de elementos de processamento $V$ sujeito a algum critério de otimização (CHAPIN; WEISSMAN, 2004). Dentre os critérios mais comuns estão a redução do tempo de execução e o aumento da ocupação de recursos (DONG; AKL, 2006). No contexto de ambientes scale-oute, consequentemente, de grades computacionais, entende-se por elementos de processamento (EPs) os diferentes computadores do sistema, os quais podem apresentar diferentes características em termos de CPU, memória, rede, etc.

A fim de compreender melhor o problema de escalonamento, Casavant e Kuhl (1988) definem três componentes básicos: os consumidores, ou seja, processos de usuários ou do sistema; os recursos, i.e., os computadores (processadores, dispositivos de armazenamento e comunicação, memória, etc.) e a política ou algoritmo de escalonamento. Os consumidores utilizam os recursos e o algoritmo de escalonamento é responsável por atribuir os processos aos diferentes computadores, de acordo com suas demandas e/ou disponibilidade de recursos.

O escalonamento de processos em ambientes scale-out é realizado em duas etapas. $\mathrm{Na}$ primeira, o algoritmo de escalonamento é responsável por decidir quais processos terão acesso aos recursos disponíveis, bem como a localização e a quantidade relativa de recursos que serão utilizados. Em seguida, os recursos são efetivamente alocados em função das decisões tomadas na etapa anterior.

De modo a enumerar e definir termos utilizados para classificar algoritmos de esca- 
lonamento de processos, Casavant e Kuhl (1988) propuseram uma taxonomia a qual é amplamente adotada por pesquisadores nas áreas de sistemas distribuídos e paralelos de propósito geral. Maiores detalhes sobre essa taxonomia são apresentados na Seção 2.2. Em seguida, a Seção 2.3 apresenta a classificação proposta por Dong e Akl (2006), a qual estende o trabalho de Casavant e Kuhl (1988) a fim de organizar os algoritmos de escalonamento segundo suas metas ou objetivos. Nessa seção também são descritas as principais métricas de desempenho adotadas por tais algoritmos. Finalmente, na Seção 2.4, são analisados aspectos relacionados ao projeto de algoritmos de escalonamento baseados em aproximações e em heurísticas.

\subsection{Taxonomia de Algoritmos de Escalonamento de Pro- cessos}

De modo a tratar o problema de escalonamento de processos em sistemas distribuídos, diversos algoritmos têm sido propostos. A fim de enumerar e definir as técnicas adotadas por esses algoritmos, Casavant e Kuhl (1988) desenvolveram uma nomenclatura unificada, descrevendo os aspectos centrais das abordagens de escalonamento adotadas na literatura. Devido à sua abrangência, essa classificação tem sido amplamente referenciada e utilizada, mesmo em trabalhos mais recentes. A taxonomia de Casavant e Kuhl (1988) é subdividida em classificação hierárquica e classificação plana, as quais são descritas a seguir.

\subsubsection{Classificação Hierárquica}

Na classificação hierárquica, as técnicas de escalonamento são organizadas segundo uma estrutura de árvore (Figura 2.1). Para projetar essa árvore, Casavant e Kuhl (1988) consideraram os critérios descritos a seguir.

Número de Processadores. As técnicas de escalonamento são divididas em locais e globais. A primeira classe refere-se às políticas de gerenciamento que determinam como processos residentes em uma única unidade central de processamento (CPU) são alocados e executados. No caso das políticas globais, informações sobre o sistema são utilizadas para alocar processos em múltiplos EPs, a fim de otimizar métricas de desempenho comuns a todo sistema. Algoritmos de escalonamento em aglomerados e grades computacionais são, portanto, classificados como globais.

Momento da Tomada de Decisões. No segundo nível da hierarquia, abaixo dos algoritmos globais, realiza-se a distinção em relação ao momento em que são tomadas decisões 


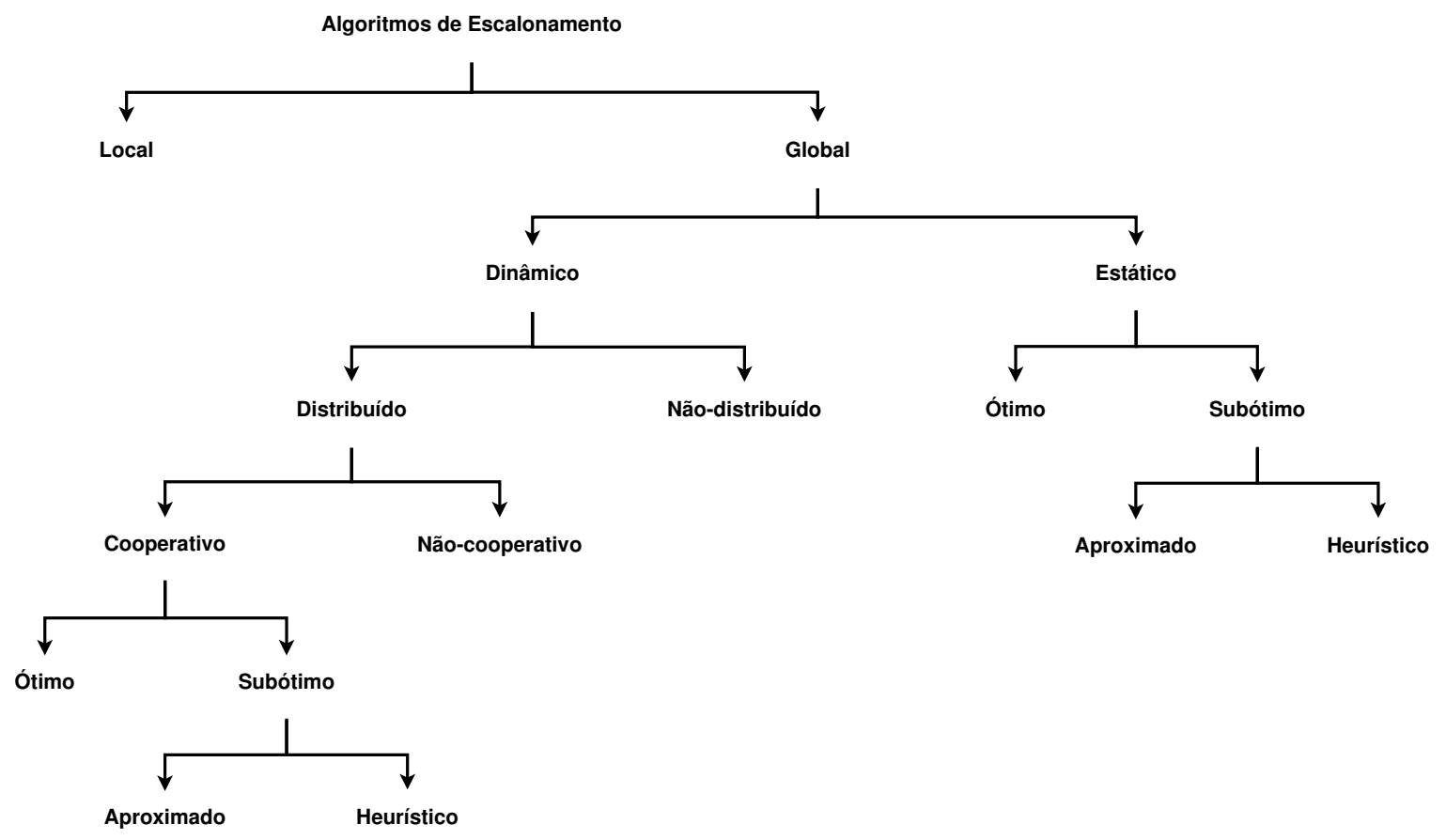

Figura 2.1: Classificação hierárquica para algoritmos de escalonamento, adaptada de Casavant e Kuhl (1988) e Dong e Akl (2006).

de escalonamento. Duas abordagens são descritas nessa categoria: escalonamento estático e escalonamento dinâmico.

No escalonamento estático, considera-se que informações sobre todos os processos e recursos do sistema estão disponíveis antes do início da tarefa de escalonamento. Assim, pode-se estimar, antecipadamente, o custo computacional de execução dessas aplicações. No entanto, a estimativa de custo baseada nas informações coletadas não pode ser adaptada em casos de falha de algum EP, ou canal de comunicação ou, ainda, em casos de aumento de carga em determinado EP, produzindo atrasos nos tempos de resposta. Uma vez que situações como essas tendem a ser comuns em ambientes distribuídos (DONG; AKL, 2006), foram propostos mecanismos como o re-escalonamento, que permite migrar processos anteriormente alocados para outra máquina, acrescentando, porém, o custo dessa transferência ao tempo total de resposta.

Por outro lado, no escalonamento dinâmico, leva-se em conta a possibilidade de mudança na organização do sistema. Considera-se, ainda, cenários nos quais a chegada de processos ocorre de maneira online, em que não há, a priori, conhecimento sobre as características dos processos a serem escalonados. Nesse caso, o escalonamento dinâmico também é chamado de escalonamento online (DONG; AKL, 2006). Os algoritmos dessa classe apresentam duas etapas principais (CASAVANT; KUHL, 1988; DONG; AKL, 2006):

1. Estimação do estado do sistema, que envolve a coleta do estado atual de processos e recursos, bem como a construção de uma estimativa; 
2. Tomada de decisão, que envolve alocação do processo sobre determinado recurso, com base na estimativa construída na etapa anterior.

Os algoritmos de escalonamento dinâmico trabalham, portanto, com informações coletadas sobre o estado atual do sistema. Essas informações podem ser obtidas por meio de ferramentas de benchmark e de monitores de sistema e processos. Os benchmarks extraem capacidades máximas de recursos enquanto os monitores de sistema avaliam a carga instantânea de recursos. Por outro lado, monitores de processos interceptam eventos de utilização de recursos (como, por exemplo, volume de processamento), podendo armazená-los em uma base de dados (SENGER et al., 2007). Com base nessas informações, é possível propor novas soluções de escalonamento que considerem alterações nas demandas de processos, a eventual falha de um EP, perdas em canais de comunicação, etc.

Otimalidade do Algoritmo. Um escalonamento ótimo pode ser encontrado apenas se todas as informações referentes aos estados dos processos e dos recursos estiverem disponíveis. No entanto, essa condição não é suficiente para a obtenção de uma solução adequada, devido à complexidade do problema (ver Seção 3.2). Além disso, tem-se, em geral, a inviabilidade da obtenção de todas as informações necessárias para o escalonamento. Por essa razão, algoritmos de escalonamento que buscam soluções subótimas têm sido empregados. Nesse contexto, duas grandes categorias de algoritmos são comumente estudadas (CASAVANT; KUHL, 1988; DONG; AKL, 2006):

1. Algoritmos aproximados: são algoritmos que utilizam modelos formais de computação de modo a encontrar soluções cuja qualidade se aproxima do ótimo por um fator $\alpha$, denominado razão de aproximação;

2. Algoritmos heurísticos: são algoritmos que realizam buscas sistemáticas pelo espaço das possíveis soluções do problema, de modo a obter alguma solução adequada em baixo tempo computacional.

Essas duas técnicas são descritas com mais detalhes na Seção 2.4, em que são discutidos os principais trabalhos relacionados a esta tese de doutorado.

Responsabilidade na Tomada de Decisões. Em escalonamento dinâmico, a responsabilidade por decisões pode ser atribuída a um único EP ou compartilhada por escalonadores distribuídos. Dois paradigmas são considerados por Casavant e Kuhl (1988):

1. Escalonamento não-distribuído ou centralizado: essa estratégia supõe a existência de um único EP responsável pelo escalonamento dos processos sobre os demais EPs do sistema. Caso o EP escalonador possua informações suficientes sobre o sistema, essa abordagem tende a produzir melhores resultados. No entanto, também 
apresenta maior probabilidade de desenvolver problemas de escalabilidade e atrasos de comunicação, tornando-se um gargalo para o sistema, além de um ponto único de falha;

2. Escalonamento distribuído: nesse cenário, a responsabilidade pela tomada de decisões é global, compartilhada por múltiplos EPs. Essa abordagem apresenta maior escalabilidade, reduzindo o atraso de comunicações. Porém, tende a apresentar soluções adequadas apenas em relação a um subconjunto dos EPs do sistema, uma vez que o escalonamento pode se limitar a computadores topologicamente próximos ao escalonador.

Hamscher et al. (2000) acrescentam a essa classificação o chamado escalonamento hierárquico. Nesse caso, um EP central redistribui entre outros EPs escalonadores as informações necessárias para a tomada de decisões, os quais passam a ser responsáveis por uma região do ambiente. Apesar de apresentar basicamente os mesmos problemas da primeira abordagem, essa estratégia permite explorar diferentes abordagens de otimização em cada EP responsável pelo escalonamento.

Cooperação entre Escalonadores. No caso da adoção de escalonamento distribuído, deve-se considerar se os EPs escalonadores cooperam entre si. No caso de escalonamento não-cooperativo, cada EP atua como uma entidade autônoma e toma decisões com base em seus critérios de otimalidade, independentemente do efeito de tais decisões sobre outros EPs. No segundo caso, chamado escalonamento cooperativo, cada EP continua sendo responsável por um subconjunto de processos, porém as decisões são tomadas de modo a satisfazer critérios comuns a um conjunto de EPs.

\subsubsection{Classificação Plana}

Algumas políticas de escalonamento não são consideradas por Casavant e Kuhl (1988) na classificação hierárquica, uma vez que não se enquadram nos critérios adotados. Por esse motivo, propuseram uma outra classificação, denominada plana, a qual é apresentada a seguir.

Escalonamento Adaptativo e Não-adaptativo. Uma solução adaptativa pode alterar seu comportamento de acordo com o estado anterior ou atual do sistema. Algoritmos adaptativos podem redefinir, dinamicamente, regras e parâmetros da política de escalonamento visando obter maior desempenho. Em oposição a esse método, o escalonamento não-adaptativo não modifica o mecanismo básico de controle da tomada de decisões durante a execução do sistema. 
Atribuição Inicial e Reatribuição Dinâmica. Algoritmos de atribuição inicial alocam de maneira fixa um processo em um EP, não permitindo migração. Por outro lado, na reatribuição dinâmica, são utilizados mecanismos de preempção, para interromper a execução de processos, e migração, para redistribuir processos entre os EPs, visando melhorar o escalonamento.

Balanceamento de Carga. Nessa categoria estão políticas que realizam a distribuição de processos no sistema buscando minimizar a variação de carga dos EPs. Promovem, assim, uma distribuição mais homogênea de cargas, utilizando, para isso, mecanismos de reatribuição dinâmica.

Licitação. Nessa categoria, considera-se um protocolo para descrever como processos serão associados a EPs. O escalonamento resultante é geralmente cooperativo, uma vez que ocorre troca de informações entre diversos EPs do sistema, de modo que a associação tende a ser feita de forma benéfica para todos os computadores envolvidos.

Escalonamento Probabilístico. Esse esquema é motivado pelo alto número de combinações entre processos submetidos ao escalonador e EPs disponíveis para alocação. Busca-se aleatoriamente, com base em alguma função de distribuição de probabilidades, selecionar o EP que receberá determinado processo.

\subsection{Classificação das Metas de Escalonamento de Pro- cessos}

No desenvolvimento de abordagens de escalonamento, é necessário otimizar funções que avaliam métricas de desempenho como, por exemplo, makespan, vazão, flowtime, balanceamento da carga total do sistema, entre outros (DONG; AKL, 2006; XHAFA; ABRAHAM, 2010). De modo a organizar essas métricas, Dong e Akl (2006) propuseram uma classificação das metas de escalonamento em duas categorias: escalonamento orientado a aplicações e escalonamento orientado a recursos. Chunlin e Layuan (2009) acrescentaram um novo ramo a essa classificação, denominado escalonamento orientado a sistemas. Essa categorias, ilustradas na Figura 2.2, são descritas nas próximas seções.

\subsubsection{Escalonamento Orientado a Aplicações}

De modo geral, o escalonamento orientado a aplicações (do inglês, application-centric ou user-centric) visa satisfazer a demanda imposta pelos usuários de um sistema computacional. Tem por objetivo otimizar o desempenho de aplicações submetidas ao sistema, minimizando, por exemplo, o tempo de execução dos processos. Formalmente, seja um 


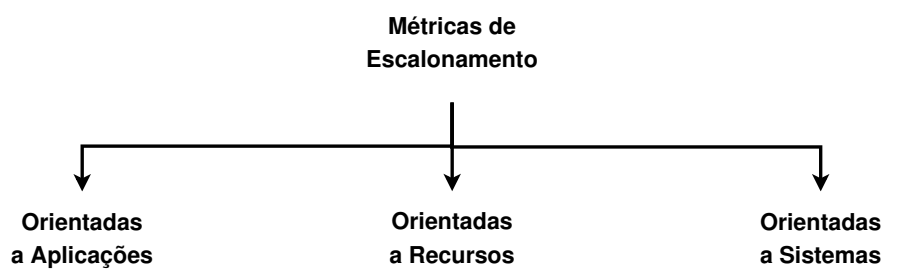

Figura 2.2: Classificação hierárquica para métricas de escalonamento de processos.

conjunto $V$ composto por $m$ EPs. Cada elemento $v_{j} \in V$ pode ser descrito por um conjunto de recursos oferecidos $R_{\mathrm{O}}$, composto por processamento $\left(r_{\text {cpu }}\right)$, memória $\left(r_{m}\right)$, disco rígido $\left(r_{h d}\right)$ e rede $\left(r_{n e t}\right)$. Nesse contexto, considera-se, também, um conjunto de $n$ processos na forma $P=\left\{p_{1}, p_{2}, \ldots, p_{n}\right\}$, os quais são alocados sobre $V$.

Assim, uma política de escalonamento orientada a aplicações tem por objetivo minimizar uma função $f\left(p_{i}\right)$ descrita pela Equação (2.1), em que o termo $R_{\mathrm{D}}$ corresponde ao conjunto de recursos requeridos pela aplicação (processamento, memória, disco e rede) e a função custo $\left(p_{i}\right)$ determina o custo de execução, em termos de tempo, de um processo $p_{i}$.

$$
f\left(p_{i}\right)=\sum_{i=1}^{n} \sum_{R_{\mathrm{D}}} \operatorname{custo}\left(p_{i}\right)
$$

Nesse cenário, as funções objetivo de escalonamento quantificam, portanto, o tempo consumido em operações realizadas por processos. Uma das métricas mais estudadas nessa quantificação é o completion time, que corresponde ao tempo que um EP requer para finalizar a execução de um processo (FEITELSON et al., 1997). Em ambientes heterogêneos, como grades computacionais, esse tempo está diretamente relacionado à capacidade do EP ao qual o processo foi escalonado. Assim, o completion time de um processo $p_{i}$ atribuído a um EP $v_{j}$ é representado por $\tau\left(p_{i}, v_{j}\right)$.

Outra métrica comumente utilizada é o makespan (FEITELSON et al., 1997), denotado por $M_{\max }$, o qual quantifica o tempo que uma aplicação leva para ser executada. Essa métrica pode ser vista como um indicador de produtividade do sistema: menores valores indicam que o escalonamento aloca eficientemente processos sobre os EPs. Como aplicações paralelas são compostas por vários processos, o makespan é definido por:

$$
M_{\max }=\max _{p_{i} \in P} \tau\left(p_{i}, v_{j}\right)
$$

para todo $v_{j} \in V$.

Nesse mesmo contexto, outra medida de desempenho é o flowtime (XHAFA; ABRAHAM, 2010) que corresponde ao tempo necessário para finalizar a execução de todos os proces- 
sos submetidos por um determinado usuário, ou seja,

$$
\sum_{p_{i} \in P} \tau\left(p_{i}, v_{j}\right), \quad j=1, \ldots, m
$$

Assim, minimizar o flowtime implica reduzir o tempo médio de resposta do sistema.

Observa-se que o flowtime totaliza a soma dos tempos de execução dos processos, enquanto que o makespan indica o tempo em que o processo mais longo levou para ser executado. Por essa razão, diferentemente do makespan, o flowtime depende da ordem em que os processos são submetidos ao sistema, uma vez que aqueles de longa duração podem provocar atrasos na execução dos demais.

Outra métrica bastante utilizada é denominada turnaround time (XHAFA; ABRAHAM, 2010), que consiste no tempo médio de processamento entre a submissão do primeiro processo e a finalização do último. Essa métrica tende a ser mais adequada para aplicações do tipo bag-of-tasks, uma vez que se evita, assim, cálculos para desconsiderar o tempo de interação com o usuário e sincronização de processos.

\subsubsection{Escalonamento Orientado a Recursos}

O escalonamento orientado a recursos (do inglês, resource-centric) visa otimizar a ocupação dos recursos computacionais disponíveis no ambiente. Esse tipo de escalonamento tem grande apelo comercial, uma vez que o melhor aproveitamento da infraestrutura tende a aumentar o retorno sobre o investimento financeiro realizado na aquisição de equipamentos. No entanto, a alta utilização de recursos pode entrar em conflito com a heterogeneidade de ambientes distribuídos, tais como grades computacionais, uma vez que um EP de menor capacidade tende a se tornar um gargalo para o desempenho de todo o sistema (DONG; AKL, 2006).

Seguindo a formalização adotada na Seção 2.3.1, as políticas sob esse ramo têm como objetivo maximizar o termo $g\left(v_{j}\right)$, apresentado na Equação (2.2), em que o parâmetro $r \in R_{\mathrm{O}}$ corresponde a um recurso (e.g., CPU, memória, disco ou rede) que um EP pode oferecer, e a função $\operatorname{util}\left(r, v_{i}\right)$ mede a utilização de recursos em um EP $v_{i} \in V$.

$$
g\left(v_{j}\right)=\sum_{r \in \mathbf{R}_{\bigcirc}} \mathbf{u t i l}\left(r, v_{j}\right)
$$

A função util $\left(r, v_{i}\right)$ é definida para cada EP do sistema, conforme apresentado na Equação (2.3), em que $\tau\left(p_{i}, v_{j}\right)$ corresponde ao completion time de um processo $p_{i}$ alocado sobre $v_{j}$ e $M_{\max }$ corresponde ao makespan da aplicação.

$$
\operatorname{util}\left(r, v_{j}\right)=\frac{\tau\left(p_{i}, v_{j}\right)}{M_{\max }}
$$


Observa-se que divisão da métrica completion time, relacionada ao tempo de execução, pelo makespan devolve um valor numérico adimensional, o qual expressa a utilização do recurso $r$. Isso ocorre uma vez que o completion time é avaliado não apenas em função do tempo de resposta da aplicação (como é o caso do makespan), mas está diretamente relacionado a um EP específico. Assim, em ambientes heterogêneos, o valor $\tau\left(p_{i}, v_{j}\right)$ não está atrelado apenas ao peso do processo $p_{i}$, mas também às capacidades dos recursos disponíveis no EP $v_{j}$.

Outra medida de utilização adotada é a chamada utilização média (util ${ }_{a v g}$ ) (XHAFA; ABRAHAM, 2010) entre todos os EPs do sistema, conforme a Equação (2.3), em que $m$ é o número total de EPs.

$$
\mathbf{u t i l}_{a v g}=\frac{\sum_{v_{j} \in V} \tau\left(p_{i}, v_{j}\right)}{M_{\max } \cdot m}
$$

Outra maneira de avaliar um escalonamento orientado a recursos é por meio da métrica de vazão, que representa a taxa (em Kbytes/s) de transferência de dados entre os diferentes EPs do sistema ou o número de requisições processadas (DONG; AKL, 2006).

\subsubsection{Escalonamento Orientado a Sistemas}

O termo escalonamento orientando a sistemas (do inglês, system-centric) foi definido por Chunlin e Layuan (2009), de modo a classificar trabalhos que envolvem tanto minimização de métricas referentes ao tempo de resposta, quanto maximização de métricas de utilização de recursos. Trabalhos que visam a otimização de ambas medidas de desempenho merecem destaque devido à crescente adoção comercial de grades computacionais. Dessa maneira, assim como no escalonamento orientado a recursos, deseja-se aumentar o retorno sobre o investimento financeiro feito na implantação da infraestrutura, reduzindo o total de EPs ociosos. Por outro lado, tem-se também a demanda de usuários pelo alto desempenho de seus processos submetidos ao sistema, havendo a necessidade de considerar escalonamentos orientados a aplicações.

No entanto, a minimização do tempo de resposta tende a ser conflitante com a maximização da utilização de recursos. Por exemplo, de modo a reduzir atrasos de comunicação, um conjunto de processos oriundos de uma mesma aplicação podem ser escalonados em recursos topologicamente próximos, o que prejudicaria o balanceamento de carga em outras regiões do ambiente distribuído.

A fim de tratar esse problema, abordagens de escalonamento orientadas a sistemas buscam ponderações entre ambos os objetivos, como mostrado na Equação 2.5, em que $a$ e $b$ são os pesos e $f\left(p_{i}\right)$ e $g\left(v_{j}\right)$ são funções que avaliam, respectivamente, métricas orientadas a aplicações e a recursos, como as mostradas nas Equações (2.1) e (2.2). Esses trabalhos, porém, são limitados por uma escolha adequada dos pesos $a$ e $b$.

$$
h\left(p_{i}, v_{j}\right)=a \cdot f\left(p_{i}\right)+b \cdot g\left(v_{j}\right)
$$




\subsection{Projeto de Algoritmos de Escalonamento de Proces- sos}

Conforme mostrado na taxonomia de Casavant e Kuhl (1988), o desenvolvimento de algoritmos de escalonamento recai, principalmente, na proposta de métodos aproximados ou heurísticos. Isso se deve ao fato de que o problema de escalonamento de processos em ambientes distribuídos ser computacionalmente complexo (a demonstração dessa complexidade é apresentada na Seção 3.2). Consequentemente, um algoritmo exato, que avalia todas as possíveis soluções do problema, consumiria muitos recursos. Como alternativa, utiliza-se algoritmos que sacrificam a otimalidade em troca de maior desempenho.

Esses algoritmos, por sua vez, são classificados em duas categorias: algoritmos de aproximação e algoritmos heurísticos. Essas duas abordagens são apresentadas nas próximas seções.

\subsubsection{Abordagens Envolvendo Algoritmos de Aproximação}

Os algoritmos aproximados ou de aproximação foram formalizados inicialmente por Garey, Graham e Ullman (1972) e por Johnson (1974), embora haja trabalhos anteriores que já desenvolvessem os conceitos de aproximação (GRAHAM, 1966). Um algoritmo de aproximação precisa ser, necessariamente, polinomial e deve sempre encontrar soluções factíveis para todas instâncias de um problema de otimização.

Formalmente, seja um algoritmo de complexidade de tempo polinomial $\mathcal{A}$ que, para toda instância factível $I$ de um dado problema de otimização, retorna uma solução factível $\mathcal{A}(I)$. O valor numérico dessa solução é dado por $\operatorname{VAL}(\mathcal{A}(I))$. Além disso, o valor ótimo do problema para essa instância é definido por $\mathrm{OPT}(I)$. Assim, para problemas de minimização, o algoritmo $\mathcal{A}$, é uma $\alpha$-aproximação para toda instância $I$ se:

$$
\operatorname{VAL}(\mathcal{A}(I)) \leq \alpha \operatorname{OPT}(I)
$$

O termo $\alpha$ é denominado razão de aproximação ou garantia de desempenho do algoritmo $\mathcal{A}$. Em problemas de minimização, tem-se que $\alpha \geq 1$ (FERNANDES et al., 2001; WILLIAMSON; SHMOYS, 2010). Analogamente, em problemas de maximização, tem-se que:

$$
\operatorname{VAL}(\mathcal{A}(I)) \geq \alpha \mathrm{OPT}(I)
$$

e, assim, $0<\alpha \leq 1$ (FERNANDES et al., 2001) ${ }^{1}$.

O primeiro algoritmo de aproximação desenvolvido para o problema de escalonamento de processos foi proposto por Graham (1966), que considerou a minimização do makes-

\footnotetext{
${ }^{1} \mathrm{~A}$ notação utilizada nessas definições é baseada em Fernandes et al. (2001).
} 
pan em ambientes compostos por computadores idênticos (ou seja, o sistema distribuído é homogêneo). Nesse modelo, deseja-se escalonar um conjunto de $n$ processos independentes $P=\left\{p_{1}, \ldots, p_{n}\right\}$ (ou seja, processos que compõem aplicações bag-of-tasks) sobre $m$ computadores $V=\left\{v_{1}, \ldots, v_{m}\right\}$, sendo que cada processo $p_{i}$ deve ser executado sem interrupção por um tempo $\tau\left(p_{i}, v_{j}\right)$ em um determinado computador $v_{j}$. Além disso, esse trabalho supõe que cada computador executa apenas um processo por vez. Como o ambiente é homogêneo, a fim de simplificar a notação, o completion time de um processo $p_{i}$ será definido apenas por $\tau\left(p_{i}\right)$. Além disso, supõe-se que a rede seja completa, i.e., cada computador está conectado a todos os demais.

Graham (1966) considerou o seguinte algoritmo guloso, denominado List Scheduling (LS): dada uma fila de processos em ordem arbitrária, aloca-se os processos um a um, destinando cada um deles ao computador menos ocupado (ver Algoritmo 2.1). Como consequência, a escolha do computador que receberá cargas não depende dos tempos de execução de processos ainda não escalonados.

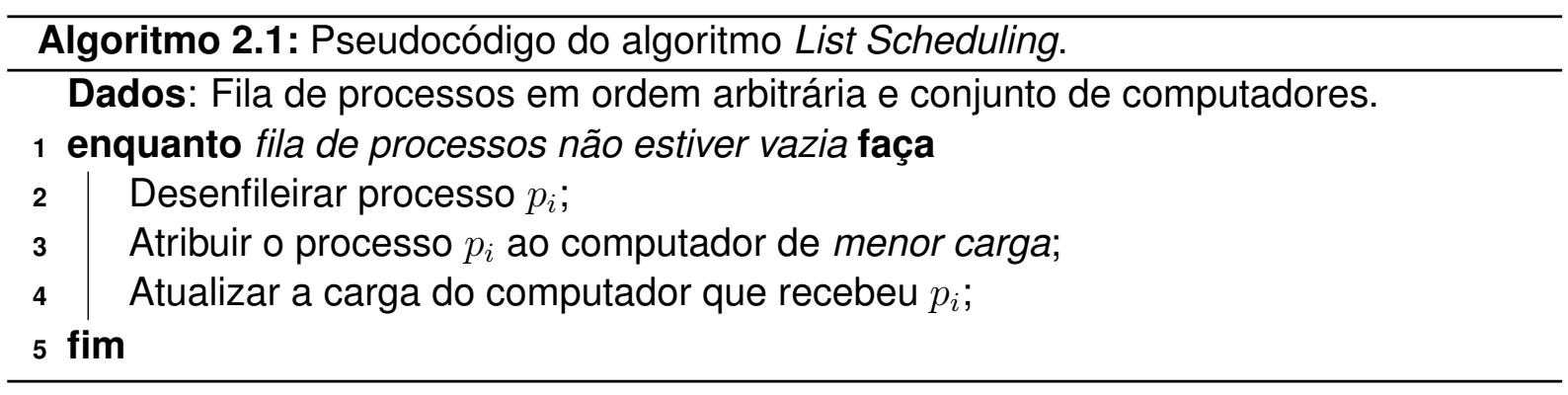

A Figura 2.3, adaptada de Fernandes et al. (2001), ilustra o comportamento desse algoritmo para uma instância do problema com três computadores e sete processos, cujos tempos de execução são dados por: $\tau\left(p_{1}\right)=4, \tau\left(p_{2}\right)=2, \tau\left(p_{3}\right)=1, \tau\left(p_{4}\right)=5, \tau\left(p_{5}\right)=9$, $\tau\left(p_{6}\right)=2$ e $\tau\left(p_{7}\right)=6$.

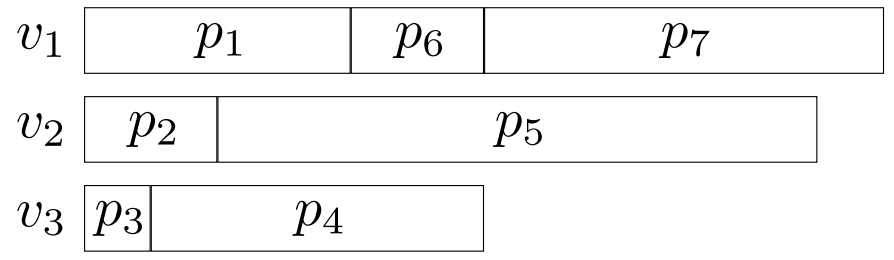

Figura 2.3: Exemplo de escalonamento utilizando o algoritmo LS para uma instância de 3 computadores e 7 processos, adaptada de Fernandes et al. (2001). O algoritmo LS produz o escalonamento $\left\{\left\{p_{1}, p_{6}, p_{7}\right\},\left\{p_{2}, p_{5}\right\},\left\{p_{3}, p_{4}\right\}\right\}$, cujo makespan é de $\tau\left(p_{1}\right)+\tau\left(p_{6}\right)+$ $\tau\left(p_{7}\right)=12$.

O autor também demonstrou que o LS tem uma taxa de aproximação de $2-\frac{1}{|V|}$, sendo que $|V|$ indica o número de elementos (cardinalidade) do conjunto de computadores $V$. Assim, conforme o número de computadores do ambiente aumenta, esse algoritmo tende a uma 2-aproximação, ou seja, o makespan no pior caso é duas vezes maior que o makespan 
ótimo (GRAHAM, 1966; HALL, 1997). Além disso, o algoritmo LS pode ser implementado com complexidade assintótica $\mathcal{O}\left(|P| \log _{2}|P|\right)$, em que $|P|$ corresponde ao número de procesSOS (GAREY; GRAHAM; JOHNSON, 1978). O autor ainda demonstrou que qualquer algoritmo de aproximação baseado no LS tem razão de aproximação da ordem de $2-\frac{1}{|V|}$ (GRAHAM, 1966; FUJITA; YAMASHITA, 2000).

Posteriormente, Graham (1969) estendeu esse algoritmo, considerando a possibilidade de ordenar a fila de processos de maneira decrescente em relação ao tempo de processamento. Dessa maneira, o processo mais longo (ou seja, que demanda maior tempo de processamento) é o primeiro a ser escalonado. Esse novo algoritmo, denominado Longest Processing Time (LPT), evita que processos longos sejam alocados em computadores com alta carga, reduzindo o makespan. Pode-se demonstrar que o algoritmo LPT é uma $\left(\frac{4}{3}-\frac{1}{3|V|}\right)$-aproximação (GRAHAM, 1969; HALL, 1997; FUJITA; YAMASHITA, 2000), além de ter complexidade assintótica igual a $\mathcal{O}(|P| \log (|P| \cdot|V|))$ (GAREY; GRAHAM; JOHNSON, 1978). O comportamento desse algoritmo é ilustrado na Figura 2.4, a qual considera a mesma instância apresentada na Figura 2.3.

\begin{tabular}{|c|c|c|c|}
\hline$v_{1}$ & \multicolumn{2}{|c|}{$p_{5}$} & $p$ \\
\hline$v_{2}$ & $p_{7}$ & $p_{2}$ & $p_{6}$ \\
\hline$v_{3}$ & $p_{4}$ & $p_{1}$ & \\
\hline
\end{tabular}

Figura 2.4: Exemplo de escalonamento utilizando o algoritmo LPT para uma instância de 3 computadores e 7 processos. A fila de processos está ordenada de maneira decrescente. O algoritmo LPT produz o escalonamento $\left\{\left\{p_{5}, p_{3}\right\},\left\{p_{7}, p_{2}, p_{6}\right\},\left\{p_{4}, p_{1}\right\}\right\}$, cujo makespan é de $\tau\left(p_{5}\right)+\tau\left(p_{3}\right)=10$.

Nesse mesmo trabalho, Graham (1969) analisou o efeito da divisão da fila de processos em duas partições: uma com processos de longa duração e outra com os de menor duração. Nesse modelo, um processo $p_{c}$ é de curta duração se $\tau\left(p_{c}\right) \leq \frac{1}{k \cdot|V|} \sum_{j=1}^{|P|} \tau\left(p_{j}\right)$, para algum inteiro positivo $k$. Dessa maneira, existem $k \cdot|V|$ processos de longa duração e, consequentemente, $|V|^{k \cdot|V|}$ possíveis soluções de escalonamento. Pode-se, portanto, enumerar todas essas soluções e, assim, selecionar a de menor makespan. A partir dessa alocação inicial, realiza-se o escalonamento dos $|P|-k \cdot|V|$ processos restantes (ou seja, os de menor duração) utilizando o algoritmo LPT.

Deve-se observar que, para o escalonamento de processos longos, existe um universo de soluções cujo tamanho depende apenas do número de computadores, sendo independente do número de processos. Caso esse número seja fixo, tem-se uma $\left(1+\frac{1}{k}\right)$ aproximação, para um dado inteiro positivo $k$ (GRAHAM, 1969; WILLIAMSON; SHMOYS, 2010).

Ainda em relação a ambientes homogêneos voltados para aplicações do tipo bag-of-tasks, Coffman Jr., Garey e Johnson (1978), estendendo um trabalho de Graham (1972), estudaram o problema de escalonamento como um caso particular do problema bin-packing. 
Bin-packing é um clássico problema de empacotamento (GAREY; JOHNSON, 1979; MARTELLO; TOTH, 1990), que consiste em um conjunto ilimitado de caixas, de mesma capacidade, e um conjunto finito de itens de tamanhos variados. O objetivo é empacotar todos os itens no menor número possível de caixas.

Diversos algoritmos têm sido propostos para esse problema, sendo que um dos mais simples e melhor estudado é o First Fit (FF). Esse algoritmo guloso processa os itens em ordem arbitrária. Para cada item, FF tenta empacotá-lo na primeira caixa que pode acomodá-lo. Se nenhuma caixa é encontrada, abre-se uma nova, empacotando o item nela. Pode-se, ainda, demonstrar que o FF é uma 2-aproximação (MARTELLO; TOTH, 1990).

Em seu trabalho, Coffman Jr., Garey e Johnson (1978) consideraram que cada caixa representa um computador e cada item corresponde a um processo, sendo que o tamanho do item define o tempo de execução do processo. Estudaram, então, uma variação do algoritmo FF, denominada First Fit Decreasing (FFD), a qual tem como diferença uma etapa inicial responsável por organizar os processos em ordem decrescente de tempo de execução. No entanto, esse algoritmo ainda considera que o número de computadores é ilimitado, pela definição do problema bin-packing. Por esse motivo, Coffman Jr., Garey e Johnson (1978) desenvolveram um procedimento adicional, denominado Multifit, que determina o maior makespan possível para o total de computadores disponíveis e, assim, executam o algoritmo FFD para atingir um makespan dentro desse limite.

Pode-se demonstrar que o algoritmo Multifit é executado em tempo similar ao LPT e que possui uma razão de aproximação da ordem de $\alpha=\frac{20}{17}$ (COFFMAN JR.; GAREY; JOHNSON, 1978; GAREY; GRAHAM; JOHNSON, 1978).

Com relação a ambientes heterogêneos, porém ainda executando processos independentes, Ibarra e Kim (1977) propuseram e analisaram dois algoritmos denominados Min-min e Max-min, além de suas possíveis variações. Ambos algoritmos consideram o completion time esperado para a execução de um processo por um determinado computador. Nesse caso, o tempo de execução de um processo $p_{i}$ sobre um computador $v_{j}$ é definido por $\tau\left(p_{i}, v_{j}\right)$.

O algoritmo Min-min inicialmente cria um conjunto $T$ com os menores completion time obtidos, ou seja:

$$
T=\min _{1 \leq j \leq|V|} \tau\left(p_{i}, v_{j}\right),
$$

para todos os processos $p_{i}, 1 \leq i \leq|P|$. Em seguida, o processo com menor completion time em relação aos computadores $v_{j} \in V$ é selecionado e escalonado sobre tal computador. Finalmente, esse processo é removido da fila de processos e o valor do makespan é atualizado. Esse algoritmo é iterado até que todos os processos sejam escalonados. Pode-se demonstrar que a complexidade assintótica desse algoritmo é da ordem de $\mathcal{O}\left(|P|^{2} \cdot|V|\right)$ (IBARRA; KIM, 1977; BRAUN et al., 2001).

Como limitação, o algoritmo Min-min pode atrasar consideravelmente a execução de 
processos cujo tempo estimado de execução seja alto. Isso acontece devido ao mecanismo que prioriza o escalonamento de processos com menor completion time; assim, em um ambiente com grande quantidade de processos de curta duração, os mais longos permanecerão na fila até que todos os demais sejam escalonados. A fim de realizar escalonamentos mais adequados em tais cenários, Ibarra e Kim (1977) propuseram o algoritmo Max-min, que prioriza o escalonamento de processos com maior valor de completion time (BRAUN et al., 2001). Visam, com isso, prover a execução concorrente de processos com maior e menor duração.

Apesar de eficientes, motivo pelo qual são largamente utilizados até os dias de hoje, os algoritmos Min-min e Max-min têm razão de aproximação proporcional a $|V|$, ou seja, a razão entre o makespan obtido e o makespan ótimo cresce conforme o número de computadores aumenta, o que limita sua escalabilidade (IBARRA; KIM, 1977).

Mais recentemente, Bougeret et al. (2010) desenvolveram uma $\frac{5}{2}$-aproximação para o escalonamento hierárquico (esse tipo de escalonamento é descrito na Seção 2.2.1) em ambientes heterogêneos, porém considerando apenas aplicações do tipo bag-of-tasks.

Finalmente, alguns algoritmos de aproximação também consideram a existência de comunicação entre processos. Nesse caso, uma dada aplicação é modelada por meio de um grafo acíclico dirigido (DAG, do inglês Directed Acyclic Graph ) representado por $\mathcal{G}_{D A G}=(P, L)$, em que $P$ corresponde ao conjunto de processos (vértices) e $L$ representa as arestas que conectam pares de processos. Cada aresta $\left(p_{i}, p_{j}\right) \in L$ mapeia a dependência entre processos, de modo que o processo $p_{i}$ deve ter sua execução finalizada antes que $p_{j}$ seja iniciado. Nesse caso, $p_{i}$ é dito predecessor de $p_{j}$ e $p_{j}$ é o sucessor de $p_{i}$ (FUJITA; YAMASHITA, 2000). Além disso, a cada aresta é associado um peso não-negativo que representa o volume de dados transferidos de $p_{i}$ para $p_{j}$ (ARABNEJAD; BARBOSA, 2011; ARABNEJAD, 2012). A Figura 2.5, adaptada de Arabnejad (2012), traz um exemplo de um DAG composto por dez processos.

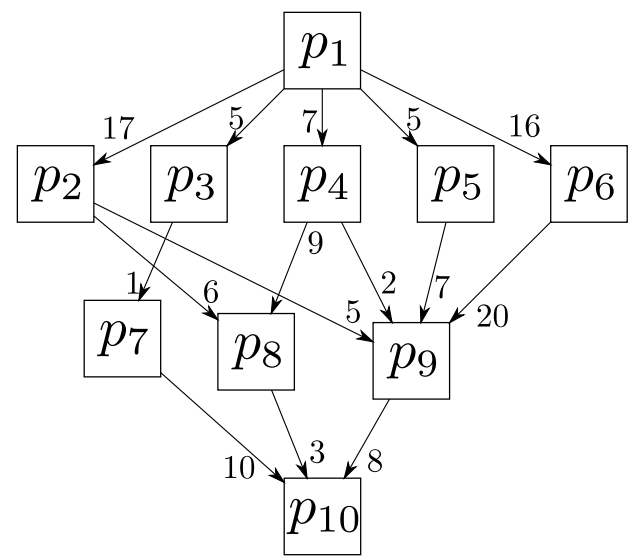

Figura 2.5: Exemplo de DAG para uma aplicação composta por 10 processos, adaptado de Arabnejad (2012).

A partir do conhecimento do DAG de aplicações, Hwang et al. (1989) desenvolveram 
o algoritmo Extended List Scheduling (ELS) que inicialmente obtém um escalonamento utilizando o algoritmo LS, sem considerar o custo de comunicação entre processos. Em seguida, ELS insere os custos de comunicação no escalonamento obtido. Foi demonstrado que a garantia de desempenho desse algoritmo é de $\left(2-\frac{1}{|V|}\right) \mathrm{OPT}+\sum_{p_{i}, p_{j} \in P} \ell\left(p_{i}, p_{j}\right)$, dado que $\ell\left(p_{i}, p_{j}\right)$ é o peso da aresta $\left(p_{i}, p_{j}\right) \in L$ e OPT é o valor da solução ótima (HWANG et al., 1989; FUJITA; YAMASHITA, 2000).

Ainda nessa linha de pesquisa, quando o DAG constitui uma árvore, i.e., um grafo sem ciclos, Munier (1999) analisou dois cenários, demonstrando a existência de algoritmos de aproximação para ambos. No primeiro caso, considerou um número ilimitado de computadores, obtendo uma aproximação da ordem de $2-\frac{1}{1+\rho}$, em que $\rho$ representa a razão máxima entre atrasos de comunicação e a duração dos processos. No segundo caso, ou seja, quando o número de computadores é fixo e igual a $|V|$, a razão de aproximação obtida é de:

$$
1-\left(1-\frac{1}{|V|}\right) \cdot\left(2-\frac{1}{1+\rho}\right) .
$$

Finalmente, Hanen e Munier (2001) estenderam esse algoritmo para DAGs gerais, obtendo uma taxa de aproximação de:

$$
\frac{4+3 \rho}{2+\rho}-\frac{2+2 \rho}{(2+\rho)|V|}
$$

porém considerando apenas pequenos valores de comunicação e supondo que todos os processos possuem o mesmo completion time.

\subsubsection{Abordagens Envolvendo Algoritmos Heurísticos}

Algoritmos heurísticos têm mostrado bons resultados em uma grande variedade de problemas computacionalmente complexos (BLUM; ROLI, 2003). De modo geral, esses algoritmos podem ser classificados em duas categorias (XHAFA et al., 2011): i) heurísticas determinísticas; e ii) meta-heuríticas. Essas duas classes são descritas a seguir.

\section{Heurísticas Determinísticas}

Esse grupo diz respeito a métodos que implementam uma estratégia de busca direta para propor uma solução. As estratégias mais adotadas nesse sentido empregam algoritmos gulosos. No entanto, não são apresentadas garantias de desempenho para tais algoritmos, em oposição ao que ocorre em relação aos algoritmos de aproximação.

Diversos algoritmos foram propostos seguindo essa linha. Alguns dos mais conhecidos são as heurísticas Opportunistic Load Balancing (OLB), Minimum Completion Time (MCT) e Minimum Execution Time (MET) (MAHESWARAN et al., 1999; MA et al., 2011). A primeira atribui um processo assim que um computador se torna ocioso. Caso mais de um computador tenha finalizado seus processos ao mesmo tempo, escolhe-se aleatoriamente aquele que 
receberá o processo. Pode-se implementar esse algoritmo com complexidade $\mathcal{O}(|V|)$, em que $|V|$ corresponde ao número de computadores do sistema, uma vez que é necessário avaliá-los constantemente.

A heurística MCT, por outro lado, escolhe entre os computadores ociosos aquele sobre o qual o processo apresentará menor completion time, enquanto a heurística MET escolhe o computador que, em média, executou seus processos em menor tempo.

Como vantagem, todas essas heurísticas podem ser adotadas para escalonamento online, uma vez que não precisam conhecer, a priori, as características de todos os processos recebidos pelo sistema. Por outro lado, estão limitadas a aplicações bag-of-tasks, pois não consideram custos de comunicação na tomada de decisão.

Com relação a processos que se comunicam, alguns algoritmos têm sido propostos considerando o DAG de aplicações, como o ilustrado na Figura 2.5. Nesse caso, um conceito utilizado por algoritmos de escalonamento é o de caminho crítico ( $\mathrm{CP}$, do inglês Critical Path ) que consiste no maior caminho entre o primeiro processo e o último. No caso da Figura 2.5, por exemplo, o CP é composto pelos vértices $\left\{p_{1}, p_{6}, p_{9}, p_{10}\right\}$, e tem custo 44 .

Adotando os conceitos de DAG e CP, um algoritmo bastante estudado é o Critical Path On a Processor (CPOP), proposto por Topcuoglu, Hariri e Wu (2002), que consiste em três etapas: i) priorização de processos; ii) seleção de computador; e iii) seleção de processo. Na primeira etapa, são atribuídos dois valores a cada processo: $r_{u}$ e $r_{d}$ que representam, respectivamente, o comprimento do maior caminho desse processo até o primeiro vértice e até o último. Ao final dessa etapa, cada processo tem um valor dado por $r_{u}+r_{d}$, que define sua prioridade. Em seguida, o algoritmo avalia qual computador permite a execução do CP em menor tempo. Assim, na terceira etapa, caso o processo com maior prioridade se encontre em um CP, esse será alocado no computador selecionado na segunda etapa.

Nesse mesmo trabalho, Topcuoglu, Hariri e Wu (2002) propuseram o algoritmo Heterogeneous Earliest Finish Time (HEFT), que segue as mesmas etapas do algoritmo CPOP. No entanto, os processos são priorizados apenas em relação ao valor $r_{u}$ e a seleção do computador é feita em relação ao menor completion time para tal processo (da mesma maneira que o algoritmo Min-min seleciona os computadores). Assim, as três etapas exigem um menor tempo de computação (TOPCUOGLU; HARIRI; WU, 2002; ARABNEJAD, 2012). Os autores também demonstraram que ambos algoritmos têm complexidade assintótica da ordem de $\mathcal{O}(|L| \times|V|)$, ou seja, complexidade proporcional ao número de arestas do DAG, definida por $|L|$, e ao número de computadores do sistema $|V|$.

Apesar de todos os algoritmos mostrados nessa seção terem sido desenvolvidos com base no algoritmo List Scheduling de Graham (1966), seus projetistas não apresentam estudos referentes a razões de aproximação. No entanto, a baixa complexidade computacional dessas heurísticas motivou diversas extensões (HAGRAS; JANECEK, 2003; ILAVARASAN; THAMBIDURAI; MAHILMANNAN, 2005; BITTENCOURT; SAKELLARIOU; MADEIRA, 2010; ARABNEJAD; BARBOSA, 2011; ARABNEJAD, 2012; FALZON; LI, 2012). 


\section{Meta-heurísticas}

Finalmente, no segundo grupo, e sem dúvidas o mais estudado, encontram-se métodos que, a partir de uma ou mais soluções aleatórias, realizam um processo de busca. Nessa categoria estão as meta-heurísticas, largamente utilizadas apesar de não apresentarem garantias de desempenho sobre a otimalidade da solução encontrada. Por outro lado, a natureza aleatória dessas técnicas evita, em muitos casos, a interrupção da busca em ótimos locais (BLUM; ROLI, 2003).

Diversas meta-heurísticas têm sido propostas, muitas das quais consideram mecanismos inspirados em fenômenos naturais, como adaptação, não-determinismo e presença de paralelismo implícito. Nesse sentido, Braun et al. (2001) e Ma et al. (2011) destacam os algoritmos genéticos (GA) e técnicas de otimização por colônias de formigas (ACO, do inglês Ant Colony Optimization ) como algumas das principais técnicas adotadas.

GAs são algoritmos evolutivos empregados tradicionalmente em problemas com grande espaço de busca. Esses algoritmos baseiam-se em populações de indivíduos, ou seja, conjuntos formados por possíveis soluções do problema. Essas soluções podem ser geradas aleatoriamente ou criadas a partir de outros algoritmos. Todas soluções (chamadas indivíduos) competem entre si, de modo que aquelas que possuírem melhor aptidão (ou seja, aquelas que forem mais adequadas para o problema) têm maior chance de se reproduzir.

A aptidão é avaliada a partir de uma função objetivo (também chamada função de aptidão ou de fitness), a qual deve ser otimizada. No caso do problema de escalonamento de processos, essa função pode avaliar, por exemplo, o makespan gerado pelos indivíduos. A reprodução consiste em combinar dois ou mais indivíduos de modo a gerar novos indivíduos, os quais podem, ainda, sofrer mutação, ou seja, perturbações aleatórias em sua estrutura. Ao final do processo de busca, o GA tende a convergir para um conjunto uniforme de soluções (BLUM; ROLI, 2003; EIBEN; SMITH, 2003). Mais detalhes sobre projeto e implementação de um GA são apresentados no Capítulo 4.

Devido à simplicidade de sua implementação, GAs têm sido empregados em diversos trabalhos. Braun et al. (2001), por exemplo, considerou apenas aplicações do tipo bag-oftasks e comparou onze heurísticas para o problema de escalonamento estático (incluindo os algoritmos OLB, MCT, MET, Min-min e Max-min), mostrando experimentalmente que o GA obteve melhores resultados tanto em termos de eficiência quanto em termos da qualidade das soluções geradas.

Isso motivou outros trabalhos como, por exemplo, o estudo proposto por Carretero, Xhafa e Abraham (2007), que avaliou um GA para minimizar o makespan e o flowtime de aplicações bag-of-tasks. Nesse caso, utilizaram como função objetivo uma soma ponderada de ambas métricas, obtendo soluções mais adequadas que outros algoritmos que consideram tais métricas separadamente, mesmo para ambientes com grande número de 
processos e computadores.

Mello et al. (2008), considerando ambientes de grades computacionais e comunicação entre processos, propuseram o algoritmo RouteGA, que utiliza um GA para escalonar processos sobre uma vizinhança de computadores, considerando o consumo de recursos da aplicação, além da capacidade e carga do ambiente. A parametrização do GA é feita com base em estimativas do comportamento médio esperado de novas aplicações que chegam à grade, além da latência e largura de banda necessárias para comunicação entre processos. Após essa primeira atribuição, são conduzidas avaliações periódicas com o objetivo de redistribuir (migrar) cargas de processos (MELLO; SENGER; YANG, 2006). Resultados experimentais mostraram que essa alocação inicial reduz o tempo necessário para estabilizar a distribuição equitativa de cargas no sistema.

Outra meta-heurística inspirada em fenômenos naturais é a ACO, que se baseia no comportamento de formigas. Basicamente, quando uma formiga busca alimento, deixa um rastro de feromônio que será seguido pelas demais formigas. Em pouco tempo, todas formigas estão percorrendo o caminho mais curto até o alimento, consequentemente, aquele com maior volume de feromônio.

Seguindo esses conceitos, Fidanova e Durchova (2006) propuseram um algoritmo para escalonamento estático que considera o sistema distribuído como um grafo. No entanto, cada computador é representado por mais de um nó, aumentando o espaço de busca. Um algoritmo de ACO é então empregado para buscar recursos (nós de grafo) que minimizem o makespan de aplicações. Outros autores (KOUSALYA; BALASUBRAMANIE, 2008) consideram a escolha dos nós do grafo a partir da estimação do completion time de processos. Assim, o ACO é usado para atualizar tais valores, com base nas cargas atuais de computadores, melhorando continuamente decisões de escalonamento. Esses trabalhos, no entanto, estão limitados a cenários com poucos computadores, devido à crescente complexidade dessa abordagem.

Trabalhos mais recentes consideram outros algoritmos baseados em colônias, bem como abordagens híbridas de algoritmos genéticos com técnicas de busca local (OMARA; ARAF, 2010; NESMACHNOW; CANCELA; ALBA, 2011; XHAFA et al., 2011; DAVIDOVIĆ et al., 2012; STEFANO; MORANA, 2012). Bons resultados têm sido obtidos, porém não se tem demonstrado preocupação em definir formalmente a qualidade das soluções geradas.

\subsection{Considerações Finais}

A fim de obter uma visão completa sobre o problema de escalonamento de processos, este capítulo apresentou a taxonomia de Casavant e Kuhl (1988), para classificar algoritmos de escalonamento, a qual foi complementada pelos estudos de Dong e Akl (2006). Essas taxonomias foram, posteriomente, utilizadas para classificar os algoritmos considerados neste trabalho. Em seguida, este capítulo destacou uma classificação para métricas de 
escalonamento segundo Dong e Akl (2006) e Chunlin e Layuan (2009). Essas metas permitem compreender em que contexto esta tese de doutorado está inserida, o qual se refere ao escalonamento orientado a sistemas. Finalmente, foram apresentados trabalhos relacionados, os quais propõem algoritmos aproximados e heurísticos para tratar o problema de escalonamento de processos.

Pela análise dos trabalhos relacionados, observa-se que muitos são focados em heurísticas e meta-heurísticas, os quais não apresentam garantias de qualidade para as soluções propostas. Além disso, do que se diz respeito ao conhecimento do autor desta tese, estudos em busca de limites ótimos para tais soluções estão direcionados a casos específicos, como ambientes homogêneos com pouca ou nenhuma comunicação entre processos. Essa lacuna motivou a proposta de um modelo de otimização matemática para avaliar a qualidade de soluções de escalonamento, bem como conduziu o projeto de um algoritmo eficiente, denominado Min Heap-based Scheduling Algorithm (MHSA), capaz de suportar a comunicação entre processos e ambientes heterogêneos. Demostrou-se, também, que esse algoritmo garante uma $\alpha$-aproximação em relação a soluções ótimas. As atividades envolvidas na proposta desse modelo de otimização e do algoritmo MHSA são apresentadas no próximo capítulo. 


\section{Abordagem para Escalonamento Orientado a Sistemas Respeitando Restrições Temporais e de Qualidade de Soluções}

\subsection{Considerações Iniciais}

Neste capítulo são descritas as etapas cumpridas para o desenvolvimento de uma abordagem orientada a sistemas para o escalonamento de processos em grades computacionais. Como parte do objetivo, essa abordagem deve executar em tempo hábil a fim de propor boas soluções de escalonamento. No que se refere a tais restrições temporais, buscou-se projetar um algoritmo com baixa complexidade de tempo e, no que se refere à qualidade das soluções, fez-se necessário computar e obter uma boa razão de aproximação do algoritmo proposto em relação à qualidade proveniente de um escalonador ótimo.

Inicialmente, com o objetivo de melhor compreender o problema de escalonamento de processos, estudou-se sua complexidade, conforme apresentado na Seção 3.2. Dessa maneira, mapeou-se as duas principais classes de algoritmos de escalonamento, ou seja, o escalonamento orientado a aplicações e orientado a recursos, em dois clássicos problemas $\mathcal{N} \mathcal{P}$-Completos. Essa complexidade, associada ao fato de se desejar algoritmos que produzam soluções de qualidade e de maneira eficiente, motivaram o estudo de diferentes abordagens de escalonamento de processos. 
Após a compreensão da complexidade, foram iniciados estudos a fim de quantificar a qualidade de soluções de escalonamento. Nessa etapa, projetou-se um modelo de otimização matemática que, com base em comportamentos de processos e computadores, quantifica o tempo de execução de processos. Demonstrou-se, assim, que o problema modelado dessa maneira é convexo, o que permite a adoção de diversos métodos de otimização, propostos na literatura, para tratá-lo. A descrição desse modelo, bem como sua resolução por meio do método dos multiplicadores de Lagrange, é mostrada na Seção 3.3.

Ao empregar métodos de otimização propostos na literatura, observou-se grande custo computacional, principalmente devido ao número de variáveis que instâncias reais do problema consideram. Isso motivou o projeto de um algoritmo eficiente que, para qualquer instância do problema, propusesse soluções de escalonamento em tempo hábil. Esse algoritmo, denominado Min Heap-based Scheduling Algorithm (MHSA), é apresentado na Seção 3.4. Além disso, estudou-se a qualidade das soluções geradas pelo MHSA, permitindo concluir que ele é uma $\alpha$-aproximação em relação a um escalonador ótimo, mesmo em ambientes distribuídos heterogêneos em que há presença de comunicação entre processos. A demonstração dessa razão de aproximação também é feita neste capítulo.

\subsection{Formalização do Problema de Escalonamento de Pro- cessos}

Nesta seção, é definido o problema de escalonamento de processos com base na notação adotada por Garey e Johnson (1979) e por Mello (2009). Inicialmente, seja um conjunto $A$ de aplicações paralelas e uma função $\operatorname{tam}\left(a_{k}\right)$ que define o número de processos contidos em uma aplicação $a_{k} \in A$. Cada aplicação é composta por diferentes números de processos. Considera-se, também, um conjunto $P$ que contém todos processos de todas aplicações, como consequência o número de elementos (ou cardinalidade) de $P$ é dada por $|P|=\sum_{k=1}^{|A|} \operatorname{tam}\left(a_{k}\right)$.

Após essas definições iniciais, pode-se especificar as características de processos e aplicações. Cada processo $p_{i} \in P$ possui demandas específicas, também chamadas de comportamento, em relação a determinados recursos, em termos de processamento de CPU, acesso a memória, entrada e saída em disco rígido e operações sobre a rede. Processos em $P$ são alocados sobre um conjunto de computadores, ou elementos de processamento (EPs), denotado por $V$, em que cada computador $v_{j} \in V$ pode ter diferentes capacidades: velocidade de processamento, tamanho e tempo de acesso à memória principal, capacidade e tempo de acesso ao disco rígido, etc.

Os computadores em $V$ estão conectados por diferentes canais de comunicação. Assim, todo esse ambiente pode ser modelado por um grafo não-dirigido $\mathcal{G}=(V, E)$, em que cada vértice $v_{j} \in V$ representa um computador e os canais de comunicação entre pares de 
vértices são descritos por arestas $\left(v_{j}, v_{l}\right) \in E$ do grafo $\mathcal{G}$. Esses canais de comunicação têm propriedades de largura de banda e latência associadas.

No cenário de interesse desta tese, o problema de escalonamento de processos consiste em distribuir todos elementos de $P$ sobre os vértices do grafo $\mathcal{G}$, com objetivo de: i) reduzir o tempo total de execução de aplicações; e ii) aumentar a utilização de computadores.

A fim de ilustrar esses conceitos, considera-se a seguinte instância do problema, adaptada de Mello (2009), com duas aplicações paralelas compostas pelos processos apresentados na Tabela 3.1.

Tabela 3.1: Comportamento dos processos das aplicações paralelas.

\begin{tabular}{llllllll}
\hline Aplicação 1 & & \multicolumn{1}{l}{} \\
\hline Processo & $\mathrm{CPU}^{a}$ & $\mathrm{ML}^{b}$ & $\mathrm{ME}^{c}$ & $\mathrm{HDL}^{d}$ & $\mathrm{HDE}^{e}$ & $\mathrm{NETR}^{f}$ & $\mathrm{NETE}^{g}$ \\
\hline$p_{1}$ & 1.234 & 123,78 & 0,00 & 78,21 & 0,00 & $12,50\left(p_{2}\right)$ & $532,12\left(p_{2}\right)$ \\
$p_{2}$ & 1.537 & 23,54 & 89,45 & 0,00 & 12,30 & $532,12\left(p_{1}\right)$ & $12,50\left(p_{1}\right)$ \\
\hline Aplicação 2 & & & & & & & \\
\hline Processo & $\mathrm{CPU}$ & $\mathrm{ML}$ & $\mathrm{ME}$ & $\mathrm{HDL}$ & $\mathrm{HDE}$ & $\mathrm{NETR}$ & $\mathrm{NETE}$ \\
\hline$p_{3}$ & 1.221 & 823,78 & 70,00 & 78,21 & 543,00 & $10,92\left(p_{4}\right)$ & $321,12\left(p_{5}\right)$ \\
$p_{4}$ & 1.137 & 223,54 & 179,45 & 324,00 & 212,31 & $423,12\left(p_{5}\right)$ & $10,92\left(p_{3}\right)$ \\
$p_{5}$ & 2.237 & 23,54 & 17,45 & 12,00 & 0,00 & $321,12\left(p_{3}\right)$ & $423,12\left(p_{4}\right)$ \\
\hline
\end{tabular}

${ }^{a}$ Número de instruções executadas pelos processos (em milhões).

${ }^{b}$ Total de bytes lidos por segundo da memória principal (em Kbytes/s) .

${ }^{c}$ Total de bytes escritos por segundo na memória principal (em Kbytes/s).

${ }^{d}$ Total de bytes lidos por segundo do disco rígido (em Kbytes/s).

${ }^{e}$ Total de bytes escritos por segundo no disco rígido (em Kbytes/s).

${ }^{\text {T}}$ Total de bytes recebidos pela rede por segundo. O segundo parâmetro identifica o processo emissor (em Kbytes/s).

9Total de bytes enviados pela rede por segundo. O segundo parâmetro identifica o processo receptor (em Kbytes/s).

Considera-se, também, um ambiente composto pelos cinco computadores descritos na Tabela 3.2. Esses computadores, que representam o conjunto $V$, estão interconectados conforme a Figura 3.1, que também apresenta a largura de banda e latência média dos canais de comunicação. Além disso, define-se uma função $\varrho: P \rightarrow V$ que indica a alocação, ou escalonamento, de um processo $p_{i} \in P$ sobre um computador $v_{j} \in V$. Um exemplo de solução para essa instância é dada por $\varrho\left(p_{1}\right)=v_{1}, \varrho\left(p_{2}\right)=v_{2}, \varrho\left(p_{3}\right)=v_{3}$, $\varrho\left(p_{4}\right)=v_{4}$ e $\varrho\left(p_{5}\right)=v_{5}$.

Para cada instância do problema, deve-se escalonar $|P|$ processos sobre um ambiente composto por $|V|$ computadores e, consequentemente, o universo de possíveis soluções de escalonamento é igual a $|V|^{|P|}$. Para a instância anteriormente apresentada, o problema teria um universo de soluções, ou hipóteses, igual a $5^{5}=3.125$. Instâncias reais para o problema tendem a considerar, por exemplo, 1.024 computadores e 64 apli- 
Tabela 3.2: Características dos computadores.

\begin{tabular}{llllll}
\hline Computador & $\mathrm{CPU}^{a}$ & $\mathrm{ML}^{b}$ & $\mathrm{ME}^{c}$ & $\mathrm{HDL}^{d}$ & $\mathrm{HDE}^{e}$ \\
\hline$v_{1}$ & 1.200 & 100.000 & 40.000 & 32.000 & 17.000 \\
$v_{2}$ & 2.100 & 120.000 & 50.000 & 42.000 & 19.000 \\
$v_{3}$ & 1.800 & 100.000 & 30.000 & 22.000 & 9.000 \\
$v_{4}$ & 1.700 & 95.000 & 20.000 & 25.000 & 11.000 \\
$v_{5}$ & 2.500 & 110.000 & 60.000 & 62.000 & 30.000 \\
\hline
\end{tabular}

${ }^{a}$ Número de instruções executadas pelo computador por segundo (em milhões).

${ }^{b}$ Vazão de leitura em memória principal (em Kbytes/s).

${ }^{c}$ Vazão de escrita em memória principal (em Kbytes/s).

dVazão de leitura em disco rígido (em Kbytes/s).

${ }^{e}$ Vazão de escrita em disco rígido (em Kbytes/s).

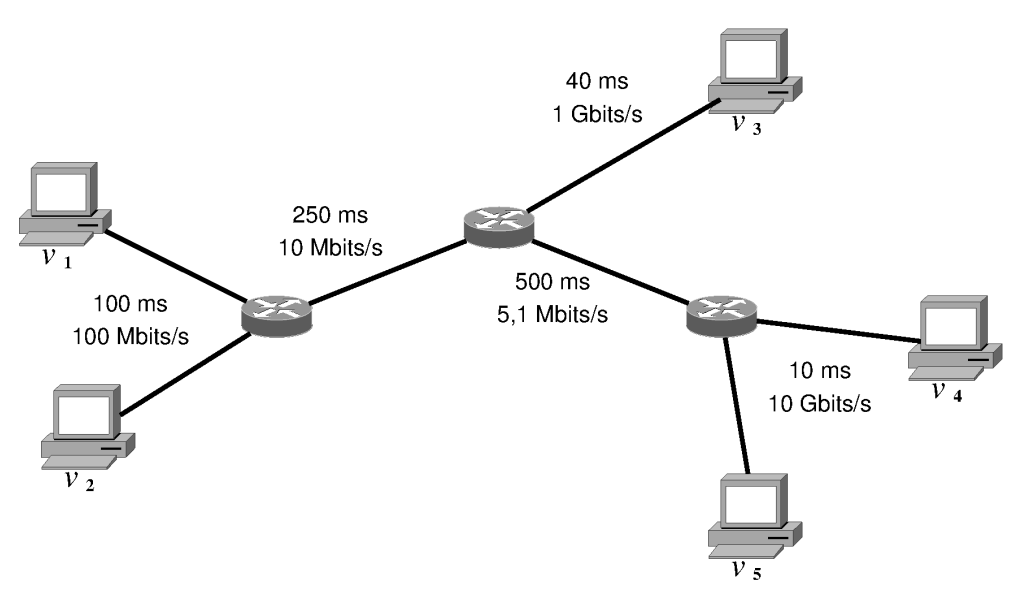

Figura 3.1: Exemplo de rede de interconexão.

cações, contendo 512 processos cada. Nesse caso o espaço de soluções seria igual a $1.024^{64 \cdot 512}=1.024^{32.768}$.

Observa-se, portanto, que o espaço de soluções para o problema de escalonamento é exponencial. Por essa razão, deve-se propor abordagens capazes de solucionar o problema em tempo computacional aceitável. No entanto, não se conhece um algoritmo de tempo polinomial que seja capaz de solucionar o problema de forma ótima, ou seja, encontrar a melhor solução, o que permite caracterizá-lo como intratável (GAREY; JOHNSON, 1979). Dessa maneira, é necessário adotar algoritmos que explorem parte do espaço de soluções e encontrem, por meio de suposições e suas avaliações, uma boa hipótese em tempo polinomial (GAREY; JOHNSON, 1979).

Após caracterizar o problema como intratável é importante compreender o quão difícil é solucioná-lo. Para isso, são considerados, a seguir, dois problemas $\mathcal{N} \mathcal{P}$-Completos clássicos, que permitem compreender a complexidade do problema de escalonamento de processos.

Inicialmente, seja o problema denominado Minimum Weighted Completion Time Scheduling (MWCTS), definido da seguinte maneira (GAREY; JOHNSON, 1979, p. 240): 
Instância. Seja um conjunto $P$ de tarefas, número $m \in \mathbb{Z}^{+}$de processadores, para cada tarefa $p \in P$ um comprimento $\iota(p) \in \mathbb{Z}^{+}$e um peso $\omega(p) \in \mathbb{Z}^{+}$, e um inteiro positivo $k$.

Questão. Existe um escalonamento $\varrho$ de $P$ sobre $m$-processadores tal que a soma, sobre todo $p \in P$, de $(\varrho(p)+\iota(p)) \cdot \omega(p)$ não é maior que $k$ ?

No contexto desta tese, considera-se $m$ computadores com suas diferentes capacidades ao invés de $m$ processadores, além disso, cada $p \in P$ é definido por um processo. O comprimento $\iota(p)$ corresponde ao tamanho de um processo $p$, ou seja, o número de instruções que $p$ demanda, e o peso $\omega(p)$ define a demanda de $p$ por um dado recurso. Da maneira como está formulado, o problema supõe a existência de um limitante superior $k$ que garante a existência de um escalonamento válido. Tem-se, para esse problema, o seguinte resultado:

Teorema 3.1. O problema MWCTS é $\mathcal{N} \mathcal{P}$-Completo para $m \geq 2$ (LENSTRA; KAN; BRUCKER, 1977; GAREY; JOHNSON, 1979).

Deve-se observar que esse problema mapeia a redução do tempo de execução de aplicações definindo, consequentemente, o objetivo de algoritmos de escalonamento orientados a aplicações (DONG; AKL, 2006). Por outro lado, o problema a seguir, denominado Integer Knapsack Problem (I-KS), ou problema da mochila inteira, representa o objetivo do escalonamento orientado a recursos (GAREY; JOHNSON, 1979, p. 247):

Instância. Seja um conjunto finito $P$, para cada $p \in P$ um tamanho $\varsigma(p) \in \mathbb{Z}^{+}$e um valor $\nu(u) \in \mathbb{Z}^{+}$, e inteiros positivos $b$ e $k$.

Questão. Existe uma atribuição de inteiros não-negativos $\varrho(p)$ para cada $p \in P$ tal que $\sum_{p \in P} \varrho(p) \cdot \varsigma(p) \leq b$ e tal que $\sum_{p \in P} \varrho(p) \cdot \nu(u) \geq k$ ?

Supondo que o termo $b$ representa a capacidade máxima de um computador (por exemplo, o número máximo de instruções que esse computador pode processar em um segundo), e que $k$ é o limitante inferior de utilização de recursos. Assim, tem-se o objetivo $k \approx b$ como sendo a maximização dessa utilização. Supõe-se, ainda que $\nu(p)=\varsigma(u)$ é o tamanho de um processo $p$ (por exemplo, seu número de instruções), consequentemente, um escalonamento $\varrho(p)$ deve respeitar a capacidade de computador, i.e., $k \leq$ $\sum_{p \in P} \varrho(p) \cdot \varsigma(p) \leq b$. Se forem considerados mais de um computador, cada um mapeado como uma mochila, tem-se a formalização do problema de escalonamento de processos orientado a recursos ${ }^{1}$.

Tem-se, para esse problema, o seguinte resultado:

Teorema 3.2. O problema I-KS é $\mathcal{N} \mathcal{P}$-Completo mesmo quando $\varsigma(p)=\nu(p)$ (LUEKER, 1975; GAREY; JOHNSON, 1979).

\footnotetext{
${ }^{1}$ Problemas envolvendo mais de uma mochila são denominado Multiple Knapsack Problems (MARTELLO; TOTH, 1990)
} 
Com base nas formalizações descritas nesta seção, i.e., nos problemas MWCTS e I-KS, conclui-se o escalonamento de processos é $\mathcal{N} \mathcal{P}$-Completo seja esse orientado a aplicações ou a recursos. Consequentemente, o escalonamento orientado a sistemas, objeto de interesse desta tese, é também um problema $\mathcal{N} \mathcal{P}$-Completo, uma vez que combina ambos objetivos.

Após compreender a complexidade do problema de interesse desta tese, apresentase, a seguir, o modelo de otimização matemática proposto a fim de quantificar o tempo de execução de processos e, consequentemente, permitir a avaliação de qualidade de soluções.

\subsection{Modelo de Otimização Matemática para Escalonamento de Processos}

Como primeira etapa desta tese, projetou-se um modelo de otimização matemática a fim de quantificar a qualidade de soluções de escalonamento de processos sobre ambientes distribuídos. Dessa maneira, tornou-se possível comparar um algoritmo de escalonamento ótimo ao proposto nesta tese, além de verificar sua razão de aproximação.

Esse modelo considera comportamentos de processos e computadores. No caso dos processos, tem-se informações sobre: i) carga de trabalho, i.e., total de operações que cada processo solicita a fim de executar instruções de processamento; e ii) taxa de comunicação, i.e., o total de bytes transferidos durante a execução de processos. Com relação aos computadores, leva-se em consideração: i) capacidade de CPU, i.e., o número de instruções que cada computador pode executar durante um segundo; e ii) capacidade de rede, i.e., o número de bytes que cada canal de comunicação pode transferir por segundo.

Essas informações podem ser disponibilizadas antes da execução do escalonador ou serem estimadas de maneira online, i.e., à medida que as aplicações são executadas. Estudos nessa segunda frente têm sido desenvolvidos pelo grupo de pesquisa no qual esta tese está inserida (MELLO; YANG, 2008; MELLO, 2009; DODONOV; MELLO, 2010), contudo, no contexto desta tese, supõe-se que tais informações encontram-se disponíveis, seja de maneira prévia ou estimadas de forma online.

O modelo proposto pode, também, ser utilizado para projetar novos algoritmos de escalonamento baseados em heurísticas. As próximas seções detalham esse modelo e o problema de otimização resultante, o qual é tratado utilizando o método dos multiplicadores de Lagrange (BOYD; VANDENBERGHE, 2004).

\subsubsection{Modelo de Otimização Matemática}

Seja um sistema distribuído tal como o descrito na Seção 3.2, i.e., um grafo $\mathcal{G}=(V, E)$, em que $V$ corresponde ao conjunto de computadores e $E$ representa o conjunto de arestas 
conectando pares de vértices. O sistema $\mathcal{G}$ executa um conjunto de aplicações $A$, sendo que cada aplicação é composta por um conjunto de processos. Combinando todos os processos, tem-se o conjunto $P$. Os processos em $P$ produzem cargas de trabalho sobre $\mathcal{G}$ em termos de instruções de processamento e eventos de comunicação.

Considera-se, então, as variáveis apresentadas a seguir. Seja w um vetor na forma:

$$
\mathbf{w}=\left[\begin{array}{c}
w_{1} \\
\vdots \\
w_{|P|}
\end{array}\right]
$$

em que $w_{k}$ é o total de instruções de processamento, i.e., instruções de CPU provenientes do processo $p_{k} \in P$.

Seja c um vetor na forma:

$$
\mathbf{c}=\left[\begin{array}{c}
c_{1} \\
\vdots \\
c_{|V|}
\end{array}\right],
$$

em que $c_{k}$ é a capacidade do computador $v_{k} \in V$ em milhões de instruções por segundo.

Seja $\Gamma$ uma matriz simétrica de $|V| \times|V|$, i.e., computadores por computadores, na forma:

$$
\boldsymbol{\Gamma}=\left[\begin{array}{ccc}
\gamma_{1,1} & \ldots & \gamma_{1,|V|} \\
\vdots & \ddots & \vdots \\
\gamma_{|V|, 1} & \ldots & \gamma_{|V|,|V|}
\end{array}\right],
$$

em que $\gamma_{i, j}$ representa a capacidade ou largura de banda, em megabytes por segundo, do canal de comunicação que é representado pela aresta $\left(v_{i}, v_{j}\right) \in E$. Como a matriz é simétrica, define-se que $\gamma_{i, j}=\gamma_{j, i}$, i.e., a capacidade da rede conectando $v_{i}$ e $v_{j}$ é a mesma em ambos sentidos. O termo $\gamma_{i, i}$, ou seja, a capacidade de conexão de um computador consigo mesmo, é dado pela capacidade de seu barramento interno, que pode ser considerada, na prática, um valor elevado quando comparado aos demais termos da matriz. Dessa maneira, todo elemento de $\Gamma$ está em $\mathbb{R}_{0}^{+}$, i.e., assume valores não-negativos.

Seja, ainda, L uma matriz $|P| \times|P|$ na forma:

$$
\mathbf{L}=\left[\begin{array}{ccc}
\ell_{1,1} & \ldots & \ell_{1,|P|} \\
\vdots & \ddots & \vdots \\
\ell_{|P|, 1} & \ldots & \ell_{|P|,|P|}
\end{array}\right]
$$

em que $\ell_{i, j}$ é o total de bytes a ser transferido do processo $p_{i}$ para o processo $p_{j}$. Se um processo $p_{i}$ não se comunica com $p_{j}$, então $\ell_{i, j}=0$. Nesse sentido, assim como a matriz $\Gamma$, a matriz $\mathbf{L}$ contém elementos na forma $\ell_{i, j} \in \mathbb{R}_{0}^{+}$, porém não é simétrica.

Finalmente, seja $\mathbf{S}$ uma matriz de escalonamento $|P| \times|V|$ que representa uma solução 
de escalonamento, mapeando processos em $P$ sobre computadores em $V$, da seguinte maneira:

$$
\mathbf{S}=\left[\begin{array}{ccc}
s_{1,1} & \ldots & s_{1,|V|} \\
\vdots & \ddots & \vdots \\
s_{|P|, 1} & \ldots & s_{|P|,|V|}
\end{array}\right]
$$

em que cada elemento $s_{i, j}$ assume apenas dois possíveis valores: $\{0,1\}$. O termo $s_{i, j}=1$ indica que o processo $p_{i}$ será atribuído ao computador $v_{j}$, e o termo $s_{i, j}=0$ significa que o $p_{i}$ não será alocado sobre $v_{j}$.

No contexto desta tese, deseja-se encontrar a melhor matriz de escalonamento $\mathbf{S}$ sem repetição de processos, ou seja, sem atribuir um mesmo processo a dois ou mais computadores $^{2}$. Para encontrar tal matriz, utiliza-se a definição do atraso total de execução, conforme apresentado na Equação (3.1), o qual corresponde ao tempo em que os recursos mantiveram-se ocupados. Ainda nessa equação, a função $\delta^{c p u}(\mathbf{S})$ é responsável por produzir um vetor com $|V|$ elementos os quais representam os atrasos de processamento gerados por computadores em $V$ e a função $\delta^{\operatorname{comm}}(\mathbf{S})$ resulta em um vetor com $|V|$ elementos que definem os atrasos impostos pela comunicação entre processos.

$$
\delta(\mathbf{S})=\sum_{i=1}^{|V|} \delta^{c p u}(\mathbf{S})+\delta^{c o m m}(\mathbf{S})
$$

A partir da soma (Equação (3.1)) dos elementos $\delta^{c p u}(\mathbf{S})$ e $\delta^{c o m m}(\mathbf{S})$, tem-se a soma de todos os atrasos, ou custos envolvidos na execução, impostos por operações de processamento e comunicação sobre $\mathcal{G}$.

A seguir, ambos vetores são definidos separadamente. O primeiro, ou seja, o vetor $\delta^{c p u}(\mathbf{S})$, é definido conforme mostrado na Equação (3.2) que considera, no instante de tempo $t$, a matriz produto na forma $\mathbf{S}^{\top}$. w a fim de obter o total de instruções de processamento atribuídas a todos computadores em $V$. Em seguida, ocorre uma divisão termo a termo pelo vetor $\mathbf{c}$, a qual resulta no custo de execução dos processos atribuídos aos computadores, em segundos ${ }^{3}$.

$$
\delta^{c p u}(\mathbf{S})=\frac{\mathbf{S}^{\top} \cdot \mathbf{w}}{\mathbf{c}}
$$

O segundo vetor, i.e., $\delta^{c o m m}(\mathbf{S})$, é definido na Equação (3.3) que considera, no instante $t$, o produto $\mathbf{S}^{\top} \cdot \mathbf{L} \cdot \mathbf{S}$ para gerar o total de bytes a ser transferido entre todos os pares de processos em $P$. A divisão termo a termo por $\Gamma$ resulta em outra matriz que representa o tempo consumido em todos os eventos de comunicação. Quando calculado o produto pelo vetor 1 , que é composto apenas por uma sequência de $|V|$ números 1 , obtém-se a soma

\footnotetext{
${ }^{2} \mathrm{~A}$ melhor matriz de escalonamento representa a solução ótima para o problema.

${ }^{3} \mathrm{~A}$ matriz $\mathbf{S}^{\top}$ é a transposta da matriz $\mathbf{S}$, i.e., o elemento da $i$-ésima linha e $j$-ésima coluna de $\mathbf{S}^{\top}$ é o elemento da $j$-ésima linha e $i$-ésima coluna de $\mathbf{S}$.
} 
de todos os atrasos de comunicação por computador.

$$
\delta^{c o m m}(\mathbf{S})=\frac{\mathbf{S}^{\top} \cdot \mathbf{L} \cdot \mathbf{S}}{\mathbf{\Gamma}} \cdot \mathbf{1}
$$

Unificando ambas equações anteriores, tem-se o vetor $\delta(\mathbf{S})$ com todos os atrasos envolvidos na solução de escalonamento representada pela matriz $\mathbf{S}$, na forma:

$$
\begin{aligned}
\delta(\mathbf{S}) & =\delta^{c p u}+\delta^{c o m m}(\mathbf{S}) \\
& =\frac{\mathbf{S}^{\top} \cdot \mathbf{w}}{\mathbf{c}}+\frac{\mathbf{S}^{\top} \cdot \mathbf{L} \cdot \mathbf{S}}{\boldsymbol{\Gamma}} \cdot \mathbf{1}
\end{aligned}
$$

De modo a ilustrar os componentes desse modelo, considere uma instância do problema de escalonamento dada por um conjunto de três processos $P=\left\{p_{1}, p_{2}, p_{3}\right\}$ e um sistema distribuído composto por um conjunto de dois computadores $V=\left\{v_{1}, v_{2}\right\}$. Supõese que os três processos são idênticos e têm carga de $1,0 \cdot 10^{6}$ milhões de instruções (MI). Dessa maneira, o vetor $\mathrm{w}$ é dado por:

$$
\mathbf{w}=\left[\begin{array}{l}
1,0 \cdot 10^{6} \\
1,0 \cdot 10^{6} \\
1,0 \cdot 10^{6}
\end{array}\right]
$$

Considera-se, também, que o processo $p_{1}$ envia, ao final de sua execução, 5,0 Mbytes de dados ao processo $p_{2}$, enquanto $p_{2}$ envia 10,0 Mbytes ao processo $p_{1}$ e que não há comunicação entre os demais processos. Assim, a matriz de comunicação L para essa instância do problema tem a seguinte forma:

$$
\mathbf{L}=\left[\begin{array}{ccc}
0 & 5 & 0 \\
10 & 0 & 0 \\
0 & 0 & 0
\end{array}\right]
$$

Supõe-se, ainda, que o sistema distribuído é homogêneo, ou seja, todos os elementos do conjunto $V$ têm as mesmas capacidades de processamento, em milhões de instruções por segundo (MIPS), representadas pelo seguinte vetor :

$$
\mathbf{c}=\left[\begin{array}{l}
1,0 \cdot 10^{4} \\
1,0 \cdot 10^{4}
\end{array}\right] .
$$

Finalmente, as capacidades dos canais de comunicação conectando computadores de $V$ são dadas pela matriz $\Gamma$ a seguir:

$$
\boldsymbol{\Gamma}=\left[\begin{array}{cc}
1,5 \cdot 10^{4} & 10 \\
10 & 1,5 \cdot 10^{4}
\end{array}\right]
$$


ou seja, a largura de banda da rede que conecta $v_{1}$ a $v_{2}$ é de 10,0 MBytes/s. Os valores da diagonal de $\Gamma$ correspondem à capacidade do barramento interno dos computadores, sendo portanto superiores à largura de banda.

Para esse cenário, uma possível solução de escalonamento (matriz $\mathrm{S}$ ) dos elementos de $P$ sobre $V$ é dada por:

$$
\mathbf{S}=\left[\begin{array}{ll}
1 & 0 \\
0 & 1 \\
0 & 1
\end{array}\right]
$$

i.e., o processo $p_{1}$ (primeira linha da matriz $\mathbf{S}$ ) é atribuído ao computador $v_{1}$ (primeira coluna de $\mathbf{S}$ ), enquanto os processos $p_{2}$ e $p_{3}$ (segunda e terceira linha de $\mathbf{S}$, respectivamente) são escalonados sobre o computador $v_{2}$ (segunda coluna de $\mathbf{S}$ ).

Uma vez obtida a matriz S, emprega-se a Equação (3.4) para computar os atrasos envolvidos nessa solução de escalonamento. Para isso, calcula-se o valor do atraso de processamento ( $\delta^{c p u}$, mostrado na Equação (3.2)) e do atraso de comunicação ( $\delta^{c o m m}$, mostrado na Equação (3.3)). Para o atraso de processamento, tem-se:

$$
\delta^{c p u}(\mathbf{S})=\frac{\left[\begin{array}{lll}
1 & 0 & 0 \\
0 & 1 & 1
\end{array}\right] \cdot\left[\begin{array}{l}
1 \cdot 10^{6} \\
1 \cdot 10^{6} \\
1 \cdot 10^{6}
\end{array}\right]}{\left[\begin{array}{l}
1 \cdot 10^{4} \\
1 \cdot 10^{4}
\end{array}\right]}=\left[\begin{array}{l}
100 \\
200
\end{array}\right]
$$

e, para o atraso de comunicação, obtém-se:

$$
\delta^{\mathrm{comm}}(\mathbf{S})=\frac{\left[\begin{array}{lll}
1 & 0 & 0 \\
0 & 1 & 1
\end{array}\right] \cdot\left[\begin{array}{ccc}
0 & 5 & 0 \\
10 & 0 & 0 \\
0 & 0 & 0
\end{array}\right] \cdot\left[\begin{array}{ll}
1 & 0 \\
0 & 1 \\
0 & 1
\end{array}\right]}{\left[\begin{array}{cc}
1,5 \cdot 10^{4} & 10 \\
10 & 1,5 \cdot 10^{4}
\end{array}\right]} \cdot\left[\begin{array}{c}
1 \\
1
\end{array}\right]=\left[\begin{array}{c}
0,5 \\
1
\end{array}\right]
$$

Como consequência, o atraso para cada computador é dado por:

$$
\delta(\mathbf{S})=\delta^{c p u}(\mathbf{S})+\delta^{c o m m}(\mathbf{S})=\left[\begin{array}{c}
100 \\
200
\end{array}\right]+\left[\begin{array}{c}
0,5 \\
1
\end{array}\right]=\left[\begin{array}{c}
100,5 \\
201,0
\end{array}\right],
$$

ou seja, $v_{1}$ permanecerá 100,5 segundos executando sua carga de trabalho, enquanto $v_{2}$ permanecerá ocupado por 201,0 segundos. 


\subsubsection{Método de Otimização}

A fim de encontrar soluções de escalonamento ótimas, é necessário analisar a convexidade do modelo representado na Equação (3.4). Após esse estudo, é utilizado o método dos multiplicadores de Lagrange (BERTSEKAS, 1996; BOYD; VANDENBERGHE, 2004) para encontrar tais soluções.

Primeiramente, é possível formular o problema de escalonamento de processos, mostrado na Equação (3.4), em termos de somas (MATTHEWS, 2000). Por meio dessa formulação, tem-se os atrasos ou custos de processamento e comunicação para um computador individual $v_{i}$, como mostrado nas Equações (3.5) e (3.6), respectivamente.

$$
\begin{gathered}
\delta_{i}^{c p u}(\mathbf{S})=\sum_{m=1}^{|P|} \frac{s_{m, i} \cdot w_{m}}{c_{i}} \\
\delta_{i}^{c o m m}(\mathbf{S})=\sum_{j=1}^{|V|} \sum_{k=1}^{|P|} \sum_{l=1}^{|P|} \frac{s_{k, i} \cdot \ell_{k, l} \cdot s_{l, j}}{\gamma_{i, j}}
\end{gathered}
$$

Pela soma desses termos, tem-se o atraso ou custo total de execução para um computador $v_{i}$, conforme definido na Equação (3.7).

$$
\begin{aligned}
\delta_{i}(\mathbf{S}) & =\delta_{i}^{c p u}(\mathbf{S})+\delta_{i}^{c o m m}(\mathbf{S}) \\
& =\sum_{m=1}^{|P|} \frac{s_{m, i} \cdot w_{m}}{c_{i}}+\sum_{j=1}^{|V|} \sum_{k=1}^{|P|} \sum_{l=1}^{|P|} \frac{s_{k, i} \cdot \ell_{k, l} \cdot s_{l, j}}{\gamma_{i, j}}
\end{aligned}
$$

A partir disso, é possível obter o vetor $\delta(\mathbf{S})$ que contém o atraso total para todos computadores do sistema. Alternativamente, soma-se ${ }^{4}$ todos os termos de $\delta(\mathbf{S})$ para simplificar a observação do custo total, tal como definido na Equação (3.8).

$$
\delta(\mathbf{S})=\sum_{i=1}^{|V|} \delta_{i}(\mathbf{S})
$$

Como o objetivo é otimizar o problema de escalonamento de processos, é necessário minimizar a função $\delta(\mathbf{S})$ a partir de modificações na matriz S. Deve-se, assim, computar as derivadas parciais de $\delta(\mathbf{S})$ em termos de todos elementos $s \in \mathbf{S}$, i.e., $\frac{\partial \delta(\mathbf{S})}{\partial s_{1,1}}, \ldots, \frac{\partial \delta(\mathbf{S})}{\partial s_{|P|,|V|}}$. Antes, porém, deve-se assumir a continuidade dos elementos em $\mathbf{S}$ e saber se $\delta(\mathbf{S})$ é convexa em termos desses elementos (BOYD; VANDENBERGHE, 2004). Caso seja convexa, pode-se considerar a diferenciação dessa função a fim de encontrar o mínimo, que corresponde à melhor decisão de escalonamento possível.

\footnotetext{
${ }^{4}$ É muito comum realizar tal soma a fim de simplificar a otimização de problemas que utilizam funções convexas.
} 
A fim de permitir tal análise, a função $\delta(\mathbf{S})$ é reorganizada em termos de cada elemento $s_{n, q} \in \mathbf{S}$ para $n=1, \ldots,|P|$ e $q=1, \ldots,|V|$, conforme mostrado na Equação (3.9), cujos termos $f(\mathbf{S}), g(\mathbf{S})$ e $h(\mathbf{S})$ estão definidos, respectivamente, nas Equações (3.10), (3.11) e (3.12).

$$
\begin{aligned}
& \delta(\mathbf{S})=f(\mathbf{S}) \cdot s_{n, q}^{2}+g(\mathbf{S}) \cdot s_{n, q}+h(\mathbf{S}) \\
& f(\mathbf{S})=\frac{\ell_{n, n}}{\gamma_{q, q}} \\
& g(\mathbf{S})=\frac{w_{n}}{c_{q}}+\sum_{\substack{l=1 \\
l \neq n}}^{|P|} \frac{\ell_{n, l} \cdot s_{l, q}}{\gamma_{q, q}}+\sum_{\substack{k=1 \\
k \neq n}}^{|P|} \frac{s_{k, q} \cdot \ell_{k, n}}{\gamma_{q, q}}+\sum_{\substack{j=1 \\
j \neq q}}^{|V|} \frac{\ell_{n, n} \cdot s_{n, j}}{\gamma_{q, j}} \\
& +\sum_{\substack{j=1 \\
j \neq q}}^{|V|} \sum_{\substack{l=1 \\
l \neq n}}^{|P|} \frac{\ell_{n, l} \cdot s_{l, j}}{\gamma_{q, j}}+\sum_{\substack{i=1 \\
i \neq q}}^{|V|} \frac{s_{n, i} \cdot \ell_{n, n}}{\gamma_{i, q}}+\sum_{\substack{i=1 \\
i \neq q}}^{|V|} \sum_{\substack{k=1 \\
k \neq n}}^{|P|} \frac{s_{k, i} \cdot \ell_{k, n}}{\gamma_{i, q}} \\
& h(\mathbf{S})=\sum_{\substack{m=1 \\
m \neq n}}^{|P|} \frac{s_{m, q} \cdot w_{m}}{c_{q}}+\sum_{\substack{i=1 \\
i \neq q}}^{|V|} \frac{s_{n, i} \cdot w_{n}}{c_{i}}+\sum_{\substack{i=1 \\
i \neq q}}^{|V|} \sum_{\substack{m=1 \\
m \neq n}}^{|P|} \frac{s_{m, i} \cdot w_{m}}{c_{i}}+\sum_{\substack{k=1 \\
k \neq n}}^{|P|} \sum_{\substack{l=1 \\
l \neq n}}^{|P|} \frac{s_{k, q} \cdot \ell_{k, l} \cdot s_{l, q}}{\gamma_{q, q}} \\
& +\sum_{\substack{j=1 \\
j \neq q}}^{|V|} \sum_{\substack{k=1 \\
k \neq n}}^{|P|} \frac{s_{k, q} \cdot \ell_{k, n} \cdot s_{n, j}}{\gamma_{q, j}}+\sum_{\substack{j=1 \\
j \neq q}}^{|V|} \sum_{\substack{k=1 \\
k \neq n}}^{|P|} \sum_{\substack{l=1 \\
l \neq n}}^{|P|} \frac{s_{k, q} \cdot \ell_{k, l} \cdot s_{l, j}}{\gamma_{q, j}}+\sum_{\substack{i=1 \\
i \neq q}}^{|V|} \sum_{\substack{l=1 \\
l \neq n}}^{|P|} \frac{s_{n, i} \cdot \ell_{n, l} \cdot s_{l, q}}{\gamma_{i, q}} \\
& +\sum_{\substack{i=1 \\
i \neq q}}^{|V|} \sum_{\substack{k=1 \\
k \neq n}}^{|P|} \sum_{\substack{j=1 \\
j \neq n}}^{|P|} \frac{s_{k, i} \cdot \ell_{k, l} \cdot s_{l, q}}{\gamma_{i, q}}+\sum_{\substack{i=1 \\
i \neq q}}^{|V|} \sum_{\substack{j=1 \\
j \neq q}}^{|V|} \frac{s_{n, i} \cdot \ell_{n, n} \cdot s_{n, j}}{\gamma_{i, j}}+\sum_{\substack{i=1 \\
i \neq q}}^{|V|} \sum_{\substack{j=1 \\
j \neq q}}^{|V|} \sum_{\substack{l=1 \\
l \neq n}}^{|P|} \frac{s_{n, i} \cdot \ell_{n, l} \cdot s_{l, j}}{\gamma_{i, j}} \\
& +\sum_{\substack{i=1 \\
i \neq q}}^{|V|} \sum_{\substack{j=1 \\
j \neq q}}^{|V|} \sum_{\substack{k=1 \\
k \neq n}}^{|P|} \frac{s_{k, i} \cdot \ell_{k, n} \cdot s_{n, j}}{\gamma_{i, j}}+\sum_{\substack{i=1 \\
i \neq q}}^{|V|} \sum_{\substack{j=1 \\
j \neq q}}^{|V|} \sum_{\substack{k=1 \\
k \neq n}}^{|P|} \sum_{\substack{l=1 \\
l \neq n}}^{|P|} \frac{s_{k, i} \cdot \ell_{k, l} \cdot s_{l, j}}{\gamma_{i, j}}
\end{aligned}
$$

De modo a garantir que $\delta(\mathbf{S})$ seja convexa, deve-se garantir que $f(\mathbf{S}) \geq 0$, ou seja, $\frac{\ell_{n, n}}{\gamma_{q, q}} \geq 0$, o que satisfaz a condição de segunda ordem para problemas de otimização convexa (BOYD; VANDENBERGHE, 2004). Essa condição afirma que uma função é convexa desde que sua Hessiana ou derivada segunda exista e seja positiva semidefinida. Sabendo que $\ell_{i, j}$ pertence ao conjunto dos números reais não-negativos, tal condição é satisfeita. Pode-se, como realizado nesta tese, somar uma constante positiva a esse termo, permitindo que $x>0$, para $\gamma_{q, q} \in \mathbb{R}_{0}^{+}$. Assim, $\delta(\mathbf{S})$ tem concavidade voltada para cima e, consequentemente, tem valor mínimo para todo $s_{n, q}$, evitando o caso em que a função descreve uma reta, a qual forma uma função tanto côncava quanto convexa (BOYD; VANDENBERGHE, 
2004).

Assim, para encontrar esse valor mínimo, tem-se que diferenciar a função $\delta(\mathbf{S})$ em termos de $\mathbf{S}$, como mostrado na Equação (3.13).

$$
\frac{\partial \delta(\mathbf{S})}{\partial \mathbf{S}}=\left[\begin{array}{ccc}
\frac{\partial \delta(\mathbf{S})}{\partial s_{1,1}} & \cdots & \frac{\partial \delta(\mathbf{S})}{\partial s_{1,|V|}} \\
\vdots & \ddots & \vdots \\
\frac{\partial \delta(\mathbf{S})}{\partial s_{|P|, 1}} & \cdots & \frac{\partial \delta(\mathbf{S})}{\partial s_{|P|,|V|}}
\end{array}\right]
$$

Agora, isolando $s_{n, q}$, como visto na Equação (3.9), pode-se computar cada derivada parcial $\frac{\partial \delta(\mathbf{S})}{\partial s_{n, q}}$ como mostrado na Equação (3.14).

$$
\frac{\partial \delta(\mathbf{S})}{\partial s_{n, q}}=2 \cdot s_{n, q} \cdot f(\mathbf{S})+g(\mathbf{S})
$$

Finalmente, torna-se viável empregar um método de otimização para encontrar o atraso ou custo mínimo, respeitando a seguinte restrição: cada linha de $\mathbf{S}$ deve somar 1 , o que indica que cada processo (representado pelas linhas em $\mathbf{S}$ ) deve ser atribuído a apenas um computador (colunas em $\mathbf{S}$ ). Essa restrição é definida na Equação (3.15).

$$
\theta(\mathbf{S})=\sum_{i=1}^{|P|}\left(\left(\sum_{j=1}^{|V|} s_{i, j}\right)-1\right)^{2}+\sum_{i=1}^{|P|}\left(\left(\sum_{j=1}^{|V|} s_{i, j}^{2}\right)-1\right)^{2}
$$

Consequentemente, o problema de otimização de escalonamento de processos em ambientes distribuídos é definido por:

$$
\begin{array}{ll}
\text { minimizar } & \delta(\mathbf{S}) \\
\text { sujeito a } & \theta(\mathbf{S}) \leq 0
\end{array}
$$

A fim de proceder com a minimização de $\delta(\mathbf{S})$ considerando a função de restrição $\theta(\mathbf{S})$, formula-se o problema utilizando a função de Lagrange (BERTSEKAS, 1996; BOYD; VANDENBERGHE, 2004), definida na Equação (3.17) (para mais detalhes sobre o método dos multiplicadores de Lagrange ver Apêndice A).

$$
\Lambda(\mathbf{S}, \lambda)=\delta(\mathbf{S})+\lambda \cdot \theta(\mathbf{S})
$$

Então, para resolver a função de Lagrange, é necessário encontrar as seguintes derivadas parciais: $\frac{\partial \Lambda(\mathbf{S}, \lambda)}{\partial \lambda}$ e $\frac{\partial \Lambda(\mathbf{S}, \lambda)}{\partial \mathbf{S}}$. A primeira diferenciação resulta na restrição em si (Equação (3.15)) enquanto a segunda é definida pela derivada parcial apresentada na Equação (3.18), em que $\frac{\partial \delta(\mathbf{S})}{\partial \mathbf{S}}$ já foi mostrado na Equações (3.13) e (3.14). O termo $\frac{\partial \lambda \cdot \theta(\mathbf{S})}{\partial \mathbf{S}}$ é apresentado na Equação (3.19) e o termo $\frac{\partial \lambda \cdot \theta(\mathbf{S})}{\partial s_{n, q}} \quad \forall s_{n, q} \in \mathbf{S}$ é definido na Equação (3.20).

$$
\frac{\partial \Lambda(\mathbf{S}, \lambda)}{\partial \mathbf{S}}=\frac{\partial \delta(\mathbf{S})}{\partial \mathbf{S}}+\frac{\partial \lambda \cdot \theta(\mathbf{S})}{\partial \mathbf{S}}
$$




$$
\begin{gathered}
\frac{\partial \lambda \cdot \theta(\mathbf{S})}{\partial \mathbf{S}}=\left[\begin{array}{ccc}
\frac{\partial \lambda \cdot \theta(\mathbf{S})}{\partial s_{1,1}} & \ldots & \frac{\partial \lambda \cdot \theta(\mathbf{S})}{\partial s_{1,|V|}} \\
\vdots & \ddots & \vdots \\
\frac{\partial \lambda \cdot \theta(\mathbf{S})}{\partial s_{|P|, 1}} & \ldots & \frac{\partial \lambda \cdot \theta(\mathbf{S})}{\partial s_{|P|,|V|}}
\end{array}\right] \\
\frac{\partial \lambda \cdot \theta(\mathbf{S})}{\partial s_{n, q}}=\lambda \cdot\left[2 \cdot\left(\left(\sum_{j=1}^{|V|} s_{n, j}\right)-1\right)+4 \cdot\left(\left(\sum_{j=1}^{|V|} s_{n, j}^{2}\right)-1\right) \cdot s_{n, q}\right]
\end{gathered}
$$

De maneira análoga à simplificação da Equação (3.9), simplifica-se, também, a Equação (3.20), como mostrado na Equação (3.21), em que $\theta_{1}(\mathbf{S})$ e $\theta_{2}(\mathbf{S})$ são, respectivamente, definidos nas Equações (3.22) e (3.23).

$$
\begin{gathered}
\frac{\partial \lambda \cdot \theta(\mathbf{S})}{\partial s_{n, q}}=\lambda \cdot \theta_{1}(\mathbf{S})+\lambda \cdot \theta_{2}(\mathbf{S}) \cdot s_{n, q} \\
\theta_{1}(\mathbf{S})=2 \cdot\left(\left(\sum_{j=1}^{|V|} s_{n, j}\right)-1\right) \\
\theta_{2}(\mathbf{S})=4 \cdot\left(\left(\sum_{j=1}^{|V|} s_{n, j}^{2}\right)-1\right)
\end{gathered}
$$

Seguindo a abordagem dos multiplicadores de Lagrange (BERTSEKAS, 1996), deve-se resolver $\frac{\partial \Lambda(\mathbf{S}, \lambda)}{\partial \mathbf{S}}=0$ e $\frac{\partial \Lambda(\mathbf{S}, \lambda)}{\partial \lambda}=0$ de modo a encontrar os pontos extremos da função de Lagrange $\Lambda(\mathbf{S}, \lambda)$, os quais correspondem aos mínimos de interesse. A solução para $\frac{\partial \Lambda(\mathbf{S}, \lambda)}{\partial \mathbf{S}}$ produz a matriz apresentada na Equação (3.24).

$$
\frac{\partial \Lambda(\mathbf{S}, \lambda)}{\partial \mathbf{S}}=\left[\begin{array}{ccc}
\frac{\Lambda(\mathbf{S}, \lambda)}{\partial s_{1,1}} & \cdots & \frac{\partial \Lambda(\mathbf{S}, \lambda)}{\partial s_{1,|V|}} \\
\vdots & \ddots & \vdots \\
\frac{\partial \Lambda(\mathbf{S}, \lambda)}{\partial s_{|P|, 1}} & \cdots & \frac{\partial \Lambda(\mathbf{S}, \lambda)}{\partial s_{|P|,|V|}}
\end{array}\right]
$$

Em seguida, iguala-se $\frac{\partial \Lambda(\mathbf{S}, \lambda)}{\partial s_{n, q}}=0$ para encontrar os extremos da função como mostrado a seguir:

$$
\frac{\Lambda(\mathbf{S}, \lambda)}{\partial s_{n, q}}=2 \cdot f(\mathbf{S}) \cdot s_{n, q}+g(\mathbf{S})+\lambda \cdot\left(\theta_{1}(\mathbf{S})+\theta_{2}(\mathbf{S}) \cdot s_{n, q}\right)=0
$$

e, então, resolver para o termo $s_{n, q}, \operatorname{com} n=1, \ldots,|P|$ e $q=1, \ldots,|V|$, na forma:

$$
s_{n, q}=\frac{g(\mathbf{S})+\theta_{1}(\mathbf{S}) \cdot \lambda}{2 \cdot f(\mathbf{S})+\theta_{2}(\mathbf{S}) \cdot \lambda}
$$

Assim, resolve-se $\frac{\partial \Lambda(\mathbf{S}, \lambda)}{\partial \mathbf{S}}=0$ para todo termo $s_{n, q}$ a fim de obter a solução para $\mathbf{S}$ ainda 
sem considerar a restrição de Lagrange:

$$
\mathbf{S}=\left[\begin{array}{ccc}
s_{1,1} & \ldots & s_{1,|V|} \\
\vdots & \ddots & \vdots \\
s_{|P|, 1} & \ldots & s_{|P|,|V|}
\end{array}\right]
$$

Essa matriz é aplicada em $\frac{\partial \Lambda(\mathbf{S}, \lambda)}{\partial \lambda}=0$, o que é o mesmo que resolver a restrição (Equação (3.15)) para encontrar os extremos para o problema. Ao aplicar cada termo $s_{n, q} \in \mathrm{S}$ na restrição, esses são elevados à segunda e à quarta potência, nas primeiras e segundas somas respectivamente (Equação (3.15)). Isso resultará no fato de que cada termo $s_{n, q}$ estará, no máximo, elevado à quarta potência. Isso é o mesmo que:

$$
\left(s_{n, q}\right)^{4}=\left(\frac{f(\mathbf{S})+\theta_{1}(\mathbf{S}) \cdot \lambda}{2 \cdot g(\mathbf{S})+\theta(\mathbf{S}) \cdot \lambda}\right)^{4},
$$

o que resulta em $\lambda^{4}$. Quando soluciona-se $\frac{\partial \Lambda(S, \lambda)}{\partial \lambda}=0$ em $\lambda$, de acordo com o método dos multiplicadores de Lagrange, encontra-se quatro soluções (sabendo que a potência das restrições para os termos $s_{n, q}$ é igual a quatro). Na etapa seguinte do método, aplica-se as quatro soluções para $\lambda$ novamente na Equação (3.26) e, assim, obtém-se quatro matrizes na forma da Equação (3.27), que definem o conjunto $\mathcal{S}^{*}=\left\{\mathbf{S}_{1}, \mathbf{S}_{2}, \mathbf{S}_{3}, \mathbf{S}_{4}\right\}$ das quatro soluções que respeitam as restrições, i.e., a soma dos elementos de cada linha é igual a um (garantindo que cada processo é alocado em apenas um computador).

Finalmente, aplica-se cada matriz $\mathbf{S}_{i} \in \mathcal{S}^{*}$ em $\delta(\mathbf{S})$ a fim de avaliar os atrasos ou custos totais envolvidos no processamento e comunicação do ambiente distribuído, como formulado na Equação (3.8). Cada solução candidata para $\mathbf{S}$ representa um ponto crítico, i.e., um extremo da função respeitando a restrição, o que resulta em ótimos locais e globais para $\delta(\mathbf{S})$. Assim, considera-se somente a solução $\mathbf{S}^{*}$ que produz valor mínimo global para $\delta(\mathbf{S})$, como definido na Equação (3.29). Em outras palavras, $\mathbf{S}^{*}$ é a melhor solução de escalonamento resultante da atribuição dos processos sobre os computadores do sistema.

$$
\mathbf{S}^{*}=\underset{\mathbf{S}_{i} \in \mathcal{S}^{*}}{\arg \min } \delta\left(\mathbf{S}_{i}\right)
$$

Nesse sentido, a abordagem proposta define a função $\delta(\mathbf{S})$ (Equação (3.4)) a ser otimizada em termos do total de atrasos impostos por instruções de processamento e eventos de comunicação sobre o sistema distribuído. No entanto, essa função não pode assumir todos os valores em $\mathbb{R}$ para $\mathrm{S}$, o que implica a restrição definida na Equação (3.15), que, por sua vez, é considerada na função de Lagrange (Equação (3.18)). Resolvendo-se a função de Lagrange, obtém-se quatro possíveis soluções para a matriz $\mathrm{S}$, ou seja, existem quatro soluções de escalonamento possíveis a serem avaliadas de acordo com a formulação proposta. O escalonamento representado por $\mathrm{S}^{*}$ (Equação (3.29)) provê o mínimo 
para a função $\delta(\mathbf{S})$ respeitando as restrições necessárias.

\subsubsection{Discussão}

A formulação apresentada nesta seção provê resultados exatos para instâncias de escalonamento estático, i.e., quando se tem acesso a toda informação de instruções de processamento (representada pelo vetor $\mathbf{w}$ ), eventos de comunicação (vetor $\mathbf{L}$ ) e capacidade da rede (vetor $\Gamma$ ), além disso, todas essas informações não são alteradas ao longo do tempo. Pode-se supor tais situações em ambientes controlados, em que se deseja escalonar uma aplicação conhecida em um aglomerado local. Em cenários dinâmicos, w, L e $\Gamma$ variam ao longo do tempo, porém seus valores podem ser estimados utilizando medidas estatísticas, a fim de, periodicamente, empregar métodos de otimização que busquem por soluções adequadas (MELLO, 2009; MELLO; YANG, 2008; DODONOV; MELLO, 2010).

Além disso, em cenários dinâmicos, em vez de considerar a função de Lagrange presente na Equação (3.18), pode-se considerar métodos de otimização iterativos utilizando a função $\delta(\mathbf{S})$ (Equação (3.26)) como custo e $\theta(\mathbf{S})$ (Equação (3.15)) como restrição. Nessas circunstâncias, o método de otimização será guiado pelas mesmas condições definidas aqui e a matriz de escalonamento seria continuamente adaptada para reduzir a função de custo, respeitando simultaneamente a restrição.

\subsection{O Algoritmo MHSA}

Nesta seção, é apresentado o Min Heap-based Scheduling Algorithm (MHSA), um algoritmo de aproximação proposto para o problema de escalonamento de processos em ambientes distribuídos. Esse algoritmo foi projetado após a proposta do modelo apresentado na seção anterior e a partir das primeiras simulações realizadas (as quais são detalhadas no Capítulo 4). Essas simulações consideraram um algoritmo força-bruta e outro que resolve o modelo de otimização matemática proposto por meio de relaxações de técnicas provenientes da programação linear (DONGARRA; STEWART, 1984; ARENALES et al., 2007). O primeiro foi excessivamente lento mesmo para resolver pequenas instâncias do problema. O segundo apresentou lentidão e soluções de menor qualidade para instâncias maiores. Esses fatos motivaram a proposta do Min Heap-based Scheduling Algorithm (MHSA), que respeita as condições formalizadas na Seção 3.3 e tem baixa complexidade de tempo. Além disso, desde o princípio, esse algoritmo destacou-se pela qualidade de suas soluções de escalonamento, as quais tendem a reduzir o tempo de execução de processos e aumentar a ocupação de recursos distribuídos.

A próxima seção detalha o funcionamento desse algoritmo e, em seguida, é feita a análise de sua razão de aproximação em relação a um escalonador ótimo, tanto para ambientes heterogêneos que executam aplicações bag-of-tasks, quanto para situações 
em que há comunicação entre processos.

\subsubsection{Funcionamento}

O MHSA inicialmente coleta e armazena em um vetor três informações sobre os computadores do sistema: i) um identificador para cada computador do sistema, o qual consiste em um número inteiro; ii) a capacidade, ou seja, o número total de instruções que determinado computador processa por segundo; e iii) o tempo de fila, que corresponde ao tempo dispendido antes de iniciar a execução do próximo processo (KLEINROCK, 1975). Esse vetor, denominado vetor de computadores, é então ordenado de acordo com as capacidades dos computadores de maneira decrescente, conforme ilustrado na Figura 3.2. Desse modo, um computador no índice $i$ do vetor é sempre mais veloz que outro associado ao índice $i+1$.

\begin{tabular}{|cc|c|c|ccc|c|}
\multicolumn{1}{c}{$0 \mathrm{~s}$} & $0 \mathrm{~s}$ & $0 \mathrm{~s}$ & $0 \mathrm{~s}$ & $0 \mathrm{~s}$ & $0 \mathrm{~s}$ & $0 \mathrm{~s}$ \\
\hline$v_{1}$ & $v_{2}$ & $v_{3}$ & $v_{4}$ & $v_{5}$ & $v_{6}$ & $v_{7}$ \\
$10 \mathrm{k}$ & $7 \mathrm{k}$ & $5 \mathrm{k}$ & $4 \mathrm{k}$ & $2 \mathrm{k}$ & $1 \mathrm{k}$ & $1 \mathrm{k}$ \\
\hline 1 & 2 & 3 & 4 & 5 & 6 & 7
\end{tabular}

Figura 3.2: Vetor de computadores ordenado, de maneira decrescente, por capacidade de processamento.

Em um primeiro momento, o MHSA considera que todos computadores estão $100 \%$ ociosos e que o vetor de computadores forma uma árvore min-heap (CORMEN et al., 2001) com base nas ociosidades. Uma árvore heap é uma árvore binária que possui algumas propriedades específicas, sendo uma estrutura de dados muito utilizada na Ciência da Computação, principalmente no desenvolvimento de algoritmos de ordenação (heapsort) e filas de prioridade. No caso da min-heap, cada nó (elemento da árvore) possui uma chave que é, obrigatoriamente, menor que as chaves de seus dois filhos. No caso do vetor de computadores, os tempos de fila são adotados como chave. Assim, inicialmente, todos os nós possuem chaves iguais a zero (Figura 3.3), o que indica que nenhuma carga de trabalho foi atribuída, ainda, aos computadores.

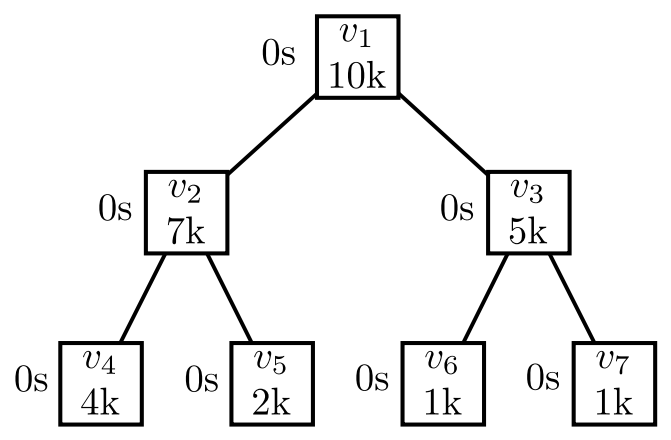

Figura 3.3: Vetor de computadores da Figura 3.2 organizado como uma árvore min-heap. Os números fora das caixas representam o tempo de fila atual, ou seja, as chaves envolvidas na manutenção da árvore (0 segundos, inicialmente). 
É importante observar que, nesta tese, optou-se por ilustrar a árvore por meio da representação hierárquica, a qual é mais usual; no entanto, deve-se salientar que essa estrutura de dados foi implementada como um vetor, em que o elemento na posição $i=1$ é o nó raiz e os filhos de um nó na posição $i$, se existirem, ocupam as posições $2 i$ e $2 i+1$ (como consequência, o pai de um nó $i$ é dado por $\left\lfloor\frac{i}{2}\right\rfloor$, supondo que o primeiro elemento do vetor está no índice 1 ).

Dois procedimentos são utilizados na construção da min-heap. O primeiro, denominado Heapify, tem como objetivo verificar se um nó pai tem chave, de fato, menor que seus filhos; caso contrário, é necessário que esse nó desça na árvore, em direção às folhas. Como consequência, pode ser necessário modificar a posição de outros nós, de modo a satisfazer as propriedades da min-heap. O Algoritmo 3.1, adaptado de Cormen et al. (2001), apresenta o pseudocódigo desse procedimento, cuja complexidade assintótica é da ordem de $\mathcal{O}\left(\log _{2}|V|\right)$, em que $|V|$ é o número de nós da árvore.

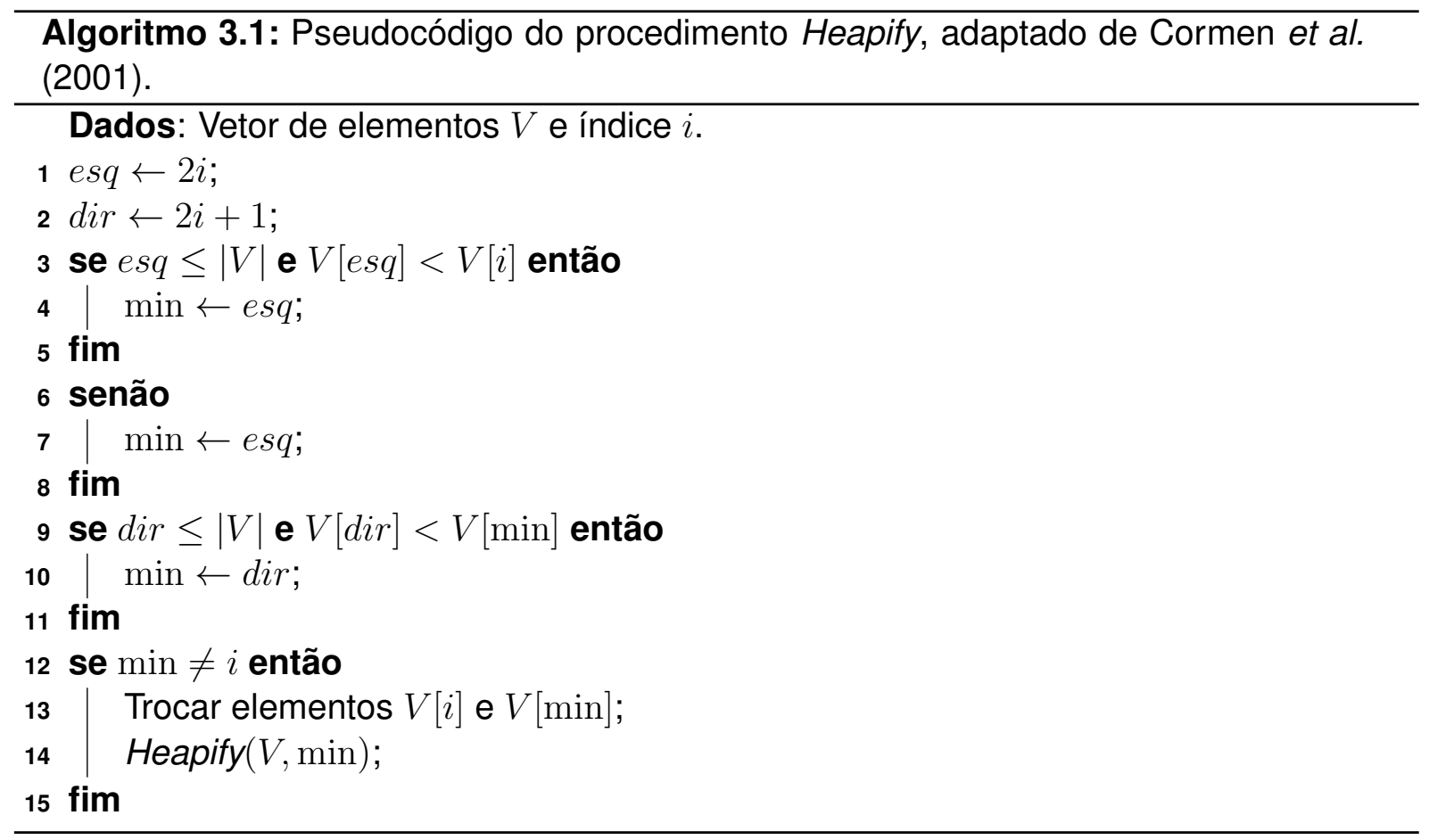

O outro procedimento é denominado BuildHeap, o qual constrói a árvore. Esse procedimento, apresentado no Algoritmo 3.2 (adaptado de Cormen et al. (2001)), percorre os elementos da árvore e verifica se esses encontram-se na posição correta. Em caso negativo, utiliza-se o procedimento Heapify para posicioná-los corretamente. Como o BuildHeap possui um comando de repetição cujo número de iterações é proporcional ao número de nós da árvore, sua complexidade assintótica é da ordem de $\mathcal{O}\left(|V| \log _{2}|V|\right)$.

Uma vez construída a min-heap de computadores, inicia-se a etapa de escalonamento. Seguindo a notação adotada na Seção 3.3, sempre que um conjunto de processos $P$ chega ao escalonador, o MHSA é responsável por associar um computador $v_{j} \in V$ a cada processo $p_{i} \in P$. O MHSA atribui o primeiro processo, i.e., $p_{1}$ ao computador $v_{\text {raiz }}$ localizado 


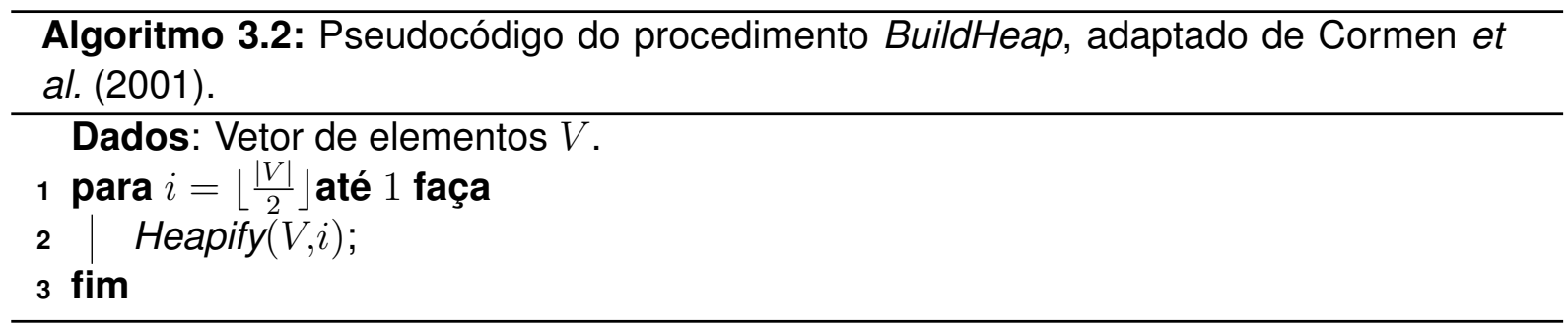

na raiz da min-heap. Essa atribuição tem complexidade $\mathcal{O}(1)$. Em seguida, o MHSA atualiza a árvore com a nova carga de trabalho da raiz, incrementando sua chave, ou seja, o tempo de fila. Assim, o nó raiz tende a ser movido em direção às folhas (ver Figura 3.4). Esse movimento demanda $\mathcal{O}\left(\log _{2}|V|\right)$ operações, no pior caso.

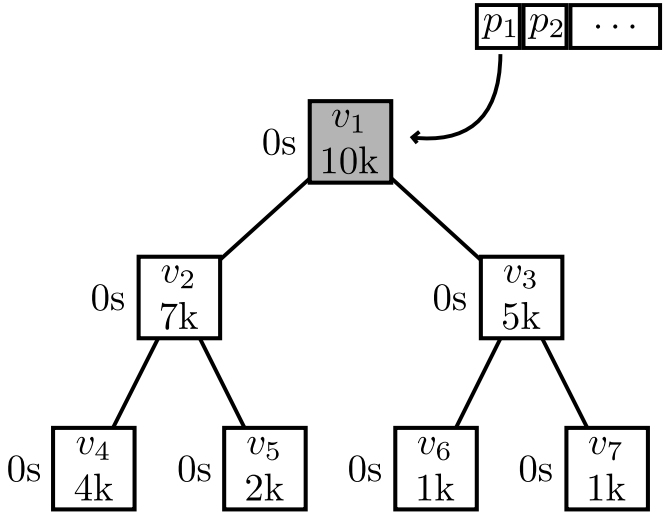

(a) Atribuindo $p_{1}$ a $v_{\text {raiz }}$.

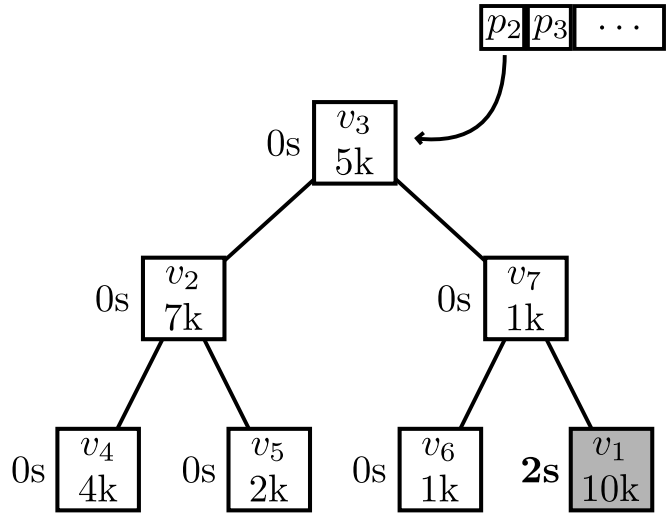

(b) Atribuindo $p_{2}$ a $v_{\text {raiz }}$.

Figura 3.4: Exemplo de escalonamento. Em 3.4a, o processo $p_{1}$ (de carga $20.000 \mathrm{MI}$ ) é atribuído ao nó $v_{\text {raiz }}$, i.e., $v_{1}$, cuja capacidade é de 10.000 MIPS. Então, em $3.4 \mathrm{~b}, v_{1}$ é movido em direção às folhas uma vez que sua chave torna-se maior que as outras; isso é feito pelo procedimento Heapify (Algoritmo 3.1). Finalmente, o processo $p_{2}$ é atribuído à nova raiz, i.e., $v_{3}$.

No passo seguinte, MHSA escalona o processo $p_{2}$ ao novo nó $v_{\text {raiz }}$ (Figura $3.4 \mathrm{~b}$ ), que passou a ser a raiz da min-heap após a movimentação da antiga raiz. O Algoritmo 3.3 apresenta o pseudocódigo do MHSA, desde a etapa de construção da árvore até as operações relacionadas ao escalonamento.

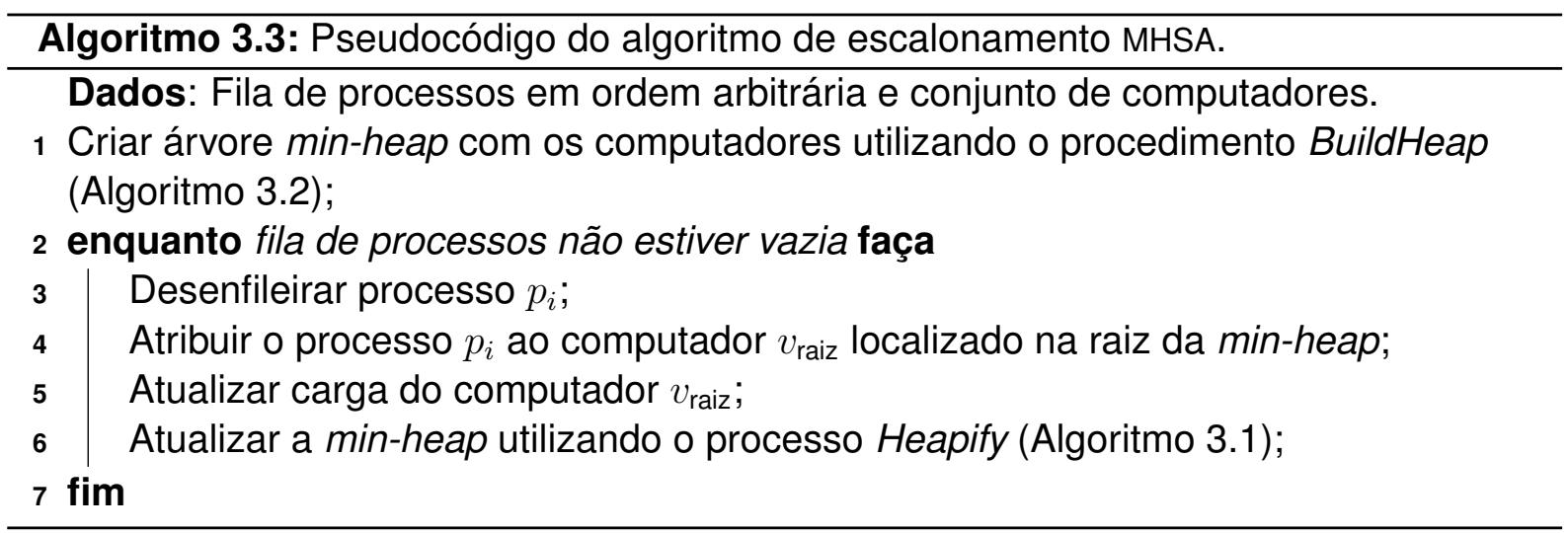


À medida que um computador executa sua carga de trabalho, sua chave ou tempo de fila começa a decrescer e, consequentemente, esse nó da min-heap começa a ser movido para a raiz. Quanto mais rápido um computador executa sua carga, mais rápido ele voltará a assumir a posição raiz.

Nas próximas seções é discutida a qualidade das soluções de escalonamento propostas pelo MHSA. Inicialmente (Seção 3.4.2), formula-se a razão de aproximação do MHSA sobre ambientes distribuídos heterogêneos considerando apenas o consumo de CPU, ou seja, todo processo que chega ao sistema consume apenas recursos de CPU e nenhuma comunicação é realizada (i.e., considera-se aplicações bag-of-tasks). Em seguida, essa análise é estendida de modo a incluir a utilização da rede (Seção 3.4.3).

\subsubsection{Razão de Aproximação Considerando Aplicações Bag-of-tasks}

Esta seção apresenta os primeiros estudos realizados para obter a razão de aproximação do MHSA para ambientes distribuídos formados por computadores de capacidade heterogênea e aplicações do tipo bag-of-tasks. Esses estudos foram conduzidos utilizando as mesmas ferramentas matemáticas apresentadas e discutidas por Williamson e Shmoys (2010). A fim de simplificar o entendimento, será considerado o escalonamento de apenas uma aplicação, i.e., o conjunto $P$ é formado por processos de uma mesma aplicação. Neste cenário, considera-se processos heterogêneos que chegam simultaneamente ao escalonador. Cada processo deve ser atribuído a um único computador e nenhum processo deve ser descartado. Computadores apresentam capacidades heterogêneas. Considerase, ainda, que o escalonador não permite migrações nem re-escalonamento, i.e., uma vez que um processo é alocado, o computador é responsável por sua completa execução.

Considere que cada processo $p_{i} \in P$ apresenta uma carga de trabalho, em milhões de instruções (MI), definida por $w_{i}$, conforme apresentado na Seção 3.3. O objetivo do MHSA é escalonar todos os processos de modo a reduzir o makespan ${ }^{5}$ da aplicação dado por:

$$
M_{\max }=\max _{i=1, \ldots,|P|} \tau\left(p_{i}, v_{j}\right)
$$

em que $\tau\left(p_{i}, v_{j}\right)$ é o tempo de execução (completion time) do processo $p_{i}$ após ser escalonado no computador $v_{j}$. Isso significa que o tempo de execução de um processo é definido por $\frac{w_{i}}{c_{j}}$, em que $c_{j}$ corresponde à capacidade do computador $v_{j}$ em milhões de instruções por segundo (MIPS).

De modo a definir a garantia de desempenho (ver Seção 2.4.1) do MHSA, define-se inicialmente o limitante inferior natural do makespan para um escalonamento ótimo, denotado por $M_{\mathrm{max}}^{*}$. Uma vez que todo processo deve ser executado e atribuído a somente um com-

\footnotetext{
${ }^{5} \mathrm{O}$ objetivo do MHSA é reduzir o makespan, no entanto, dada a maneira em que processos são atribuídos sobre o min-heap, esse algoritmo consegue utilizar todos os recursos disponíveis, consequentemente, ele é considerado orientado a sistemas (CHUNLIN; LAYUAN, 2009).
} 
putador, considera-se que o processo com maior carga $p_{\mathrm{mc}}$ é escalonado no computador

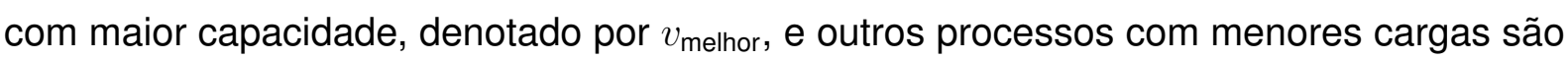
atribuídos aos demais computadores. Assim, pode-se afirmar que:

$$
M_{\mathrm{max}}^{*} \geq \frac{w_{\mathrm{mc}}}{c_{\mathrm{melhor}}}
$$

em que $w_{\mathrm{mc}}$ é a carga de trabalho de $p_{\mathrm{mc}}$ e $c_{\text {melhor }}$ é a capacidade de $v_{\text {melhor }}$. Deve-se observar que $w$ representa a carga de trabalho de um processo em $\mathrm{Ml}$, enquanto que $c$ é a capacidade de um computador em MIPS; consequentemente, o valor de $M_{\max }^{*}$ é dado em segundos de execução, ou seja, o total de segundos necessários para completar a execução do processo de maior demanda computacional (uma vez que esse é o mais custoso, pode-se supor que o makespan da aplicação é limitado superiormente pela execução desse processo tal como apresentado em (WILLIAMSON; SHMOYS, 2010)). Tem-se, assim, o primeiro limitante para o makespan da solução ótima de escalonamento.

Por outro lado, existem $\sum_{i}^{|P|} w_{i}$ instruções de processamento a serem executadas e $|V|$ computadores para realizar esse trabalho. Dessa maneira, a capacidade total do sistema é dada por $\sum_{j}^{|V|} c_{j}$. Pode-se supor uma distribuição proporcional de processos sobre esses computadores, assim o makespan ótimo é também limitado por:

$$
M_{\max }^{*} \geq \frac{\sum_{i}^{|P|} w_{i}}{\sum_{j}^{|V|} c_{j}}
$$

Conclui-se, portanto, que existe ao menos um computador do sistema cujo tempo de execução será maior ou igual a $\frac{\sum_{i}^{|P|} w_{i}}{\sum_{j}^{|V|} c_{j}}$.

Para ilustrar o pior caso do MHSA, considera-se um sistema distribuído composto por três computadores, $V=\left\{v_{1}, v_{2}, v_{3}\right\}$, cujas capacidades, em MIPS, são $c_{1}=3,000, c_{2}=$ 2,000 e $c_{3}=1,000$. Esse cenário é ilustrado na Figura 3.5, que representa a árvore min-heap formada utilizando esses computadores. Inicialmente, todos esses computadores são considerados ociosos (assim, o tempo de fila, mostrado fora das caixas, é definido como zero).

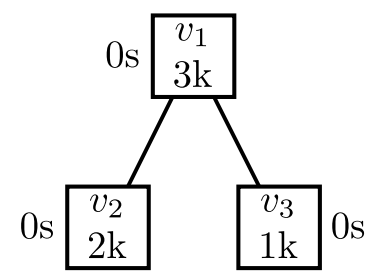

Figura 3.5: Árvore min-heap formada por três computadores ociosos.

Supondo que, em um primeiro momento, o escalonador receba seis processos idênticos, ou seja, $P=\left\{p_{1}, \ldots, p_{6}\right\}$, todos com a mesma carga de trabalho, i.e., $w_{i}=w_{j}, \forall i, j$, a qual é definida com valor 1.000.000 MI. Quando o MHSA é executado, obtém-se a sequência 
de árvores mostradas na Figura 3.6.

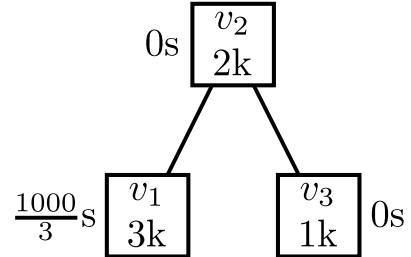

(a) Atribuindo $p_{1}$.

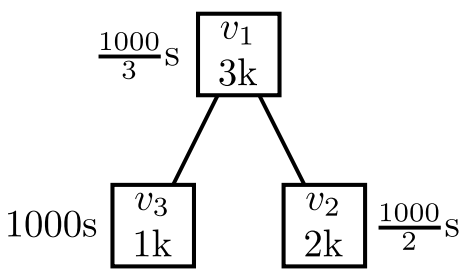

(d) Atribuindo $p_{4}$.

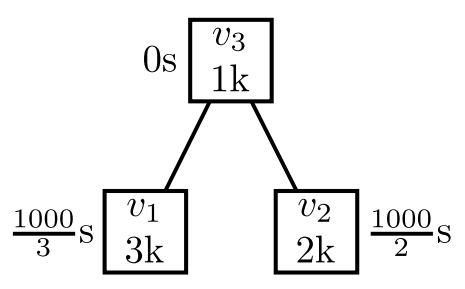

(b) Atribuindo $p_{2}$.

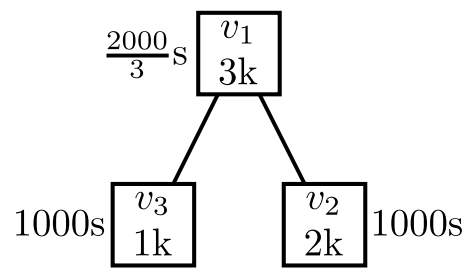

(e) Atribuindo $p_{5}$.

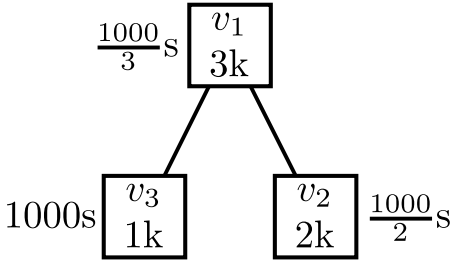

(c) Atribuindo $p_{3}$.

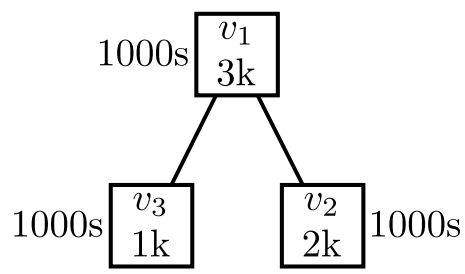

(f) Atribuindo $p_{6}$.

Figura 3.6: Exemplo de escalonamento de seis processos sobre a min-heap ilustrada na Figura 3.5.

Após escalonar o processo $p_{6}$, o MHSA obtém a árvore mostrada na Figura 3.6f, tendo $v_{\text {melhor }}$ como raiz e todos os computadores com o mesmo tempo de fila, i.e., 1.000 segundos de execução. Agora, suponha que o MHSA receba o processo $p_{7}$ de carga bem menor que os anteriores, ou seja, $w_{7}<<w_{i}, i=1, \ldots, 6$. O processo $p_{7}$ será alocando na raiz da minheap, i.e., no computador $v_{1}$, que se tornará uma folha, conforme ilustrado na Figura 3.7.

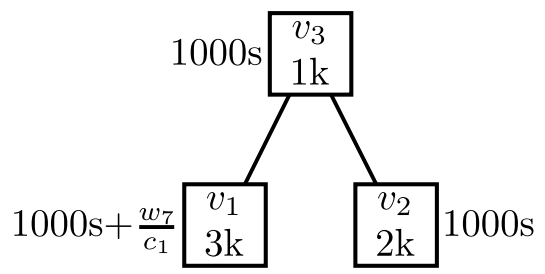

Figura 3.7: Árvore min-heap após a atribuição do processo $p_{7}$ ao computador $v_{1}$.

Considere, então, que o processo de maior carga $p_{\mathrm{mc}}$ chega ao sistema. Esse processo será atribuído ao computador $v_{3}$, resultando na árvore ilustrada na Figura 3.8. Como consequência, tem-se o pior cenário, uma vez que o computador mais lento terá que executar o processo de maior carga, enquanto que o computador mais rápido executará o menor processo.

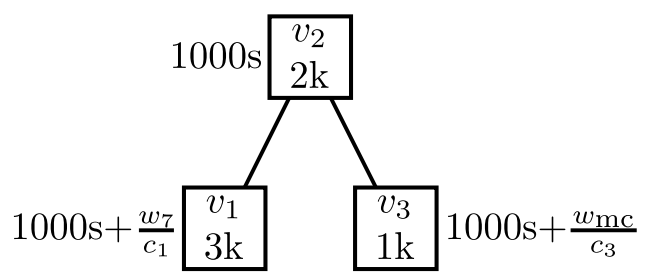

Figura 3.8: Árvore min-heap após a atribuição do processo $p_{\mathrm{mc}}$ ao computador $v_{3}$. 
Suponha que o tempo de fila de um computador $v_{j} \in V$ é medido por uma função $q\left(v_{j}\right)$ e que o processo $p_{\mathrm{mc}}$ é o último a chegar ao sistema. Esse processo é atribuído ao computador $v_{\text {raiz }}$ que consome um tempo de fila igual a $q\left(v_{\text {raiz }}\right)$ antes de iniciar a execução de $p_{\mathrm{mc}}$. Com base nas condições anteriores, o cenário de pior caso ocorrerá somente se $v_{\text {raiz }}=v_{\text {pior }}$ no momento em que $p_{\text {mc }}$ chegar ao sistema e se, além disso, todos os computadores possuírem aproximadamente as mesmas chaves (ou seja, tempo de fila), i.e., se:

$$
q\left(v_{i}\right) \approx q\left(v_{j}\right), \forall i, j
$$

Consequentemente, o processo $p_{\mathrm{mc}}$ será atribuído ao computador $v_{\text {pior }}$ que possui tempo de fila igual a $q\left(v_{\text {pior }}\right)$ segundos. Sabe-se que todos os $|V|$ computadores possuem tempo de fila aproximadamente igual, assim:

$$
q\left(v_{\text {pior }}\right) \leq q\left(v_{i}\right), \forall i
$$

Consequentemente, antes de $q\left(v_{\text {pior }}\right)$ segundos, o número de instruções a ser processado para todo sistema sem considerar $p_{\mathrm{mc}}$ é de:

$$
\sum_{i}^{|V|} q\left(v_{i}\right) \cdot c_{i}
$$

que é menor que a carga de trabalho total considerando $p_{\mathrm{mc}}$, dada por: $\sum_{j}^{|P|} w_{j}$. Portanto, pode-se supor que:

$$
q\left(v_{\text {pior }}\right) \leq \frac{\sum_{i}^{|P|} w_{i}}{\sum_{j}^{|V|} c_{j}}
$$

Consequentemente, o tempo de fila para o computador $v_{\text {pior }}$ é menor que o tempo de fila médio considerando a chegada de $p_{\mathrm{mc}}$. Combinando as Equações (3.30) e (3.31), tem-se:

$$
q\left(v_{\text {pior }}\right) \leq M_{\max }^{*}
$$

Portanto, o tempo de fila do computador $v_{\text {pior }}$ antes de receber $p_{\mathrm{mc}}$ é, no máximo, $M_{\max }^{*}$. Assim, quando $p_{\mathrm{mc}}$ chega, tem-se um makespan máximo igual a $M_{\max }^{*}$ e, após o escalonamento de $p_{\mathrm{mc}}$ em $v_{\text {pior }}$, um custo extra é adicionado ao makespan dado por:

$$
M_{\text {adicional }}=\frac{w_{\mathrm{mc}}}{c_{\text {pior }}}
$$

Considerando o makespan ótimo $M_{\max }^{*} \geq \frac{w_{\text {mc }}}{c_{\text {melhor }}}$ e supondo o pior caso, a razão de aproximação $(\alpha)$ entre o MHSA e o escalonador ótimo é dada por:

$$
\alpha=\frac{M_{m h s a}}{M_{\max }^{*}}=\frac{M_{\max }^{*}}{q\left(v_{\text {pior }}\right)}+\frac{M_{\max }^{*}}{M_{\text {adicional }}},
$$


em que $M_{m h s a}$ é o makespan do MHSA. Essa equação pode ser algebricamente transformada em

$$
\frac{M_{m h s a}}{M_{\max }^{*}}=1+\frac{\frac{w_{\mathrm{mc}}}{c_{\mathrm{melhor}}}}{\frac{w_{\mathrm{mc}}}{c_{\text {pior }}}},
$$

com $M_{\text {max }}^{*}=\frac{w_{\text {mc }}}{c_{\text {melhor }}}$ e $M_{\text {adicional }}$ dado pela Equação (3.32).

Dessa maneira, a aproximação do MHSA em relação ao escalonador ótimo é definida na Equação (3.33).

$$
\alpha=\frac{M_{m h s a}}{M_{\max }^{*}}=1+\frac{c_{\text {pior }}}{c_{\text {melhor }}}
$$

Portanto, se todos os computadores possuem a mesma capacidade, ou seja, se o ambiente é homogêneo, o algoritmo MHSA é uma 2-aproximação em relação ao escalonador ótimo, o que significa que produz um makespan duas vezes maior que o ótimo para o pior caso. Outros algoritmos podem apresentar razão de aproximação melhor, como descrito na Seção 2.4.1, no entanto somente para ambientes homogêneos. Em contrapartida, a formulação apresentada nesta seção considera inclusive ambientes heterogêneos. Nesse caso, se o grau de heterogeneidade é muito elevado, a aproximação do MHSA torna-se maior que 2, o que tende a motivar a adoção de uma regra para selecionar apenas um subconjunto de computadores com maior capacidade para receber cargas de trabalho. Assim, a aproximação torna-se próxima a 2 novamente. Na próxima seção será detalhada a razão de aproximação do MHSA para ambientes heterogêneos executando processos com comunicação.

\subsubsection{Razão de Aproximação Considerando Comunicação entre Pro- cessos}

Esta seção apresenta a razão de aproximação do MHSA considerando ambientes heterogêneos em que há presença de comunicação entre processos. Essa formulação foge ao tradicional (WILLIAMSON; SHMOYS, 2010), que se atém à ausência de comunicação e presença de computadores de capacidade homogênea. Da mesma maneira que a formulação apresentada na seção anterior, esta seção considera as ferramentas matemáticas apresentadas e discutidas por Williamson e Shmoys (2010).

A fim de analisar o cenário com comunicação, seja $\ell_{i, j}$ o total de bytes transferidos entre dois processos $p_{i}$ e $p_{j}$, para $i \neq j$, conforme a notação adotada na Seção 3.3. Nessa análise, supõe-se as mesmas condições descritas na Seção 3.4.2, ou seja, processos são heterogêneos e oriundos da mesma aplicação. Supõe-se, também, que o processo $p_{\mathrm{mc}}$ tem maior número de instruções e que $\ell_{\mathrm{mc}, j}$ corresponde ao maior volume de dados transferido.

Supõe-se, ainda que o computador mais veloz $v_{\text {melhor }}$ também possui o melhor canal de 
comunicação com todos os demais computadores ${ }^{6}$. Com base na notação apresentada na Seção 3.3, denota-se esse canal por $\gamma_{\text {melhor }, k}$, para $v_{\text {melhor }} \neq v_{k}$. Dessa maneira, define-se que o makespan ótimo, $M_{\max }^{*}$, é dado por:

$$
M_{\text {max }}^{*} \geq \max \left(\frac{w_{\mathrm{mc}}}{c_{\mathrm{melhor}}}+\frac{\ell_{\mathrm{mc}, j}}{\gamma_{\text {melhor }}}, \frac{w_{j}}{c_{\text {melhor }}}+\frac{\ell_{j, \mathrm{mc}}}{\gamma_{\text {melhor }}}\right)
$$

em que $w$ é o total de instruções de processamento e $c$ é a capacidade do computador.

Observa-se que $\frac{w_{\mathrm{mc}}}{c_{\text {melhor }}}$ é sempre maior que $\frac{w_{j}}{c_{\text {melhor }}}$, visto que $w_{\mathrm{mc}}>w_{j}$ para todo $j \neq \mathrm{mc}$. Então:

$$
M_{\text {max }}^{*} \geq \frac{w_{\mathrm{mc}}}{c_{\text {melhor }}}+\frac{\ell_{\mathrm{mc}, j}}{\gamma_{\text {melhor }, k}}
$$

Considerando o pior caso para o MHSA, i.e., quando $p_{\mathrm{mc}}$ é atribuído ao computador $v_{\text {pior }}$, supondo que esse é o nó raiz da árvore min-heap, tem-se que:

$$
\frac{M_{m h s a}}{M_{\max }^{*}} \geq \frac{\frac{w_{\mathrm{mc}}}{c_{\text {pior }}}+\frac{\ell_{\mathrm{mc}, j}}{\gamma_{\text {pior }, k}}}{\frac{w_{\mathrm{mc}}}{c_{\mathrm{melhor}}}+\frac{\ell_{\mathrm{mc}, j}}{\gamma_{\mathrm{melhor}, k}}} .
$$

Consequentemente, a razão de aproximação do MHSA em relação ao escalonador ótimo em ambientes com comunicação entre processos é definida por:

$$
\frac{M_{\text {mhsa }}}{M_{\max }^{*}} \geq \frac{\left(w_{\mathrm{mc}} \cdot \gamma_{\text {pior }, k}+\ell_{\mathrm{mc}, j} \cdot c_{\text {pior }}\right) \cdot c_{\text {pior }} \cdot \gamma_{\text {melhor }, k}}{\left(w_{\mathrm{mc}} \cdot \gamma_{\text {melhor }, k}+\ell_{\mathrm{mc}, j} \cdot c_{\text {melhor }}\right) \cdot c_{\text {melhor }} \cdot \gamma_{\text {pior }, k}}
$$

Considerando, novamente, o tempo de fila e também a relação $\frac{M_{\max }^{*}}{q\left(v_{\text {pirr }}\right)}$ (Seção 3.4.2), quando $p_{\mathrm{mc}}$ chega ao sistema tem-se uma vez o valor de $M_{\max }^{*}$ e, então, a razão de aproximação $(\alpha)$ entre o MHSA e o escalonador ótimo é dada pela Equação (3.34).

$$
\alpha=\frac{M_{\text {mhsa }}}{M_{\max }^{*}}=1+\frac{\left(w_{\mathrm{mc}} \cdot \gamma_{\text {pior }, k}+\ell_{\mathrm{mc}, j} \cdot c_{\text {pior }}\right) \cdot c_{\text {pior }} \cdot \gamma_{\text {melhor }, k}}{\left(w_{\mathrm{mc}} \cdot \gamma_{\text {melhor }, k}+\ell_{\mathrm{mc}, j} \cdot c_{\text {melhor }}\right) \cdot c_{\text {melhor }} \cdot \gamma_{\text {pior }, k}}
$$

Portanto, se os computadores são homogêneos, o algoritmo MHSA é também uma 2aproximação em relação ao escalonador ótimo, i.e., MHSA produz duas vezes o makespan ótimo no pior caso. Entretanto, se a heterogeneidade é alta, essa aproximação torna-se pior que 2. Por essa razão, pode-se utilizar uma regra que seleciona apenas um subconjunto com os melhores computadores, em termos de CPU e capacidade de rede. Como consequência da adoção de um subconjunto de computadores com menor grau de heterogeneidade, o MHSA apresenta uma aproximação próxima de 2 , resultando em soluções de melhor qualidade.

\footnotetext{
${ }^{6}$ Essa suposição é razoável, uma vez que, em geral, computadores com boas capacidades de processamento tendem, também, a apresentar melhor hardware em termos de placa de rede, disco rígido, etc.
} 


\subsection{Considerações Finais}

Este capítulo apresentou as atividades desenvolvidas no contexto desta tese de doutorado com o objetivo de propor um algoritmo de escalonamento orientado a sistemas e voltado para ambientes distribuídos heterogêneos. Parte do objetivo consiste no fato de que esse algoritmo deveria ser capaz de prover soluções cuja qualidade se aproxima, com certa razão, da solução ótima.

No início deste capítulo, formalizou-se o problema de escalonamento de processos de modo a compreender sua complexidade segundo a classe orientada a sistemas. Essa formalização complementou os conhecimentos do grupo de pesquisa no qual esta tese está inserida. Em seguida, projetou-se um modelo de otimização matemática a fim de avaliar a qualidade de soluções de escalonamento com base nos comportamentos de processos e ocupações de recursos. Com base nesse modelo, pôde-se avaliar e comparar a qualidade de soluções provenientes de qualquer escalonador em relação a um escalonador ótimo. Esse modelo resultou, finalmente, na proposta de um algoritmo de aproximação para o escalonamento de processos sobre ambientes distribuídos de larga escala, tais como grades computacionais, a fim de reduzir o tempo de execução de processos e prover uma melhor ocupação de recursos. Esse algoritmo, denominado Min Heap-based Scheduling Algorithm (MHSA), foi analisado com o objetivo de definir sua complexidade assintótica e encontrar sua razão de aproximação em relação a um escalonador ótimo. Deve-se destacar que essa análise leva em consideração ambientes heterogêneos e a existência de comunicação entre processos, sendo, portanto, mais completa que estudos apresentados nos trabalhos relacionados (Seção 2.4.1).

Após essas análises, foram realizados experimentos para comprovar a eficiência e a qualidade das soluções obtidas utilizando o MHSA. Assim, o Capítulo 4 apresenta resultados de simulação comparando o algoritmo MHSA a um algoritmo de força-bruta, que sempre encontra soluções de escalonamento ótimas, e a um método de resolução de sistemas lineares construído a partir do modelo proposto. Para complementar, MHSA é ainda comparado a uma meta-heurística de escalonamento de processos baseada em algoritmos genéticos e aos algoritmos Random, Round-Robin (RR) e List Scheduling (LS). Resultados são motivantes e permitem concluir sobre a viabilidade do novo algoritmo proposto. 


\section{CAPÍTULO}

\section{4}

\section{Experimentos}

\subsection{Considerações Iniciais}

Neste capítulo são apresentados resultados de simulação com o objetivo comparar o Min Heap-based Scheduling Algorithm (MHSA) a outros algoritmos. Inicialmente, utiliza-se como base comparativa um algoritmo de força-bruta capaz de avaliar todas as possíveis soluções factíveis do problema, selecionando a melhor de todas (ou seja, a solução ótima). Esse algoritmo, no entanto, é ineficiente devido ao tamanho do espaço das soluções de escalonamento factíveis. Dessa maneira, foi empregado apenas na avaliação de instâncias pequenas. Avaliou-se também a rotina linp, disponível no pacote LINPACK (DONGARRA; STEWART, 1984), para a resolução de problemas de programação linear. No entanto, essa rotina adota diferentes relaxações do problema de otimização, o que em alguns casos interrompe o processo de busca em ótimos locais. Além disso, essa rotina requer um pré-processamento nos dados de entrada, requerendo tempo de execução adicional.

Considerou-se, também, uma meta-heurística baseada em algoritmos genéticos (GAs), desenvolvida a partir do modelo de otimização proposto. A escolha do GA se deve ao fato de ser uma das meta-heurísticas mais empregadas para o problema de escalonamento de processos em grades computacionais (Seção 2.4.2), além de apresentar bons resultados em diversos cenários práticos. Outro algoritmo adotado é o List Scheduling (LS), descrito na Seção 2.4.1, cuja razão de aproximação foi estudada na literatura, porém apenas para cenários homogêneos sem comunicação (GRAHAM, 1966; HALL, 1997; WILLIAMSON; SHMOYS, 2010). Finalmente, considerou-se outros dois algoritmos bastante utilizados na literatura: i) Random, que gera soluções aleatórias para o cada instância do problema (EA- 
GER; LAZOWSKA; ZAHORJAN, 1986); e ii) Round-Robin (RR), que organiza os computadores em uma lista circular, atribuindo processos em sequência (SILBERSCHATZ; GALVIN; GAGNE, 2009).

Esses algoritmos são descritos na Seção 4.2. Na Seção 4.3, esses algoritmos são classificados segundo as taxonomias de Casavant e Kuhl (1988) e Dong e Akl (2006), as quais foram introduzidas no Capítulo 2. A Seção 4.4 descreve as instâncias consideradas nos experimentos, cujos resultados são apresentados nas Seções 4.5, para instâncias pequenas, e 4.6, para instâncias grandes. A Seção 4.7 apresenta uma discussão sobre esses resultados.

\subsection{Algoritmos Considerados}

A seguir são descritos os algoritmos comparados, por meio de simulações, ao Min Heapbased Scheduling Algorithm (MHSA), ou seja: i) força-bruta; ii) linp; iii) algoritmo genético (GA); iv) Random; e v) Round-Robin (RR). O algoritmo List Scheduling (LS) está descrito na Seção 2.4.1.

\subsubsection{Algoritmo de Força-bruta}

Seja uma instância do problema de escalonamento definida por valores referentes às cargas de processos (vetor $\mathrm{w}$ ), capacidades de computadores (vetor $\mathbf{c}$ ), taxa de comunicação entre processos (matriz L) e capacidade dos canais de rede (matriz $\Gamma$ )). Uma solução de escalonamento factível é dada pela matriz de escalonamento $\mathrm{S}$, tal que a soma dos elementos de cada linha totaliza 1. Essa restrição é suficiente para garantir que um processo é atribuído a um, e apenas um, computador (ver Seção 3.3.1).

Nesse contexto, o algoritmo de força-bruta produz e avalia todas as possíveis soluções para uma instância do problema de escalonamento, garantindo que tais soluções sejam factíveis. Em outras palavras, constrói-se todas possíveis matrizes de escalonamento $\mathbf{S}$ que respeitam as restrições do problema. Essas matrizes são, então, avaliadas de acordo com a Equação (3.4) (ver Seção 3.3). Entretanto, esse algoritmo não é eficiente, uma vez que o espaço de busca cresce exponencialmente em termos do número de processos $|P|$ e computadores $|V|$. Mais exatamente, existem $|V|^{|P|}$ soluções factíveis para uma dada instância do problema (mais detalhes na Seção 3.2). Por essa razão, o método de força-bruta é empregado apenas em instâncias pequenas a fim de encontrar as melhores soluções e definir limites de qualidade para os demais algoritmos.

\subsubsection{Método de Resolução de Sistemas Lineares}

O modelo de otimização matemática, detalhado na Seção 3.3, pode ser relaxado para um problema de programação linear o qual pode ser tratado utilizando métodos disponíveis 
na literatura (ARENALES et al., 2007). Por essa razão, decidiu-se considerar a rotina linp, disponível no pacote LINPACK (DONGARRA; STEWART, 1984), o qual é amplamente divulgado e utilizado para a resolução de sistemas lineares, inclusive executando sobre ambientes distribuídos. Essa rotina considera o problema de otimização na forma:

$$
\begin{array}{ll}
\underset{\mathrm{S}}{\operatorname{minimizar}} & \delta(\mathbf{S}) \\
\text { sujeito a } & \mathbf{H} \cdot \mathbf{s}=\mathbf{1} \\
& s_{i} \in\{0,1\} \quad \forall s_{i} \in \mathbf{S}
\end{array}
$$

em que $\delta(\mathbf{S})$ é a função definida na Equação (3.8) e a restrição de igualdade $\mathbf{H} \cdot \mathbf{s}=$ 1 corresponde à restrição $\theta(\mathbf{S})$ do problema abordado nesta tese (ver Equação (3.15) definida na Seção 3.3.2). A matriz de escalonamento $\mathbf{S}$ é originalmente representa na forma $(|P| \times|V|)$ e reorganizada aqui como um vetor de $(|P| \cdot|V| \times 1)$ elementos, denotado por s. Essa representação é comumente utilizada em Cálculo Vetorial (MATTHEWS, 2000) para simplificar a compreensão e implementação das restrições de igualdade. Finalmente, a matriz $\mathbf{H}$ tem dimensão $(|V| \times|P| \cdot|V|)$ e $\mathbf{1}$ é um vetor composto apenas por uma sequência de números 1 .

A fim de exemplificar o uso do linp, seja a seguinte instância em que $|P|=3,|V|=3$, $\mathbf{1}=\{1,1,1\}$ e a matriz $\mathbf{H}$ tem a forma:

$$
\mathbf{H}=\left[\begin{array}{lllllllll}
1 & 1 & 1 & 0 & 0 & 0 & 0 & 0 & 0 \\
0 & 0 & 0 & 1 & 1 & 1 & 0 & 0 & 0 \\
0 & 0 & 0 & 0 & 0 & 0 & 1 & 1 & 1
\end{array}\right]
$$

Observa-se que, ao calcular o produto vetorial $\mathbf{H} \cdot \mathbf{s}$ deve-se obter o vetor 1 . Se $\mathbf{S}$ é infactível, essa igualdade não será válida. Por exemplo, supondo que o processo $p_{1}$ não seja atribuído a nenhum computador, a primeira linha de $\mathbf{S}$ terá apenas uma sequência de zeros e, consequentemente, os primeiros três elementos do vetor s serão iguais a zero. Como resultado, o produto $\mathbf{H} \cdot \mathbf{s}$ produzirá zero na primeira posição do vetor resultante, invalidando a igualdade em relação ao vetor 1 . Por outro lado, caso $p_{1}$ seja atribuído a dois computadores, o produto resultará será igual a dois na primeira linha, também invalidando a igualdade.

Dessa maneira, caso a matriz $\mathrm{S}$ seja válida, então a restrição de igualdade $\mathbf{H} \cdot \mathbf{s}=\mathbf{1}$ também será. No entanto, essa rotina considera algumas soluções iniciais para o vetor $\mathbf{s}$, por exemplo $\mathbf{s}=\{0, \ldots, 0\}$. Além disso, o linp modifica a restrição $\mathbf{H} \cdot \mathbf{s}$, tratando-a como uma restrição linear. Após interromper a busca, o vetor resultante é arredondado para 0 ou 1 , dando origem a uma solução de escalonamento. Essas duas características fazem com que a rotina linp, em muitos casos, interrompa a busca em ótimos locais. 


\subsubsection{Algoritmo Genético}

Algoritmos genéticos (GAs) são meta-heurísticas de busca e otimização inspiradas em conceitos de evolução natural que têm sido aplicadas a vários problemas do mundo real (BLUM; ROLI, 2003). Basicamente, um GA considera o seguinte princípio (EIBEN; SMITH, 2003): dada uma população de indivíduos, pressões ambientais causam um processo de seleção natural (ou seja, a sobrevivência do indivíduo mais apto), o que causa uma melhoria na qualidade da população. Assim, dada uma função de otimização (denominada função objetivo), cria-se um conjunto de soluções candidatas, ou seja, elementos do domínio da função, e avalia-se tais candidatas a partir de um critério de qualidade, atribuindo-lhes valores de aptidão. Com base nessa aptidão, as melhores soluções são escolhidas para dar origem a uma nova geração de candidatas por meio da aplicação de operadores de recombinação e mutação (EIBEN; SMITH, 2003).

Após a aplicação desses operadores, as novas soluções candidatas (chamadas descendentes ou filhos) competem, com base na aptidão, com as soluções da geração atual de modo a compor uma nova população. Esse mecanismo é iterado até que algum critério de parada (como, por exemplo, um número máximo de iterações) seja satisfeito. Cada iteração é também denominada geração.

Os operadores de reprodução (conhecidos como recombinação e mutação) tendem a criar diversidade populacional, facilitando o aparecimento de novas boas soluções na população, enquanto a seleção age como uma força para melhorar a qualidade da população. Deve-se ressaltar que muitos componentes de um GA são estocásticos. A seleção privilegia indivíduos que têm maior chance de ser selecionados, porém tipicamente indivíduos menos adaptados podem vir a gerar descendentes ou mesmo a sobreviver para a próxima geração. Além disso, a recombinação combina partes de indivíduos de maneira aleatória, assim como as modificações causadas pela mutação. O esquema geral de um GA é mostrado no Algoritmo 4.1, adaptado de Eiben e Smith (2003), na forma de um pseudocódigo.

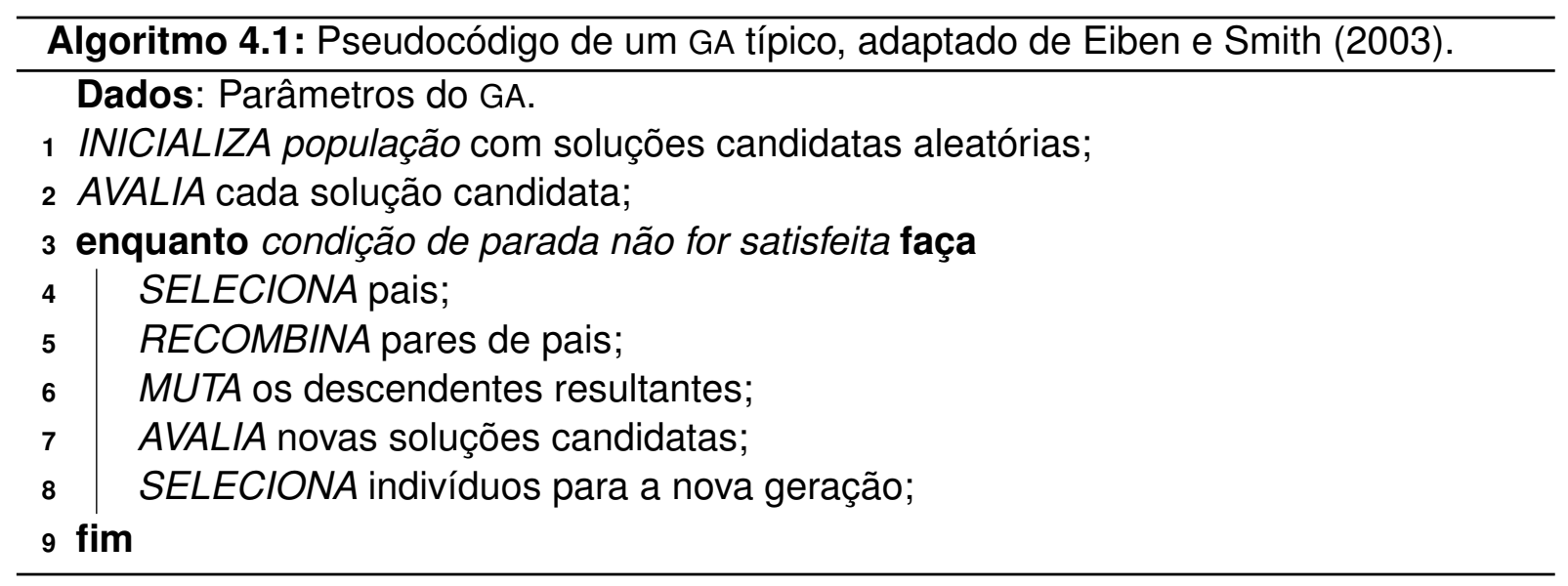

No caso do problema de escalonamento de processos, os indivíduos mais adequados possuem, por exemplo, menor makespan. Outras métricas podem ser consideradas, como 
as mostradas na Seção 2.3. No contexto desta tese, a aptidão $f(\mathbf{S})$ é definida a partir da função de atraso ou custo total $\delta(\mathbf{S})$, formalizada na Seção 3.3 (mais especificamente, na Equação (3.4)), da seguinte maneira:

$$
f(\mathbf{S})=\frac{1}{1+\delta(\mathbf{S})}
$$

Consequentemente, quanto menor o valor de $\delta(\mathbf{S})$, maior será a aptidão das soluções candidatas, ou seja, tais soluções reduzem o atraso total do sistema. A Figura 4.1 mostra um exemplo do comportamento da Equação (4.1) em relação a diferentes valores de $\delta(\mathbf{S})$. Nesse exemplo, supõe-se a execução de um GA para uma instância do problema de escalonamento durante 50 gerações, o que reduz o valor médio do atraso de execução sobre uma determinada instância do problema.

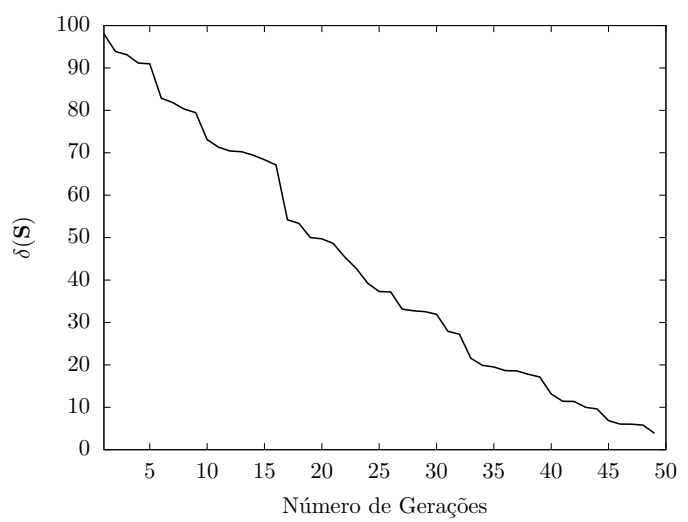

(a) Valor médio de $\delta(\mathbf{S})$ durante 50 gerações.

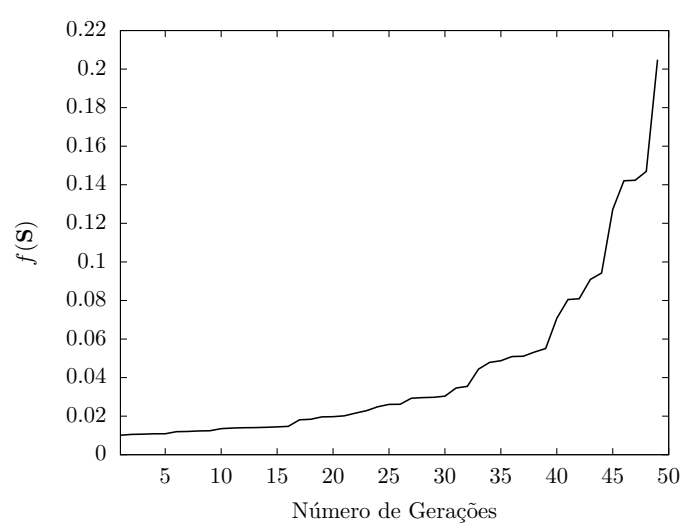

(b) Valor médio de $f(\mathbf{S})$ durante 50 gerações.

Figura 4.1: Exemplo de aplicação da função de aptidão, supondo um cenário em que o GA é executado por 50 gerações. Assim, à medida que o valor médio de $\delta(\mathbf{S})$ diminui (4.1a), indicando que a qualidade dos indivíduos da população melhora, o valor de $f(\mathbf{S})$ aumenta (4.1), resultando na melhor aptidão dos indivíduos.

Outra etapa importante no projeto de um GA é a codificação dos indivíduos ou soluções. Nesta tese, considerou-se que cada indivíduo é codificado por um vetor de números inteiros, o qual é denominado, no contexto de algoritmos genéticos, cromossomo. Esse cromossomo tem comprimento $|P|$, ou seja, o número de processos. Cada posição do cromossomo, denominada gene, pode assumir $|V|$ possíveis valores, indicando, assim, sobre qual computador um determinado processo deve ser escalonado. A Figura 4.2 mostra uma possível solução do problema, para uma instância de sete processos. Nesse exemplo, seguindo a notação adotada na Seção 3.2, tem-se que $\varrho\left(p_{1}\right)=v_{5}$, ou seja, $p_{1}$ é atribuído a $v_{5}, \varrho\left(p_{2}\right)=v_{1}, \varrho\left(p_{3}\right)=v_{5}, \varrho\left(p_{4}\right)=v_{2}, \varrho\left(p_{5}\right)=v_{1}, \varrho\left(p_{6}\right)=v_{2}$ e $\varrho\left(p_{7}\right)=v_{2}$, em que $\varrho: P \rightarrow V$ indica o escalonamento de um processo $p_{i}$ sobre um computador $v_{j}$. Esse esquema de codificação foi adotado pois evita o aparecimento de soluções infactíveis, uma vez que cada processo é atribuído a apenas um computador. Além disso, essa codificação é empregada em outros trabalhos de escalonamento, como no algoritmo RouteGA (MELLO 
et al., 2008).

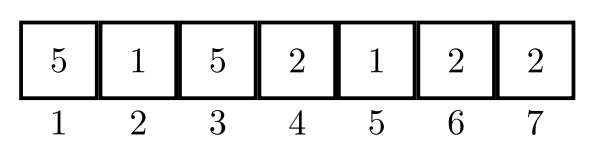

Figura 4.2: Exemplo de codificação de uma solução na forma de um cromossomo. Nesse caso, tem-se que $\varrho\left(p_{1}\right)=v_{5}, \varrho\left(p_{2}\right)=v_{1}, \varrho\left(p_{3}\right)=v_{5}, \varrho\left(p_{4}\right)=v_{2}, \varrho\left(p_{5}\right)=v_{1}, \varrho\left(p_{6}\right)=v_{2}$ e $\varrho\left(p_{7}\right)=v_{2}$.

A partir dessa codificação, define-se o comportamento dos operadores de reprodução. No caso da recombinação, para cada indivíduo selecionado para reprodução, escolhese aleatoriamente um ponto de corte em seu cromossomo, dividindo-o em uma partição à direita e outra à esquerda do corte. Cada descendente é composto pela junção da partição à esquerda de um pai com a partição à direita de outro pai, e vice-versa. Finalmente, a mutação substitui um gene (escolhido aleatoriamente) por outro valor dentro do total de $|V|$ possíveis valores. A Figura 4.3 ilustra um exemplo de aplicação desses operadores. $\mathrm{Na}$ Figura 4.3a, os indivíduos têm seus cromossomos divididos entre as posições 4 e 5; as duas partições originadas são, então, recombinadas de modo que o Filho 1 é composto pelos quatro primeiros genes do Pai 1 e pelos três últimos do Pai 2 (analogamente, o Filho 2 recebe os quatro primeiros genes do Pai 2 e os três últimos do Pai 1). Como exemplo, na Figura 4.3b seleciona-se a posição 3 do cromossomo, a qual recebe um novo valor aleatório.

\subsubsection{Algoritmo Random}

Dada uma instância do problema de escalonamento (a qual é definida por valores referentes às variáveis $\mathbf{w}, \mathbf{L}, \mathrm{c}$ e $\Gamma$ ), o algoritmo Random tem como objetivo gerar uma matriz de escalonamento $\mathbf{S}$ aleatória, porém factível, sem utilizar nenhuma informação sobre o domínio do problema, exceto o número de processos e computadores. Esse algoritmo é baseado no algoritmo proposto por Eager, Lazowska e Zahorjan (1986) e utilizado por Zhou e Ferrari (1987) em testes experimentais. O algoritmo Random foi adotado nesta tese por ser considerado base para diversos trabalhos de escalonamento (MELLO et al., 2008; DODONOV; MELLO, 2010).

$\mathrm{Na}$ implementação do Random, utilizou-se a mesma codificação de soluções mostrada na Figura 4.2, ou seja, um vetor de $|P|$ posições sendo que cada posição indica o computador ao qual o processo é atribuído. Assim, é possível garantir que todas as soluções geradas sejam válidas, uma vez que todos processos são atribuídos a um único computador e não há repetição de processos. Devido a sua simplicidade e eficiência, esse algoritmo permite comparar a qualidade de soluções geradas pelos demais métodos (ZHOU; FERRARI, 1987). 
Pai 1

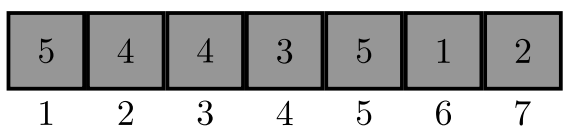

Pai 2

\begin{tabular}{|l|l|l|l|l|l|l|}
\hline 5 & 1 & 5 & 2 & 1 & 2 & 2 \\
\hline 1 & 2 & 3 & 4 & 5 & 6 & 7
\end{tabular}

Filho 1

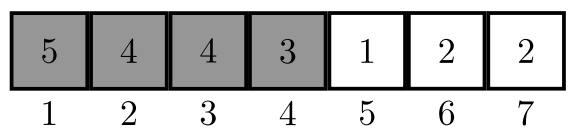

Filho 2

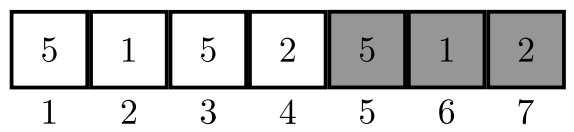

a) Recombinação.

Indivíduo Original

\begin{tabular}{|l|l|l|l|l|l|l|}
\hline 5 & 1 & 5 & 2 & 1 & 2 & 2 \\
\hline 1 & 2 & 3 & 4 & 5 & 6 & 7
\end{tabular}

Indivíduo Alterado

\begin{tabular}{|l|l|l|l|l|l|l|}
\hline 5 & 1 & 4 & 2 & 1 & 2 & 2 \\
\hline 1 & 2 & 3 & 4 & 5 & 6 & 7 \\
\hline
\end{tabular}

(b) Mutação.

Figura 4.3: Exemplo de operadores de reprodução. Em 4.3a, dois indivíduos dão origem a dois novos indivíduos por meio do operador de recombinação, criando assim duas novas soluções de escalonamento. Em 4.3b, um indivíduo sofre uma mutação no terceiro gene, dando origem a um novo indivíduo (em outras palavras, o processo $p_{3}$ passa a ser alocado sobre $v_{4}$ ).

\subsubsection{Algoritmo Round-Robin}

Outro algoritmo considerado nas comparações é o Round-Robin (RR). Esse algoritmo, inicialmente, organiza todos os computadores do sistema distribuído em uma lista circular, os quais são selecionados em sequência. Assim, o primeiro processo que chega ao sistema é atribuído ao primeiro computador, o segundo processo ao segundo computador e assim por diante. Quando todos os computadores já receberam carga, o RR volta a selecionar o primeiro computador, repetindo a sequência de computadores selecionados (SILBERSCHATZ; GALVIN; GAGNE, 2009). O Algoritmo 4.2 mostra o esquema geral do RR em forma de pseudocódigo.

\subsection{Classificação dos Algoritmos}

Esta seção apresenta a classificação do algoritmo MHSA bem como dos demais algoritmos considerados no contexto desta tese de acordo com as taxonomias mostradas no Capítulo 2, ou seja, em relação à classificação hierárquica de Casavant e Kuhl (1988) e à classificação das metas de escalonamento, proposta por Dong e Akl (2006) e estendida por Chunlin e Layuan (2009). A Tabela 4.1 mostra essas classificações.

Tem-se, assim, que o algoritmo MHSA favorece o escalonamento orientado a sistemas 


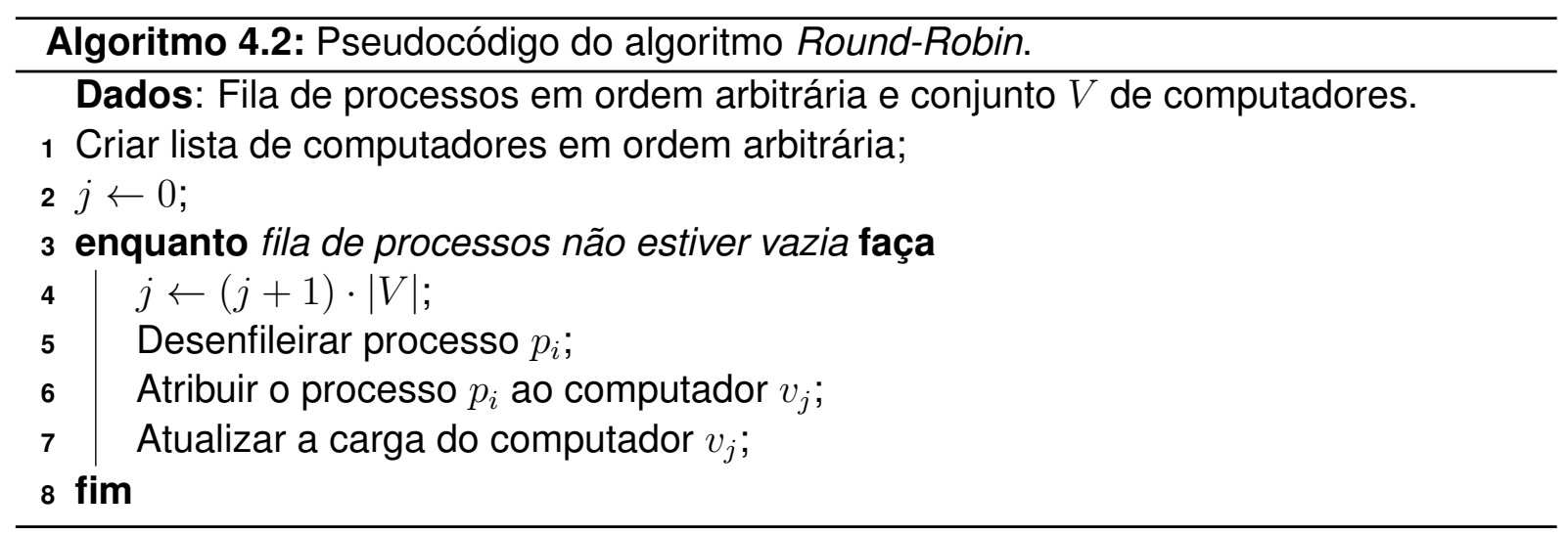

Tabela 4.1: Classificações dos algoritmos de escalonamento segundo as taxonomias mostradas no Capítulo 2.

\begin{tabular}{l|l|l}
\hline Algoritmo & Casavant e Kuhl (1988) & Dong e Akl (2006) \\
\hline Força-bruta & Estático ótimo & Orientado a aplicações \\
linp & Não-distribuído & Orientado a aplicações \\
GA & Não-distribuído & \\
Random & Não-distribuído & Orientado a aplicações \\
RR & Não-distribuído & Orientado a aplicações \\
LS & Não-distribuído & Orientado a recursos \\
MHSA & Não-distribuído & Orientado a aplicações \\
\hline
\end{tabular}

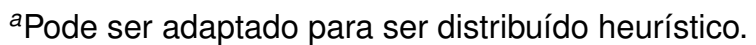

${ }^{b}$ Pode ser adaptado para ser distribuído aproximado.

${ }^{c}$ Apesar de utilizar o modelo de otimização proposto nesta tese, o qual é orientado a aplicações, por considerar uma árvore min-heap, esse algoritmo também favorece a distribuição de processos a todos os computadores disponíveis no sistema distribuído.
}

devido à maneira como foi projetado, utilizando uma árvore min-heap para organizar os computadores do ambiente. Como consequência, todos os computadores considerados nessa árvore podem assumir o nó raiz e, portanto, receber cargas. Os demais algoritmos, com exceção do RR, são tradicionalmente modelados considerando apenas requisitos de redução de tempo de execução de aplicações, conforme o modelo de otimização matemática proposto nesta tese.

\subsection{Planejamento dos Experimentos}

Para os experimentos, foram produzidas instâncias aleatórias para o problema de escalonamento de processos, conforme descrito a seguir. As cargas de processo, i.e., os elementos do vetor w, seguem uma distribuição Normal (EVANS; HASTINGS; PEACOCK, 2000), com média $\mu=10^{10}$ milhões de instruções (MI) e desvio padrão $\sigma=10^{8} \mathrm{Ml}$. A partir desse vetor, oito matrizes $\mathrm{L}$ (contendo o total de bytes transferidos entre processos) foram construídas, cada uma representando um diferente grau de comunicação entre processos: $0 \%$, 
ou seja, uma aplicação bag-of-tasks, 1\%, 5\%, 10\%, 25\%, 50\%, 75\% e 100\%. O grau de comunicação refere-se ao total de bytes transferidos entre processos em termos do número de instruções que um processo possui. Por exemplo, um processo com $1000 \mathrm{Ml}$ e $10 \%$ de comunicação transfere $100 \mathrm{MB}$ via rede em operações entrelaçadas ao processamento.

As capacidades dos computadores (i.e., o vetor c), também foram geradas de acordo com uma distribuição Normal, com $\mu=120.000$ milhões de instruções por segundo (MIPS) e $\sigma=15.000$ MIPS. Esses valores foram escolhidos com base em resultados de benchmarks disponibilizados por Bennett (2011). Finalmente, a matriz que representa as capacidades da rede, i.e., $\Gamma$, também segue uma distribuição Normal, com $\mu=5200 \mathrm{MB} / \mathrm{s}$ e $\sigma^{2}=1300 \mathrm{MB} / \mathrm{s}$. Consequentemente, a pior conexão de rede se comporta como uma Fast Ethernet enquanto a melhor tende a uma Gigabit Ethernet. Além disso, tais canais de comunicação foram atribuídos aos computadores de maneira proporcional às capacidades de CPU, ou seja, os melhor computadores possuem também as redes mais velozes.

Todos algoritmos foram comparados utilizando a Equação (3.8), que fornece o atraso ou custo total imposto por uma solução de escalonamento ao ambiente distribuído. Os algoritmos força-bruta, Random, RR, LS e MHSA foram implementados em linguagem C. No caso do linp, utilizou-se o pacote limSolve (SOETAERT; MEERSCHE; OEVELEN, 2009), do ambiente $R^{1}$. Esse pacote, no entanto, está todo implementado em linguagem Fortran utilizando rotinas do pacote LINPACK (DONGARRA; STEWART, 1984). Finalmente, no caso do GA, utilizou-se a implementação disponível no pacote GA (SCRUCCA, 2013) do R. Suas rotinas, no entanto, estão implementadas em linguagem $\mathrm{C}$.

Ainda em relação ao GA, escolheu-se populações de 100 indivíduos gerados aleatoriamente e o número máximo de gerações é igual a 200, em todos os cenários apresentados neste capítulo. Esses valores foram definidos após experimentos iniciais que mostraram a pouca eficiência do GA para valores maiores de população e gerações. Os valores adotados neste capítulo, no entanto, mostraram-se adequados para a maioria dos cenários analisados. Utilizou-se os operadores de reprodução disponíveis do pacote GA: i) recombinação de um ponto; e ii) e mutação de um gene (conforme descrito na Seção 4.2.3). A seleção dos indivíduos para reprodução é feita por meio do meio do método classificação (do inglês, rank) linear, ou seja, todos os indivíduos de uma determinada geração são ordenados e recebem uma nota linearmente proporcional à sua aptidão. Assim, os melhores indivíduos têm maiores chances de serem selecionados para compor a próxima geração. Adotou-se, ainda, probabilidade de recombinação de $70 \%$ e probabilidade de mutação de $0,01 \%$.

Finalmente, o MHSA foi implementado de acordo com o descrito na Seção 3.4. Não se considerou, entretanto, a escolha de um subconjunto de computadores. Assim, pôde-se avaliar o comportamento desse algoritmo em relação a diferentes volumes de comunicação.

\footnotetext{
${ }^{1}$ cran.r-project.org.
} 
Os experimentos foram organizados em dois cenários. No primeiro cenário, considerou-se instâncias muito pequenas, comparando-se o MHSA ao algoritmos de força-bruta, ao GA e à rotina linp. Esse primeiro cenário é justificado pelo fato do algoritmo de força-bruta ser inviável para instâncias maiores, devido a seu alto consumo de CPU. Mesmo assim, é possível observar a tendência das soluções do MHSA em relação às soluções ótimas (definidas pelo algoritmos de força-bruta), bem como observar o comportamento de dois métodos implementados de acordo com o modelo propostos, ou seja, o linp e o GA. Nesse cenário, dois parâmetros foram variados: o número de computadores $(|V|)$ e o número de processos $(|P|)$. No primeiro caso, i.e., quando $|V|$ varia, mantém-se o número de processos fixo; analogamente, para $|P|$ variável, tem-se $|V|$ contante. Dessa maneira, pode-se extrair conclusões sobre a influência do tamanho da instância tanto na qualidade da solução quanto no tempo de execução dos algoritmos.

No segundo cenário, considerou-se inicialmente instâncias maiores, realizando-se comparações entre os algoritmos linp, Random, RR, LS, GA e MHSA. Variou-se os parâmetros $|P|$ e $|V|$ da mesma maneira que no cenário anterior. Finalmente, considerou-se um total de 1024 computadores executando diferentes cargas de trabalho. Nesse caso, apenas os algoritmos Random, RR, LS e MHSA são considerados nas comparações, devido ao alto tempo requerido pela rotina linp e pelo GA para executar instâncias maiores.

É importante observar que todas as simulações consideraram o mesmo conjunto de processos e computadores. Assim, por exemplo, quando se aumenta o número de processos de 2 para 3 , são considerados os mesmo 2 processos originais acrescidos de mais 1 processo gerado aleatoriamente. O mesmo ocorre quando se aumenta o número de computadores.

\subsection{Primeiro Cenário: Instâncias Pequenas}

As Figuras 4.4 e 4.5 mostram a média e o desvio padrão do atraso ou custo total de processamento e comunicação para as diferentes instâncias consideradas do problema de escalonamento. Foram consideradas 10 execuções de cada algoritmo. Na Figura 4.4a, foram considerados 6 processos independentes atribuídos a 8 sistemas distribuídos distintos, cada um com diferentes números de computadores, i.e., $|V|=\{2,3,4,5,6,7,8,9\}$. Por outro lado, na Figura 4.5a, o sistema tem um número fixo de computadores igual a 6 , no entanto o número de processos bag-of-tasks foi variado na forma $|P|=\{2,3,4,5,6,7,8,9\}$.

Observa-se que, na Figura 4.4a, o MHSA produz as melhores soluções para os casos com menos de 5 computadores, i.e., quando a carga de trabalho sobre tais computadores é maior. Nesse caso, tais soluções têm qualidade inferior apenas se comparadas ao escalonador ótimo, que corresponde à menor barra referente ao algoritmo de força-bruta. Por outro lado, o comportamento do GA sofreu pouca variações, indicando que esse algoritmo está convergindo para uma determinada solução, a qual, no entanto, não é a ótima. Isso 
se deve ao grande espaço de busca com o qual esse algoritmo precisa lidar para encontrar soluções factíveis (lembrando que há $|V|^{|P|}$ possíveis soluções de escalonamento), assim a busca em muitos casos é interrompida em ótimos locais. Nesse caso, ainda, a rotina linp não obteve bons resultados, produzindo atrasos maiores que os demais algoritmos. $\mathrm{Na}$ Figura 4.5a, em que $|V|$ é constante, os algoritmos força-bruta, GA e MHSA produzem soluções similares.

$\mathrm{Na}$ Figura 4.4b é mostrado o valor de $\delta(\mathbf{S})$ quando a comunicação entre processos tem grau $1 \%$. Observa-se que MHSA provê soluções com maiores valores de $\delta(\mathbf{S})$ quando comparado aos demais algoritmos. Além disso, no caso do força-bruta e do linp, a partir de 6 computadores, o valor do atraso total mantém-se o mesmo, indicando que o aumento no número de computadores não foi suficiente para reduzir a carga máxima do sistema. Observa-se, ainda, um maior desvio padrão apresentado pelo GA.

Quando o número de computadores é constante (Figura 4.5), o atraso total das soluções dos quatro algoritmos cresce de maneira acentuada à medida em que o número de computadores aumenta. Essa tendência nos resultados deve-se ao grande número de soluções factíveis para uma dada instância de escalonamento. Assim, quando o número de processos varia, as barras do gráfico crescem exponencialmente, como mostrado na Figura 4.5b, enquanto na Figura 4.4b esse crescimento não é tão expressivo².

Resultados semelhantes são apresentados nas demais figuras, com graus de comunicação de $5 \%, 10 \%, 25 \%, 50 \%, 75 \%$ e $100 \%$. Nota-se que as curvas do MHSA e do algoritmo de força-bruta têm a mesma forma mostrada na Figura 4.4b, no caso em que $|P|$ é constante, e na Figura 4.5, caso em que $|V|$ é constante, havendo diferença apenas em relação à escala dos gráficos, i.e., ao valores de $\delta(\mathbf{S})$. Isso ocorre porque as soluções de escalonamento geradas por esses algoritmos são as mesmas em todos os casos. No caso do MHSA, utiliza-se todos os computadores do sistema na composição da min-heap sem, contudo, levar em consideração as capacidades de seus canais de comunicação. Dessa maneira, o atraso total de CPU, definido na Equação (3.2) será constante enquanto o atraso de comunicação, definido na Equação (3.3), aumentará à medida que a taxa de comunicação entre processos tornar-se maior. O mesmo ocorre com o algoritmo de força-bruta, que sempre aloca os processos sobre o mesmo conjunto de computadores, garantindo, no entanto, a otimalidade dessas soluções de escalonamento.

Além de avaliar a qualidade das soluções, comparou-se também esses algoritmos segundo seus tempos de execução, conforme apresentado na Tabela 4.2. Esse tempo consiste no tempo que cada algoritmo demandou para encontrar soluções de escalonamento quando simulados em um computador Intel i7-3930X com 3,20 GHz e 64 GB de memória principal. Para computar o tempo de execução do algoritmo de força-bruta, considerou-se apenas o tempo dispendido na avaliação de todas as possíveis soluções de escalona-

\footnotetext{
${ }^{2} \mathrm{~A}$ fim de ilustrar esse crescimento, seja um cenário com $|V|=6$ e com $|P|$ variando em $\{7,8\}$. Nota-se que $6^{8}$ é muito maior que $6^{7}$, em oposição à diferença entre $7^{6}$ e $8^{6}$, que não é tão grande.
} 
mento, desconsiderando o tempo consumido na construção das matrizes de escalonamento $\mathbf{S}$ (é importante ressaltar que a simples construção dessas matrizes consome horas de processamento, mesmo para instâncias com apenas $|P|=6$ e $|V|=9$ ). Em relação ao linp, considerou-se o tempo de pré-processamento, i.e., o tempo consumido para construir as matrizes necessárias para essa rotina (ver Seção 4.2.2), e o tempo de encontrar as soluções. Com relação ao GA, considerou-se o tempo gasto para que a população convergisse; caso não houvesse convergência, considerou-se todas as 200 iterações previamente definidas. Deve-se destacar, novamente, que um maior número de iterações requer maior tempo de execução desse algoritmo, além de não contribuírem, nos cenários considerados, para a melhoria na qualidade das soluções ${ }^{3}$. Finalmente, no caso do MHSA, todas as etapas envolvidas em sua execução foram consideradas, ou seja, a construção e ordenação de vetor de computadores, a construção a árvore min-heap e todas as operações envolvidas no escalonamento. Deve-se observar que esse tempo é independente do grau de comunicação, sendo diretamente relacionado apenas ao tamanho das instâncias.

Tabela 4.2: Tempo médio de execução (em segundos) apresentado pelos algoritmos força-bruta, linp, GA e MHSA quando $|P|=6$ e quando $|V|=6$. É apresentado, também, o desvio-padrão (em segundos).

\begin{tabular}{l|llll}
\hline$|V|$ & Força-bruta & linp & GA & MHSA \\
\hline 2 & $0,002 \pm 0,0015$ & $0,003 \pm 0,0009$ & $4,39 \pm 0,15$ & $2,89 \mathrm{e}-05 \pm 6,34 \mathrm{e}-06$ \\
3 & $0,034 \pm 0,004$ & $0,0011 \pm 0,0017$ & $4,38 \pm 0,11$ & $2,81 \mathrm{e}-05 \pm 1,16 \mathrm{e}-06$ \\
4 & $0,22 \pm 0,02$ & $0,0007 \pm 1,98 \mathrm{e}-05$ & $4,45 \pm 0,11$ & $3,13 \mathrm{e}-05 \pm 6,46 \mathrm{e}-06$ \\
5 & $0,94 \pm 0,035$ & $0,0008 \pm 2,49 \mathrm{e}-05$ & $4,50 \pm 0,15$ & $3,15 \mathrm{e}-05 \pm 6,86 \mathrm{e}-06$ \\
6 & $3,18 \pm 0,044$ & $0,001 \pm 3,43 \mathrm{e}-05$ & $4,51 \pm 0,16$ & $3,26 \mathrm{e}-05 \pm 6,58 \mathrm{e}-06$ \\
7 & $9,35 \pm 0,098$ & $0,0013 \pm 4,42 \mathrm{e}-05$ & $4,57 \pm 0,17$ & $3,30 \mathrm{e}-05 \pm 7,45 \mathrm{e}-06$ \\
8 & $23,89 \pm 0,22$ & $0,0018 \pm 6,13 \mathrm{e}-05$ & $4,56 \pm 0,19$ & $3,34 \mathrm{e}-05 \pm 7,65 \mathrm{e}-06$ \\
9 & $55,75 \pm 0,60$ & $0,0022 \pm 6,89 \mathrm{e}-05$ & $4,63 \pm 0,17$ & $3,32 \mathrm{e}-05 \pm 4,16 \mathrm{e}-06$ \\
\hline$|P|$ & Força-bruta & linp & GA & MHSA \\
\hline 2 & $0,0008 \pm 0,0008$ & $0,0007 \pm 0,0006$ & $3,71 \pm 0,31$ & $2,79 \mathrm{e}-05 \pm 7,65 \mathrm{e}-07$ \\
3 & $0,01 \pm 0,003$ & $0,0005 \pm 5,38 \mathrm{e}-06$ & $3,81 \pm 0,19$ & $3,55 \mathrm{e}-05 \pm 1,14 \mathrm{e}-05$ \\
4 & $0,068 \pm 0,009$ & $0,0007 \pm 0,0003$ & $4,21 \pm 0,18$ & $3,11 \mathrm{e}-05 \pm 7,03 \mathrm{e}-06$ \\
5 & $0,47 \pm 0,013$ & $0,0008 \pm 9,63 \mathrm{e}-06$ & $4,33 \pm 0,16$ & $3,05 \mathrm{e}-05 \pm 1,29 \mathrm{e}-06$ \\
6 & $3,14 \pm 0,07$ & $0,0011 \pm 1,63 \mathrm{e}-05$ & $4,56 \pm 0,18$ & $2,96 \mathrm{e}-05 \pm 5,27 \mathrm{e}-07$ \\
7 & $22,87 \pm 0,22$ & $0,0011 \pm 7,21 \mathrm{e}-06$ & $4,67 \pm 0,10$ & $3,41 \mathrm{e}-05 \pm 7,02 \mathrm{e}-06$ \\
8 & $156,72 \pm 0,45$ & $0,0011 \pm 1,41 \mathrm{e}-05$ & $4,93 \pm 0,093$ & $3,08 \mathrm{e}-05 \pm 6,03 \mathrm{e}-07$ \\
9 & $1064,20 \pm 6,16$ & $0,0022 \pm 1,54 \mathrm{e}-05$ & $5,06 \pm 0,14$ & $3,07 \mathrm{e}-05 \pm 7,98 \mathrm{e}-07$ \\
\hline
\end{tabular}

É possível concluir que o MHSA é um algoritmo muito eficiente devido à sua complexidade assintótica, i.e., $\mathcal{O}(1)$ para executar cada escalonamento de processo e $\mathcal{O}\left(\log _{2}|V|\right)$ para atualizar a árvore min-heap. Nota-se, também, que a qualidade das soluções en-

\footnotetext{
${ }^{3}$ Esse fato motiva experimentos adicionais utilizando a meta-heurística GA considerando outros parâmetros.
} 
contradas pelo MHSA apresenta tendências similares às encontradas pelo algoritmo de força-bruta. Além disso, o MHSA pode ser considerado um algoritmo orientado a sistemas, pois provê boas soluções em termos de makespan e aumenta a ocupação de recursos, dado o fato que qualquer computadores do sistema pode assumir a posição raiz da árvore min-heap. Tais resultados motivaram novos experimentos, considerando cenários maiores, conforme mostrado na próxima seção. 

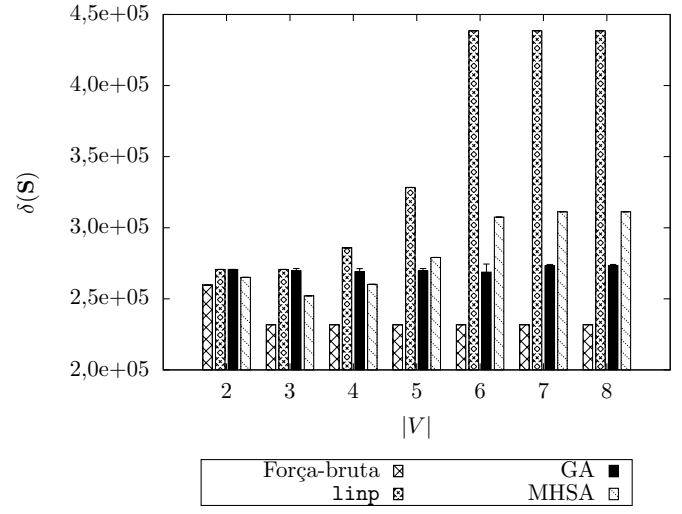

(a) $0 \%$
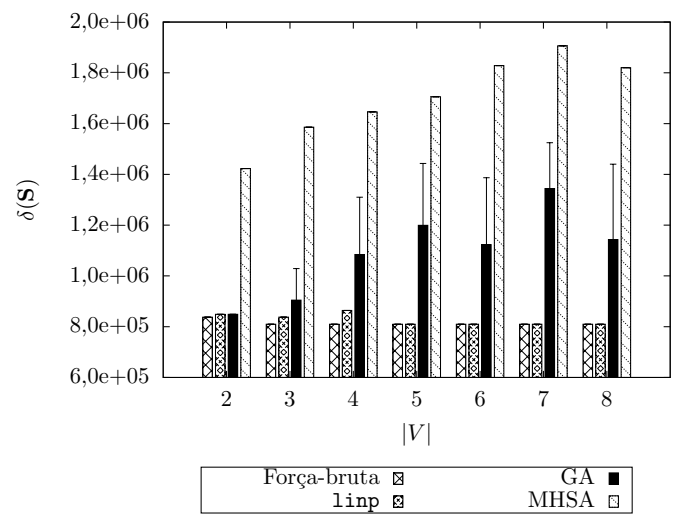

(c) $5 \%$
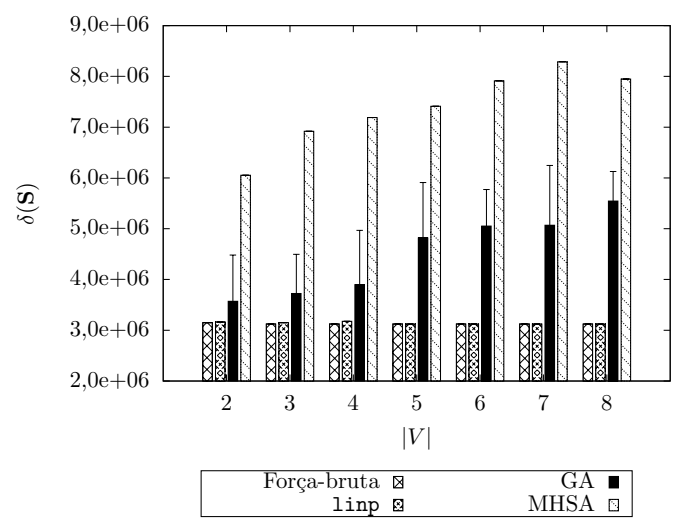

(e) $25 \%$
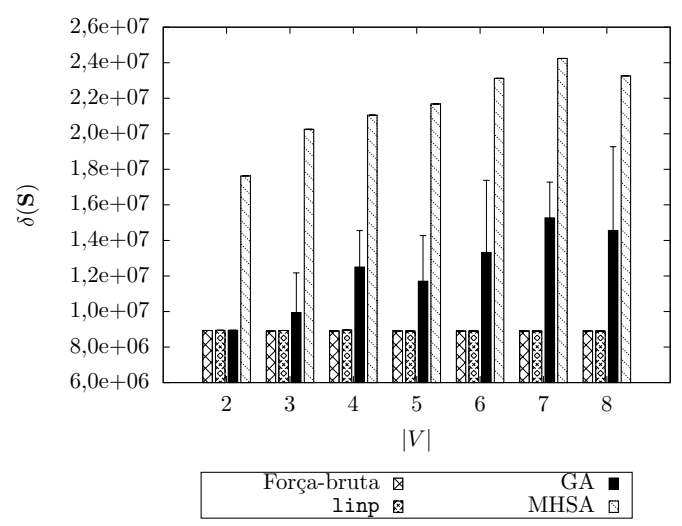

(g) $75 \%$
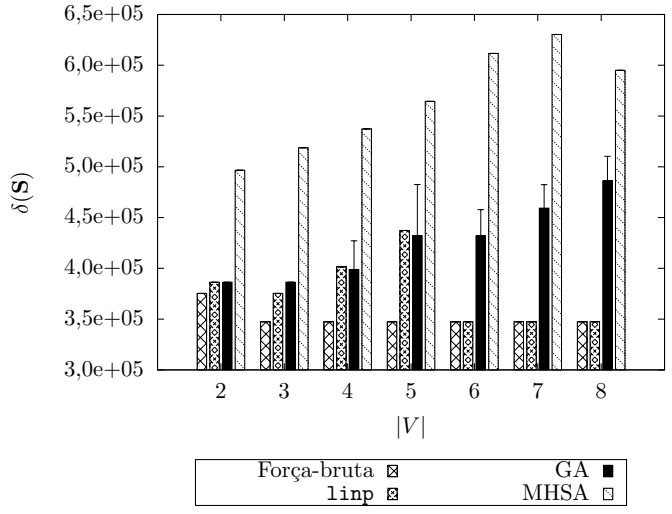

(b) $1 \%$
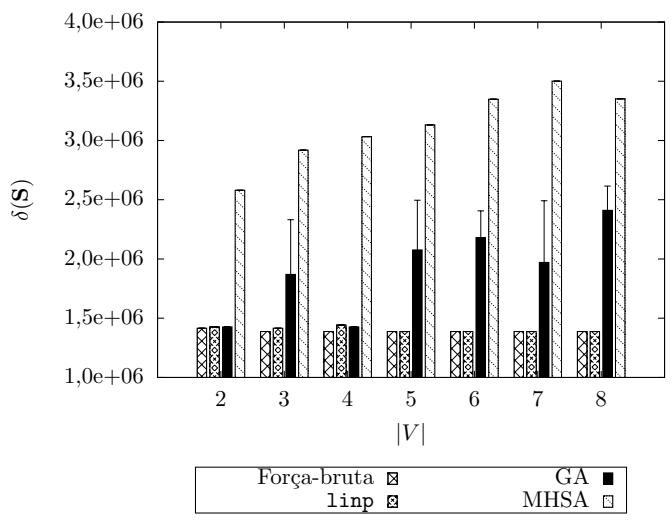

(d) $10 \%$
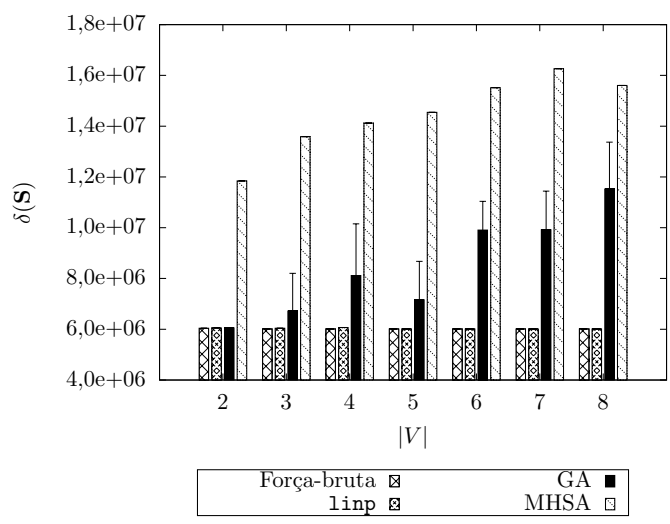

(f) $50 \%$
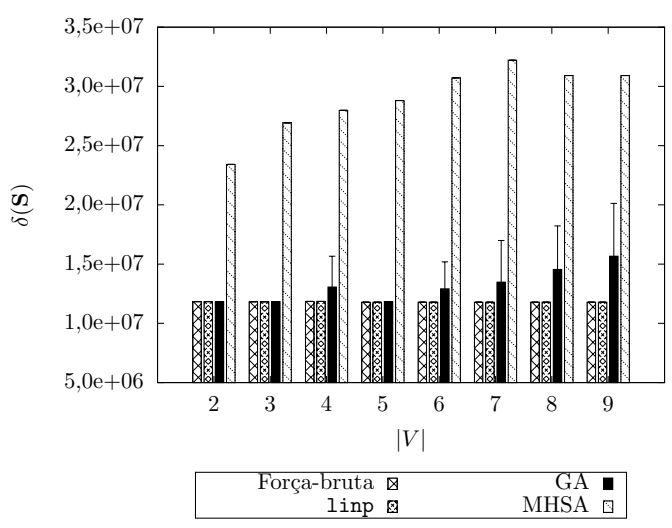

(h) $100 \%$

Figura 4.4: Resultados de simulações em que o número de processos é constante $|P|=6$ e o número de computadores varia na forma $|V|=\{2, \ldots, 9\}$. 

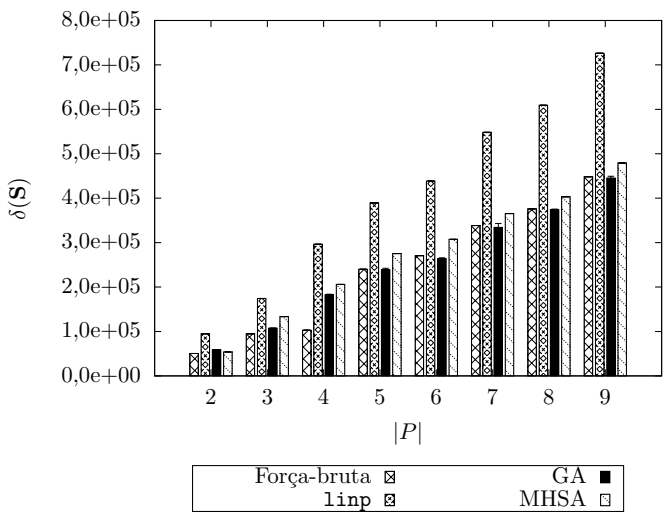

(a) $0 \%$
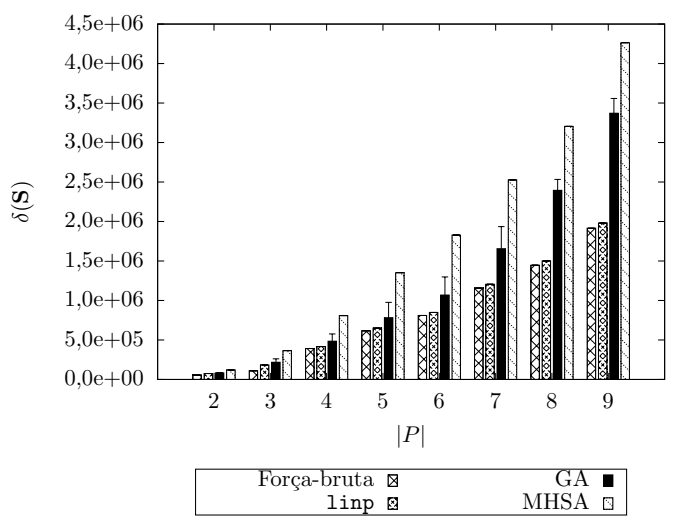

(c) $5 \%$
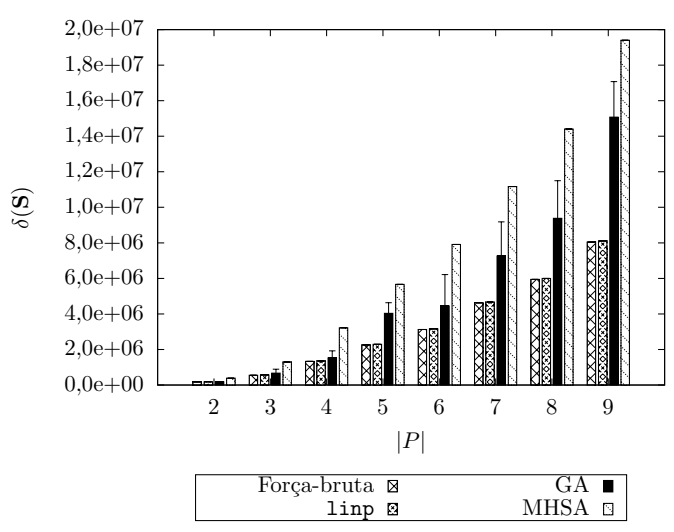

(e) $25 \%$

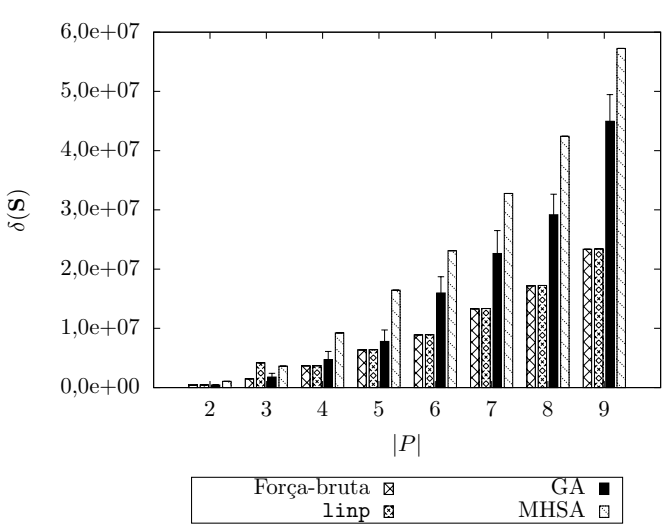

(g) $75 \%$

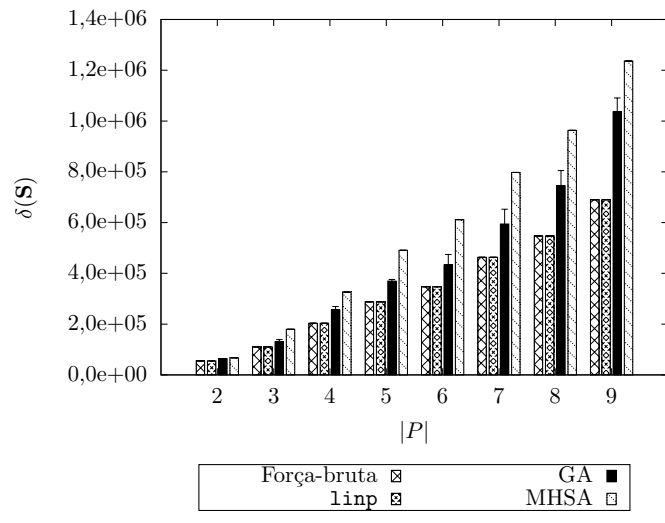

(b) $1 \%$

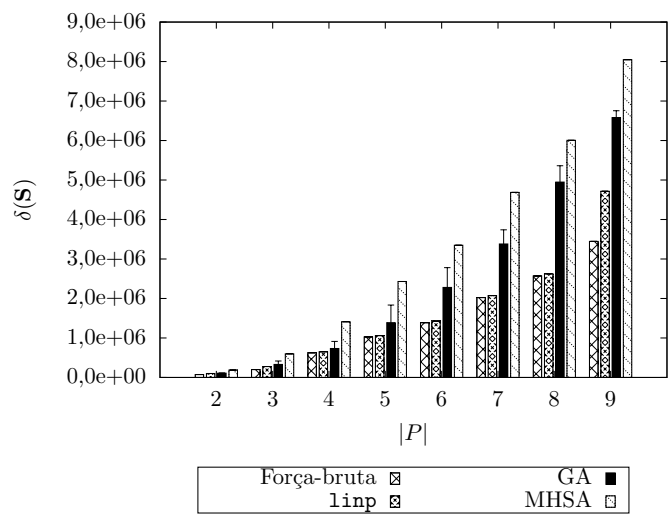

(d) $10 \%$

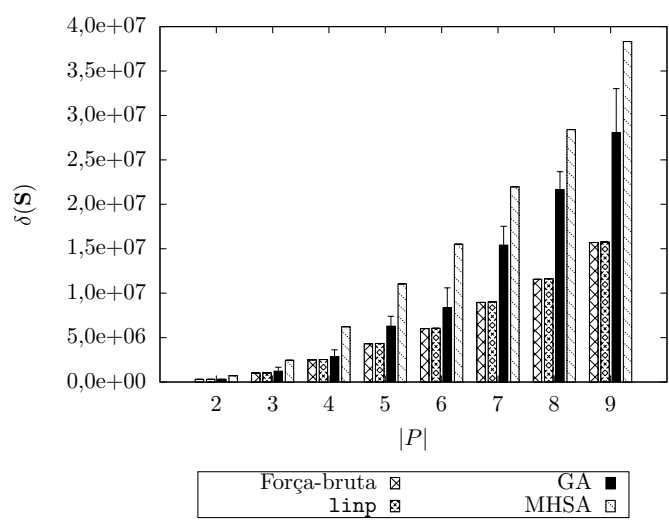

(f) $50 \%$

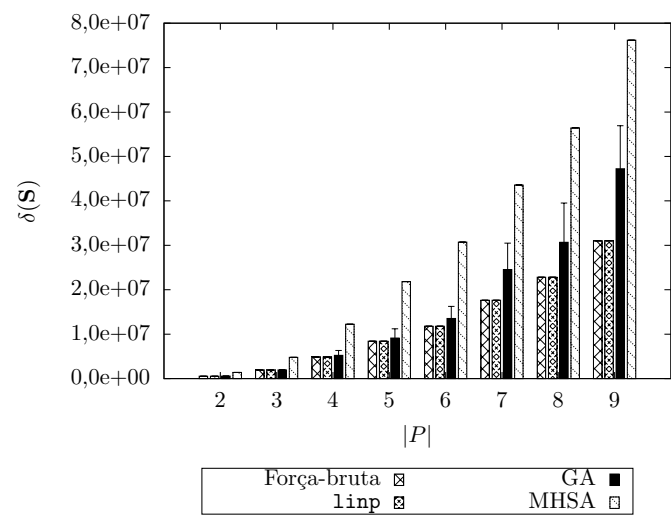

(h) $100 \%$

Figura 4.5: Resultados de simulações em que o número de computadores é constante $|V|=6$ e o número de processos varia na forma $|P|=\{2, \ldots, 9\}$. 


\subsection{Segundo Cenário: Instâncias Grandes}

As instâncias menores avaliadas na seção anterior permitiram observar as tendências do algoritmo MHSA. Para complementar esses estudos, foram propostos mais experimentos considerando um maior número de processos e computadores e comparando os resultados do MHSA aos obtidos pela rotina linp, pelo GA e por outros algoritmos de escalonamento adotados na literatura: Random, RR e LS. As Figuras 4.6 e 4.7 mostram a média e o desvio padrão do atraso ou custo total $\delta(\mathbf{S})$ para tais situações, quando $|P|$ é contante e quando $|V|$ é constante, respectivamente.

De maneira similar à seção anterior, a Figura 4.6a apresenta resultados para 32 processos independentes executando sobre ambientes distribuídos com número de computadores variando na forma $|V|=\{2,4,8,16,32,64\}$, e a Figura 4.7a mostra resultados para 32 computadores executando diferentes números de processos, $|P|=\{2,4,8,16,32,64\}$. Em ambos casos, O MHSA encontrou soluções similares aos demais algoritmos em termos do atraso ou custo total $\delta(\mathbf{S})$ em quase todos os casos. Pode-se ver que a rotina linp obteve, ainda, os melhores resultados para os casos em que há comunicação entre processos. No entanto, na Figura 4.7a, observa-se que esses resultados têm qualidade inferior quando comparados aos obtidos pelos demais algoritmos. No caso em que $|V|$ é constante (Figura 4.6a), essa rotina apresenta melhores resultados em todos os cenários.

À medida que a comunicação aumenta, essa tendência nos resultados é mantida em todos os casos observados. Observa-se, no caso em que $|P|$ é constante, que os três algoritmos de comportamento determinístico, ou seja, RR, LS e MHSA, encontram soluções similares, gerando resultados de qualidade inferior ao linp e ao GA (Figura 4.6), os quais foram projetados com base no modelo proposto. Quando $|V|$ é constante (Figura 4.7) todos os algoritmos (exceto o linp) apresentam resultados similares.

Para concluir esse conjunto de experimentos, a Tabela 4.3 apresenta os tempos de execução, em segundos, para esse cenário, sob as mesmas condições consideradas na Tabela 4.2, apresentada na seção anterior. Assim como no caso do MHSA, foi computado o tempo de execução de todas as etapas dos algoritmos Random, RR e LS. Deve-se ressaltar que os algoritmos Random e RR são bastante eficientes, pois atribuem processos a computadores em tempo constante, enquanto o MHSA tem a necessidade de, em muitos caso, atualizar sua árvore min-heap. Mesmo assim, seu tempo de execução encontra-se próximo ao dos algoritmos mais eficientes. 


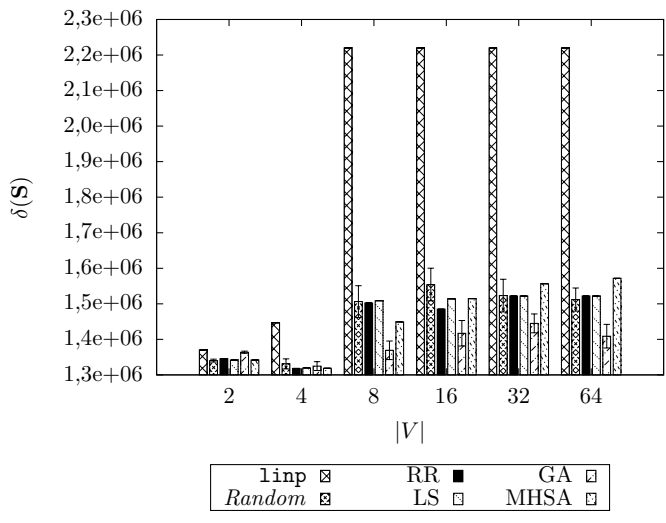

(a) $0 \%$

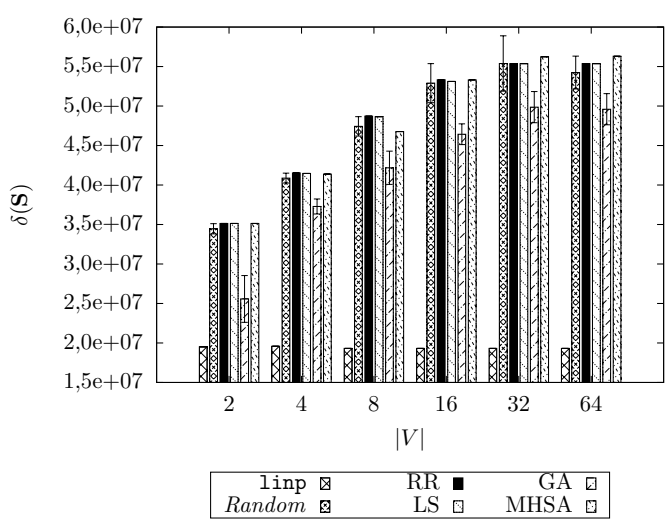

(c) $5 \%$

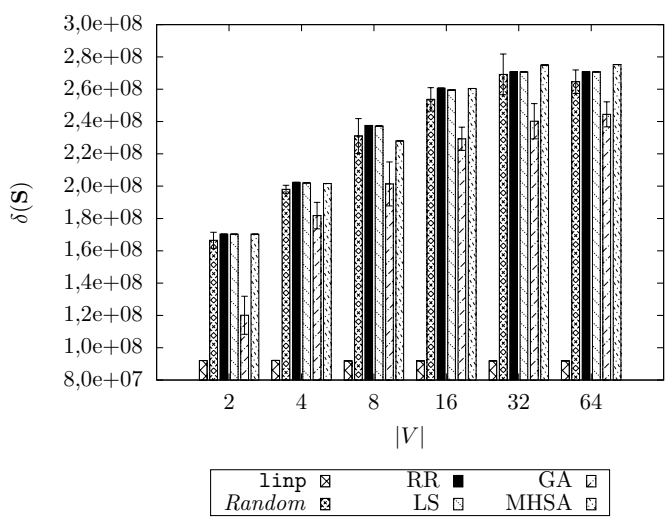

(e) $25 \%$

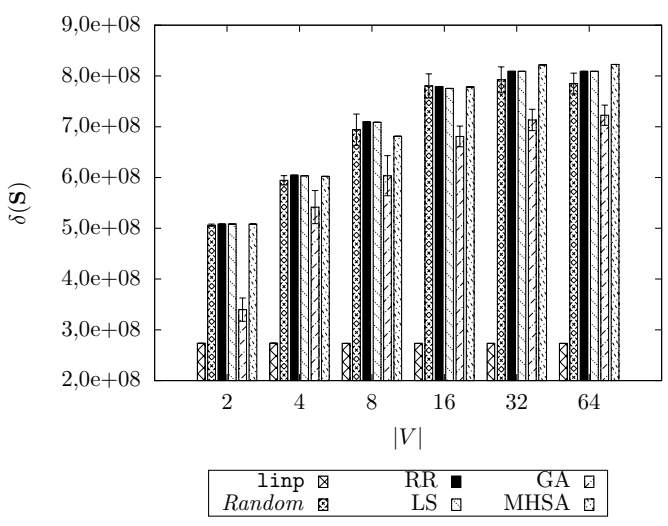

(g) $75 \%$

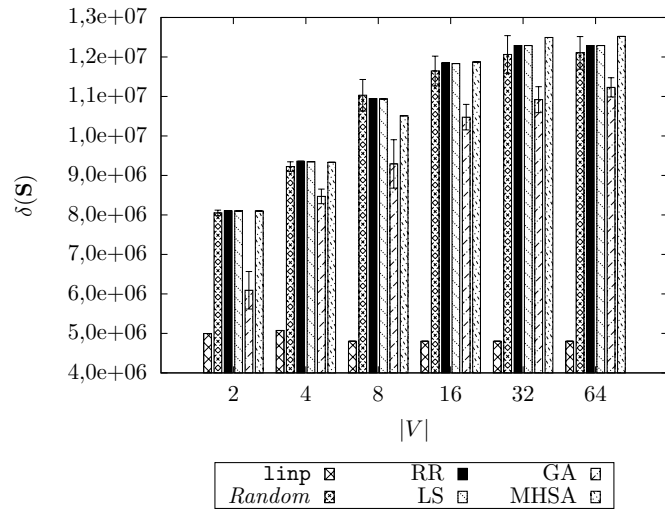

(b) $1 \%$

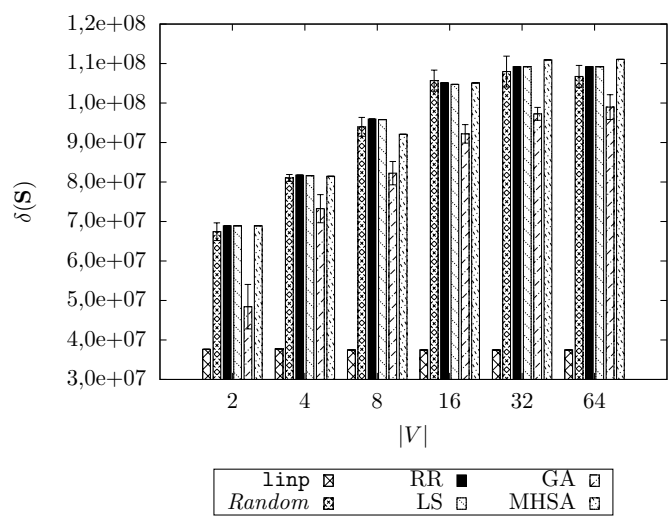

(d) $10 \%$

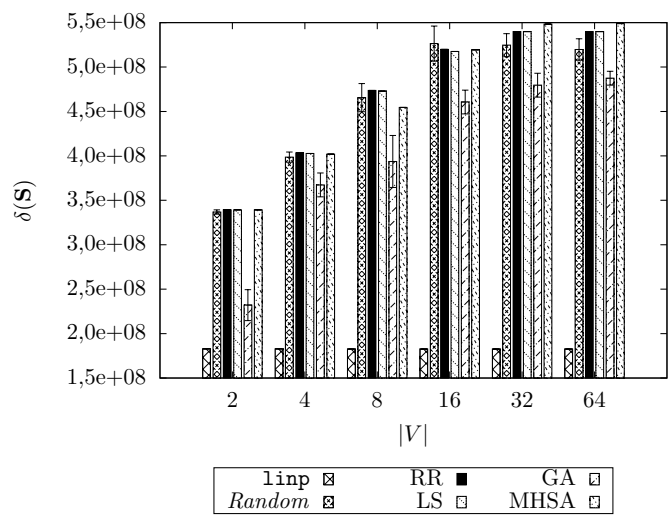

(f) $50 \%$

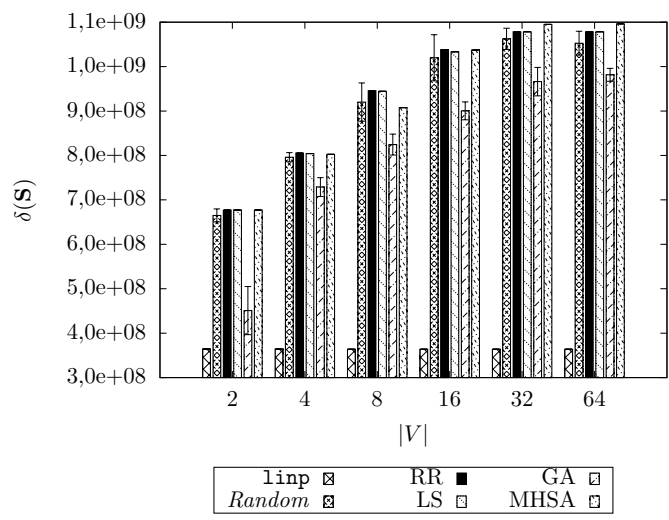

(h) $100 \%$

Figura 4.6: Resultados de simulações em que o número de processos é constante $|P|=$ 32 e o número de computadores varia na forma $|V|=\{2,4,8,16,32,64\}$. 


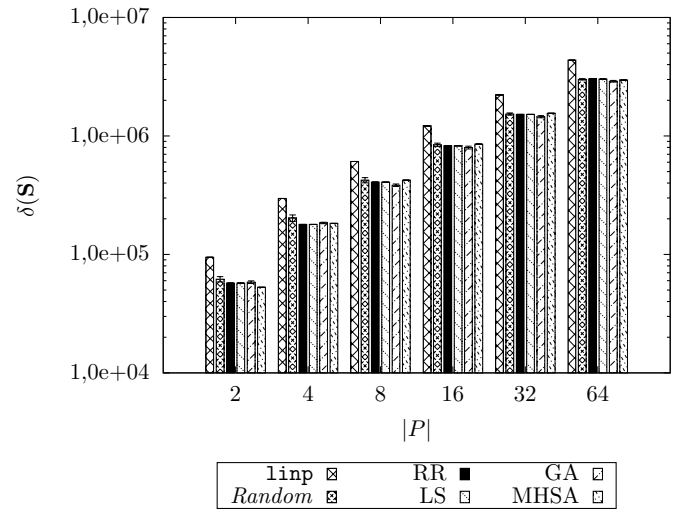

(a) $0 \%$

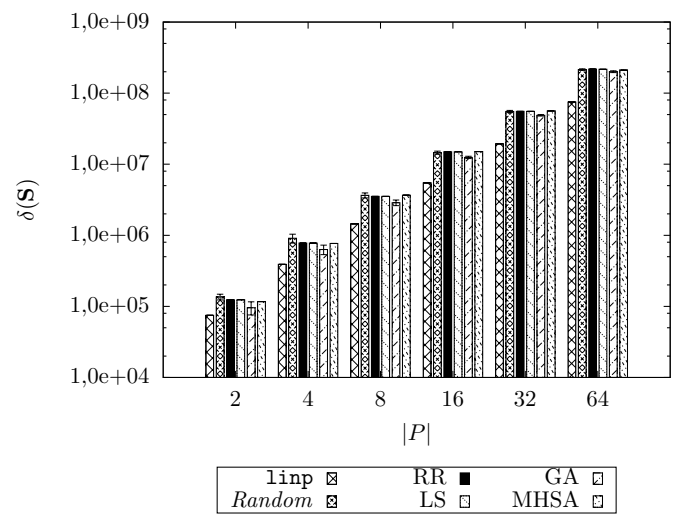

(c) $5 \%$

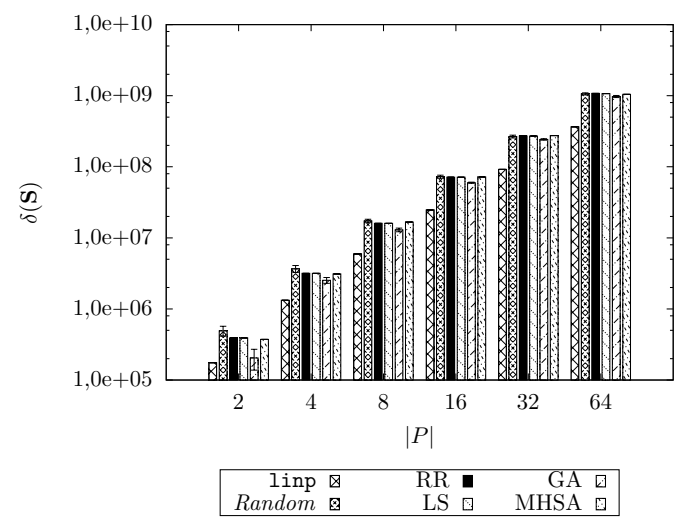

(e) $25 \%$

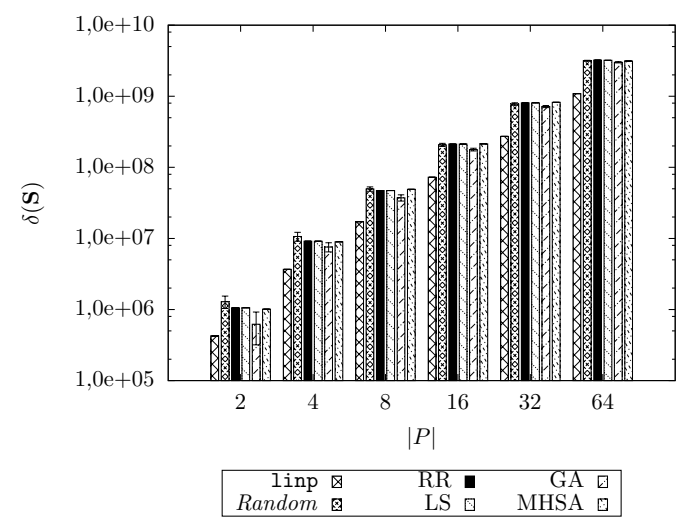

(g) $75 \%$
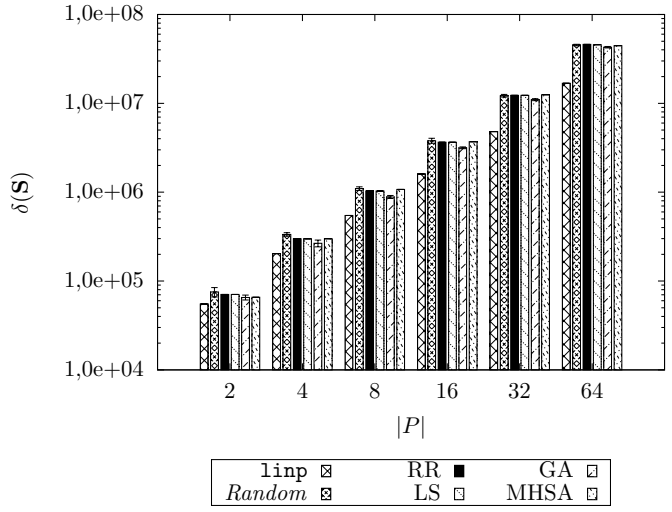

(b) $1 \%$

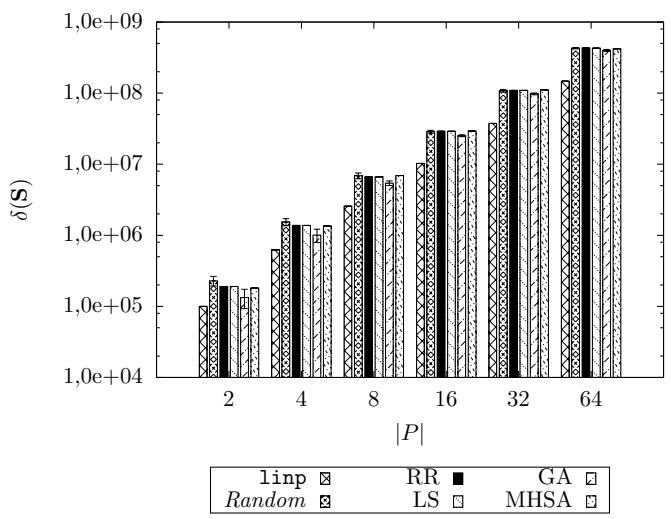

(d) $10 \%$
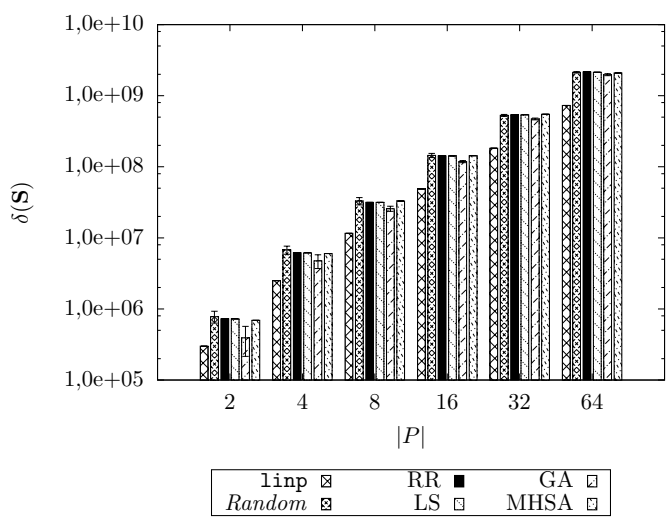

(f) $50 \%$

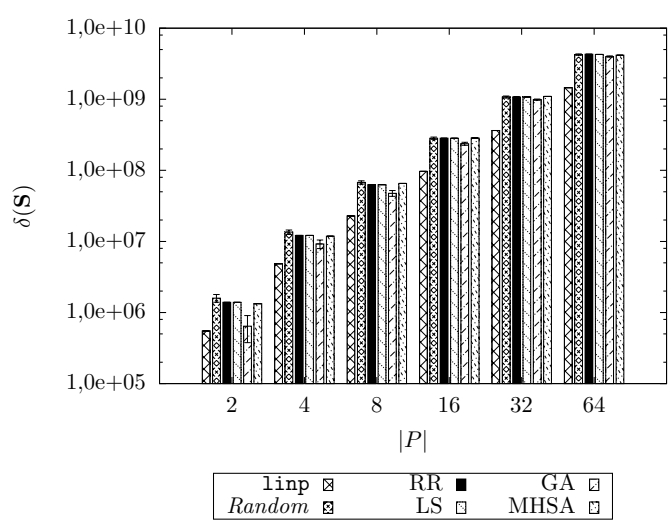

(h) $100 \%$

Figura 4.7: Resultados de simulações em que o número de computadores é constante $|V|=32$ e o número de processos varia na forma $|P|=\{2,4,8,16,32,64\}$. Os gráficos estão em escala logarítmica. 
Tabela 4.3: Tempo médio de execução (em segundos) apresentado pelos algoritmos linp, Random, RR, LS, GA e MHSA quando $|P|=6$ e quando $|V|=6$. É apresentado, também, o desvio-padrão (em segundos).

\begin{tabular}{l|llllll}
\hline$|V|$ & linp & Random & RR & LS & GA & MHSA \\
\hline 2 & $0,004 \pm 0,0004$ & $3,75 \mathrm{e}-05 \pm 1,76 \mathrm{e}-06$ & $2,75 \mathrm{e}-05 \pm 1,44 \mathrm{e}-06$ & $2,75 \mathrm{e}-05 \pm 7,88 \mathrm{e}-07$ & $9,34 \pm 0,13$ & $3,13 \mathrm{e}-05 \pm 1,84 \mathrm{e}-06$ \\
4 & $0,02 \pm 0,004$ & $3,64 \mathrm{e}-05 \pm 1,40 \mathrm{e}-06$ & $3,18 \mathrm{e}-05 \pm 7,55 \mathrm{e}-06$ & $3,16 \mathrm{e}-05 \pm 9,91 \mathrm{e}-07$ & $9,48 \pm 0,16$ & $3,51 \mathrm{e}-05 \pm 9,80 \mathrm{e}-07$ \\
8 & $0,1 \pm 0,001$ & $3,95 \mathrm{e}-05 \pm 1,81 \mathrm{e}-06$ & $3,49 \mathrm{e}-05 \pm 8,13 \mathrm{e}-06$ & $3,68 \mathrm{e}-05 \pm 1,00 \mathrm{e}-06$ & $9,82 \pm 0,17$ & $4,26 \mathrm{e}-05 \pm 7,20 \mathrm{e}-06$ \\
16 & $1,00 \pm 0,004$ & $4,36 \mathrm{e}-05 \pm 1,74 \mathrm{e}-06$ & $3,67 \mathrm{e}-05 \pm 5,20 \mathrm{e}-07$ & $4,37 \mathrm{e}-05 \pm 7,45 \mathrm{e}-07$ & $10,69 \pm 0,12$ & $4,94 \mathrm{e}-05 \pm 8,65 \mathrm{e}-07$ \\
32 & $8,44 \pm 0,04$ & $5,25 \mathrm{e}-05 \pm 1,26 \mathrm{e}-06$ & $4,64 \mathrm{e}-05 \pm 1,62 \mathrm{e}-06$ & $5,76 \mathrm{e}-05 \pm 1,82 \mathrm{e}-06$ & $12,76 \pm 0,20$ & $8,33 \mathrm{e}-05 \pm 4,44 \mathrm{e}-05$ \\
64 & $65,95 \pm 0,1$ & $7,92 \mathrm{e}-05 \pm 1,73 \mathrm{e}-05$ & $6,74 \mathrm{e}-05 \pm 1,42 \mathrm{e}-05$ & $8,89 \mathrm{e}-05 \pm 1,73 \mathrm{e}-05$ & $19,99 \pm 0,21$ & $0,0001 \pm 2,32 \mathrm{e}-05$ \\
\hline$|P|$ & linp & Random & RR & LS & GA & MHSA \\
\hline 2 & $0,005 \pm 0,001$ & $3,80 \mathrm{e}-05 \pm 2,74 \mathrm{e}-06$ & $3,00 \mathrm{e}-05 \pm 1,10 \mathrm{e}-06$ & $3,13 \mathrm{e}-05 \pm 1,68 \mathrm{e}-06$ & $4,40 \pm 0,17$ & $5,73 \mathrm{e}-05 \pm 4,17 \mathrm{e}-05$ \\
4 & $0,023 \pm 0,0006$ & $3,65 \mathrm{e}-05 \pm 1,30 \mathrm{e}-06$ & $3,12 \mathrm{e}-05 \pm 1,19 \mathrm{e}-06$ & $3,31 \mathrm{e}-05 \pm 9,95 \mathrm{e}-07$ & $4,94 \pm 0,12$ & $4,19 \mathrm{e}-05 \pm 1,19 \mathrm{e}-06$ \\
8 & $0,15 \pm 0,004$ & $4,35 \mathrm{e}-05 \pm 8,65 \mathrm{e}-06$ & $3,42 \mathrm{e}-05 \pm 9,97 \mathrm{e}-07$ & $3,72 \mathrm{e}-05 \pm 8,36 \mathrm{e}-07$ & $6,13 \pm 0,04$ & $4,57 \mathrm{e}-05 \pm 1,14 \mathrm{e}-06$ \\
16 & $1,11 \pm 0,012$ & $4,43 \mathrm{e}-05 \pm 8,44 \mathrm{e}-07$ & $3,84 \mathrm{e}-05 \pm 9,06 \mathrm{e}-07$ & $4,41 \mathrm{e}-05 \pm 9,13 \mathrm{e}-07$ & $8,35 \pm 0,10$ & $5,33 \mathrm{e}-05 \pm 1,42 \mathrm{e}-06$ \\
32 & $8,40 \pm 0,023$ & $5,40 \mathrm{e}-05 \pm 1,01 \mathrm{e}-06$ & $4,66 \mathrm{e}-05 \pm 7,35 \mathrm{e}-07$ & $5,87 \mathrm{e}-05 \pm 1,03 \mathrm{e}-06$ & $13,53 \pm 0,24$ & $6,71 \mathrm{e}-05 \pm 8,65 \mathrm{e}-07$ \\
64 & $64,13 \pm 0,06$ & $8,65 \mathrm{e}-05 \pm 1,90 \mathrm{e}-05$ & $7,51 \mathrm{e}-05 \pm 1,74 \mathrm{e}-05$ & $9,57 \mathrm{e}-05 \pm 1,83 \mathrm{e}-05$ & $25,27 \pm 0,16$ & $0,0001 \pm 3,16 \mathrm{e}-05$ \\
\hline
\end{tabular}


A partir desses resultados, observa-se que o MHSA apresenta boas soluções de escalonamento, quando comparado a outros algoritmos, além de ser bastante eficiente em termos de seu tempo de execução. Além disso, observa-se que, a rotina linp e a meta-heurística GA, projetados com base no modelo de otimização proposto, apresentam bons resultados, porém têm um custo computacional crescente em relação ao tamanho da instância do problema. Por essa razão, no último conjunto de experimentos, mostrado a seguir, desconsiderou-se essas técnicas, comparando-se apenas o MHSA em relação aos algoritmos de escalonamento Random, RR e LS. Deve-se destacar que o Random e o RR são utilizados como base de comparação em diversos trabalhos na área de Sistemas Distribuídos.

A Figura 4.8 mostra o atraso ou custo total médio, bem como o desvio padrão, para as soluções de escalonamento desses algoritmos. Foram consideradas, novamente, 10 execuções. Criou-se um ambiente com 1024 computadores executando 512, 1024, 2048 e 4096 processos. Como esperado, o algoritmo Random apresenta a maior instabilidade em termos de seus escalonamentos, enquanto os demais algoritmos têm comportamento determinístico. Nota-se, ainda, que o algoritmo MHSA apresenta os melhores resultados em termos da qualidade de suas soluções. O MHSA mantém-se próximo ao LS quando o número de processos é relativamente baixo em relação ao total de computadores, porém, quando a carga de trabalho aumenta, no caso em que há 4096 processos, o MHSA encontra as melhores soluções, devido à maneira como distribui as cargas entre os diferentes computadores, ou seja, com base nos tempos de fila. Deve-se, ainda, levar em consideração que instâncias de escalonamento reais apresentam quantidades ainda maiores de processos, o que justifica a adoção do algoritmos MHSA, cujas soluções de escalonamento são mais eficientes que as encontradas pelos demais algoritmos.

Finalmente, na Tabela 4.4, tem-se o tempo de execução médio, bem como o desvio padrão, desses algoritmos. Assim como nas simulações anteriores, todas as etapas requeridas na execução desses algoritmos forma consideradas no cálculo do tempo. Observa-se que, apesar de envolver a construção e manutenção de uma árvore min-heap, o MHSA tem desempenho próximo aos algoritmos Random e RR, os quais têm baixa complexidade assintótica. Observa-se, também, que o algoritmo Ls é o menos eficiente, pois seu tempo de execução cresce linearmente em relação ao total de computadores do sistema.

\subsection{Discussão}

Com base nas simulações apresentadas neste capítulo, conclui-se que o modelo de otimização matemática proposto (Seção 3.3) representa a alocação de processos sobre computadores, considerando os custos de processamento e comunicação entre processos. Essa conclusão surge a partir das Figuras 4.4 e 4.5, nas quais o algoritmo de força-bruta resultou em melhores soluções em termos do atraso ou custo total de execução avaliado pela 
Tabela 4.4: Tempo médio de execução (em segundos) apresentado pelos algoritmos Random, RR, LS e MHSA quando $|V|=1024$ computadores. É apresentado, também, o desviopadrão (em segundos).

\begin{tabular}{l|llll}
\hline$|P|$ & Random & RR & LS & MHSA \\
\hline 512 & $0,008 \pm 0,0003$ & $0,008 \pm 1,62 \mathrm{e}-05$ & $0,011 \pm 7,65 \mathrm{e}-06$ & $0,008 \pm 1,52 \mathrm{e}-05$ \\
1024 & $0,016 \pm 4,77 \mathrm{e}-04$ & $0,016 \pm 2,45 \mathrm{e}-05$ & $0,023 \pm 4,87 \mathrm{e}-04$ & $0,017 \pm 3,47 \mathrm{e}-04$ \\
2048 & $0,033 \pm 0,001$ & $0,033 \pm 0,001$ & $0,048 \pm 0,002$ & $0,036 \pm 0,008$ \\
4096 & $0,065 \pm 0,0005$ & $0,066 \pm 0,003$ & $0,09 \pm 0,0001$ & $0,06 \pm 0,0001$ \\
\hline
\end{tabular}

função $\delta(\mathbf{S})$. Analogamente, o GA encontrou bons resultados para $\delta(\mathbf{S})$ nas Figuras 4.6 e 4.7.

Os resultados também permitem concluir que o MHSA reduziu o atraso ou custo total ao mesmo tempo que evitou a solução trivial, atribuindo processos a mais de um computador, melhorando assim a distribuição de carga entre recursos, principalmente em instâncias maiores, quando a carga de trabalho atribuída aos computadores é grande (Figura 4.8). Em complemento, conclui-se que o MHSA propõe soluções de boa qualidade quando comparado a outros algoritmos encontrados na literatura, além de ter complexidade de tempo conhecida e apresenta tempo de execução muito inferior ao algoritmo de força-bruta, à rotina linp e ao GA. Além disso, o MHSA garante, por ser um algoritmo de aproximação, qualidade mínima para as soluções produzidas, o que não se pode afirmar em relação ao linp e ao GA.

Finalmente, deve-se levar com consideração que, em cenários do mundo real, computadores com melhores processadores tendem a ter também melhores canais de comunicação. Além disso, tais cenários usualmente apresentam baixo volume de comunicação. De fato, até onde se sabe, em aglomerados de computadores, tal volume varia entre $5 \%$ e $25 \%$, enquanto em grades computacionais esse volume em geral é inferior a $5 \%$ (NPB, 2012). Complementarmente, a heterogeneidade de sistemas distribuídos tende a não ser tão alta, especialmente em ambientes científicos. Consequentemente, o MHSA pode prover boas razões de aproximação em relação a um escalonador ótimo, ao mesmo tempo que o modelo proposto pode guiar adequadamente algoritmos baseados em heurísticas.

\subsection{Considerações Finais}

Neste capítulo foram apresentados resultados de simulações com o objetivo de comparar o algoritmo MHSA a outros algoritmos de escalonamento em termos do atraso ou custo total $\delta(\mathbf{S})$ (Seção 3.3). A escolha do algoritmo de força-bruta se deve ao fato de produzir a melhor solução possível para toda instância do problema de escalonamento, sendo portanto um escalonador ótimo. A escolha da rotina linp se deve ao fato dela resolver o modelo de otimização matemática utilizando relaxações que tendem a permitir a obtenção 
de soluções com qualidade aceitável a menor custo de execução quando comparada ao força-bruta. O GA foi escolhido por ser uma meta-heurística muito utilizada e com bons resultados reportados na literatura (MELLO et al., 2008; OMARA; ARAF, 2010; MA et al., 2011). O algoritmo LS fui utilizado por ser, assim como o MHSA, uma algoritmo de aproximação, porém projetado apenas para cenários homogêneos sem comunicação. Finalmente, os algoritmos Random e RR são utilizados como base de comparação em diversos trabalhos.

Os resultados mostrados neste capítulo permitiram concluir que o algoritmo MHSA é eficiente e produz boas soluções de escalonamento. Além disso, provê garantias mínimas de qualidade para soluções e é um algoritmo orientado a sistemas, comprovando a hipótese desta tese. Esses resultados motivam, ainda, estudos posteriores, os quais buscarão maneiras alternativas para construir a árvore min-heap, permitindo melhorar a razão de aproximação do MHSA. 


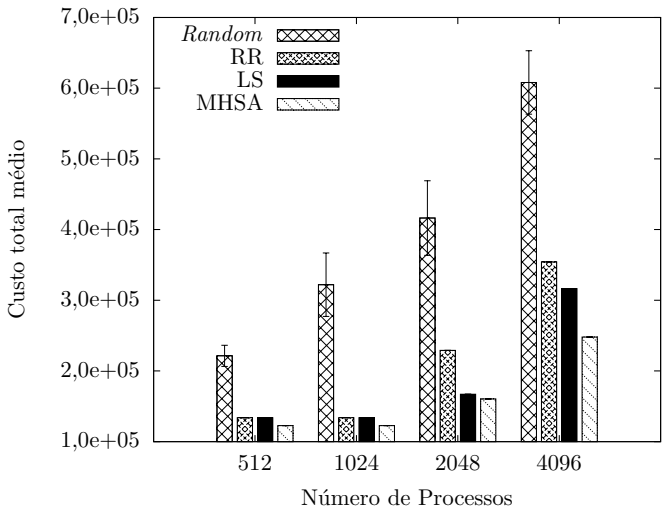

(a) $0 \%$

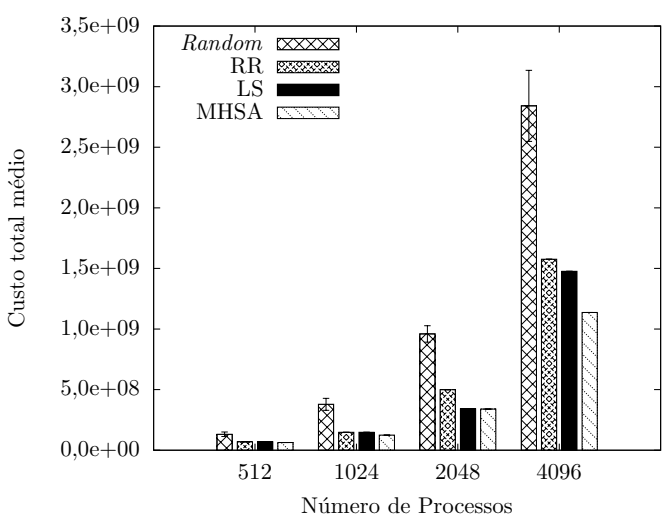

(c) $5 \%$

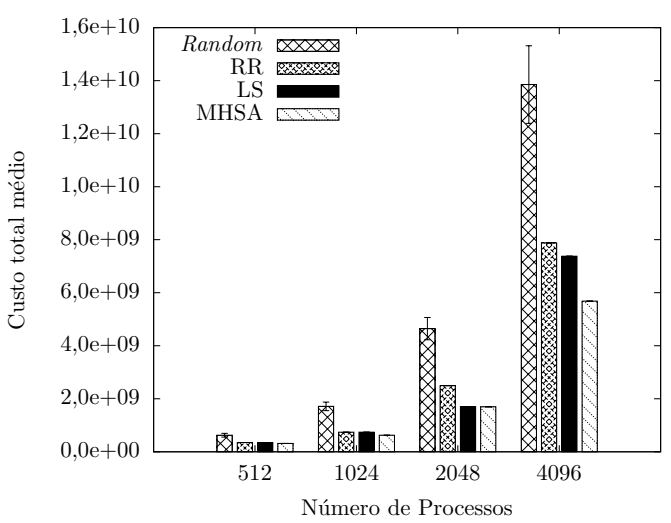

(e) $25 \%$

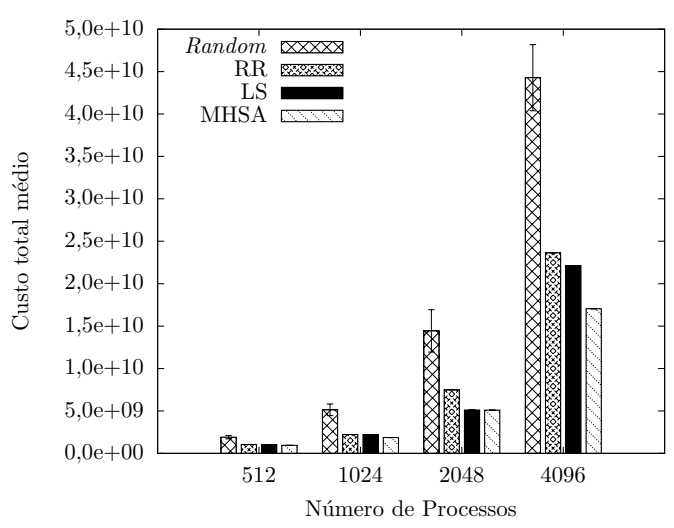

(g) $75 \%$

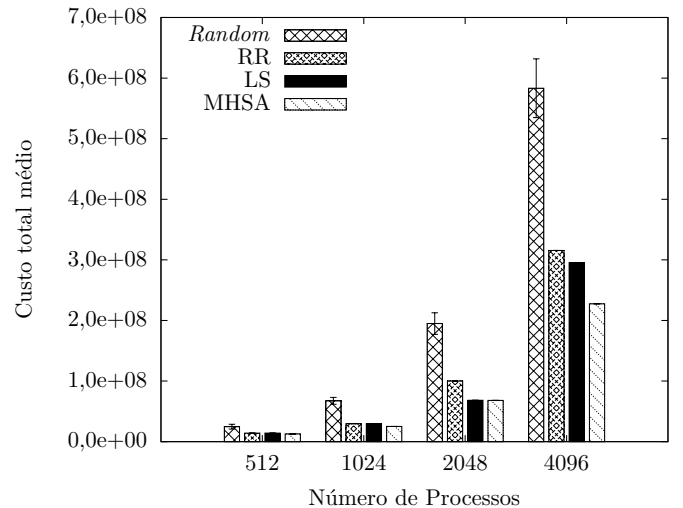

(b) $1 \%$

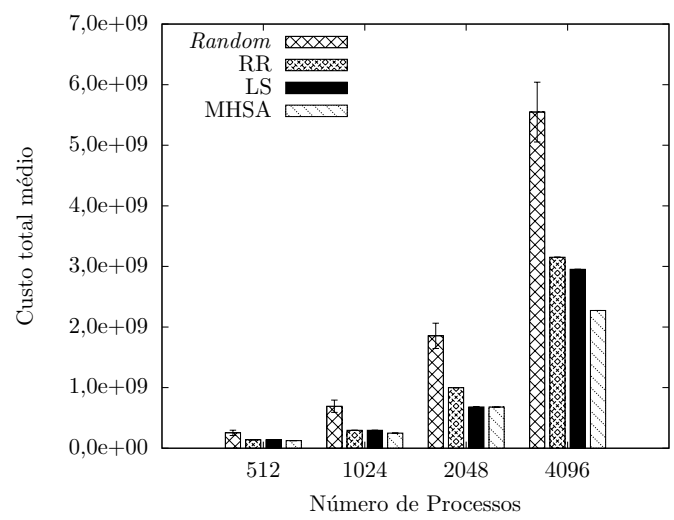

(d) $10 \%$

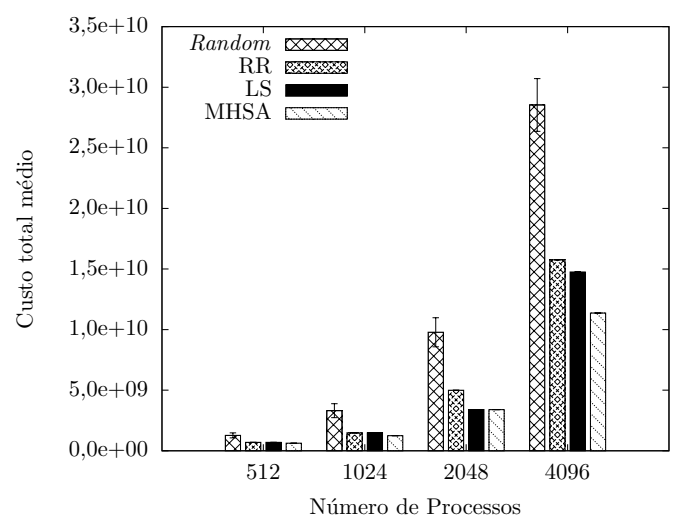

(f) $50 \%$

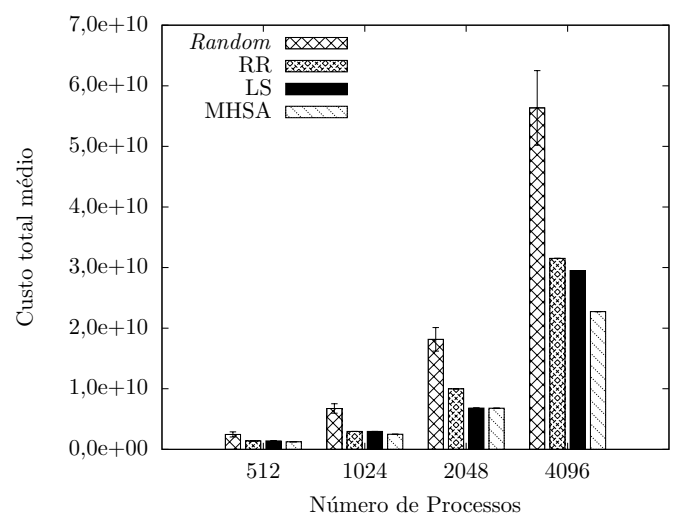

(h) $100 \%$

Figura 4.8: Resultados de simulações em que o número de computadores constante $|V|=$ 1024 e o número de processos varia na forma $|P|=\{512,1024,2048,4096\}$. 


\section{Conclusões}

\subsection{Contribuições}

A redução no custo de manufatura de microcomputadores e a rápida evolução das tecnologias de rede tornou viável o projeto e implementação de ambientes computacionais distribuídos, tais como aglomerados e grades computacionais. Esses ambientes são construídos com o objetivo de executar aplicações de alta demanda computacional. Com o desenvolvimento desses ambientes, novos desafios surgiram, dentre os quais se destaca o escalonamento de processos, o qual busca pela alocação eficiente de aplicações paralelas sobre os recursos disponíveis.

Nesse sentido, abordagens de escalonamento orientado a sistemas têm recentemente recebido maior destaque, pois otimizam tanto o tempo de execução de aplicações, garantindo a satisfação de usuários do sistema, quanto a ocupação de recursos, justificando a aquisição de equipamentos e reduzindo os desperdícios provenientes da depreciação desses bens.

Algoritmos heurísticos e de aproximação têm sido propostos com o objetivo de resolver o problema de escalonamento orientado a sistemas. Os heurísticos buscam por soluções de maneira eficiente sem apresentar garantias quanto à qualidade das soluções obtidas. Em contrapartida, os algoritmos de aproximação provêm tais garantias, contudo são mais difíceis de serem projetados, o que justifica o fato de haver apenas versões simplificadas desses algoritmos para cenários de escalonamento de processos.

A falta de algoritmos de aproximação adequados para abordar o problema de escalonamento de processos e a necessidade de soluções que atendam o escalonamento ori- 
entado a sistemas motivaram esta tese de doutorado que apresentou a proposta do Min Heap-based Scheduling Algorithm (MHSA), um algoritmo de aproximação para o problema de escalonamento de processos orientado a sistemas. Diversas contribuições surgiram durante o desenvolvimento desse algoritmo.

A primeira contribuição, apresentada na Seção 3.2, trata de um estudo da complexidade envolvida no problema de escalonamento de processos sob o viés orientado a sistemas. Nesse estudo, foram mapeadas as duas principais classes de algoritmos de escalonamento, ou seja, o escalonamento orientado a aplicações e orientado a recursos, em dois clássicos problemas $\mathcal{N} \mathcal{P}$-Completos. Consequentemente, o escalonamento orientado a sistemas, objeto de interesse desta tese, é também um problema $\mathcal{N} \mathcal{P}$-Completo, uma vez que combina ambas classes.

Após compreender a complexidade desse problema, propôs-se um modelo de otimização matemática (Equação (3.4)) que considera características de processos (número de instruções a serem executadas e volume de dados transferidos) e computadores (capacidade de CPU e largura de banda) para computar o impacto causado por aplicações sobre sistemas distribuídos em termos do atraso ou custo total de execução de processos. A convexidade desse modelo permite solucioná-lo utilizando métodos de otimização propostos na literatura ou, ainda, guiar o desenvolvimento de algoritmos baseados em heurísticas.

O alto custo computacional de métodos de otimização exatos, além do custo envolvido na utilização de um método de programação linear que considera a relaxação do modelo de otimização matemática proposto, motivou o projeto do Min Heap-based Scheduling Algorithm (MHSA). Esse algoritmo constrói uma árvore min-heap com base na carga de trabalho individual dos computadores do ambiente a fim de escalonar processos. Quando um processo chega ao sistema, o MHSA o atribui ao computador posicionado como raiz da árvore. Em seguida, a carga de trabalho desse computador é atualizada e esse nó raiz tende a ser movido em direção às folhas. Consequentemente, o algoritmo MHSA tem complexidade assintótica da ordem de $\mathcal{O}(1)$ para a operação de escalonamento, e $\mathcal{O}\left(\log _{2}|V|\right)$ para a atualização da min-heap, em que $|V|$ corresponde ao número de computadores do ambiente distribuído. Outra contribuição relevante advém de estudos da razão de aproximação do MHSA em relação a um escalonador ótimo. Esses estudos permitem conhecer a qualidade das soluções propostas pelo MHSA antes mesmo dele ser considerado em um ambientes distribuído heterogêneo, seja para aplicações do tipo bag-of-tasks, quanto para aplicações que apresentam diferentes níveis de comunicação entre processos.

Experimentos foram conduzidos de modo a comparar o MHSA a outros algoritmos de escalonamento. Considerou-se simulações envolvendo um algoritmo de força-bruta, a rotina linp para resolução de problemas de otimização linear e um algoritmo genético (GA), além do algoritmo proposto. Resultados confirmaram que o modelo de otimização matemática proposto leva a boas soluções de escalonamento, permitindo a redução do makespan ao mesmo tempo em que melhora a utilização de recursos. Também foi possível observar 
que as soluções geradas pelo MHSA têm melhor qualidade quando comparadas às encontradas por outros algoritmos de escalonamento disponíveis na literatura, ou seja, Random, Round-Robin (RR) e List Scheduling (LS), principalmente em cenários em que a carga de trabalho submetida ao sistema é alta. Além disso, o MHSA é eficiente e apresenta como benefício o fato de ser um algoritmo de aproximação.

\subsection{Trabalhos Futuros}

Os resultados desta tese de doutorado motivam a análise do modelo de otimização matemática proposto para o escalonamento de aplicações em ambientes dinâmicos, nos quais suas variáveis são modificadas ao longo do tempo. Esse estudo pode ser utilizado como base para outros trabalhos desenvolvidos pelo grupo de pesquisa no qual esta tese está inserida (MELLO; YANG, 2008; MELLO, 2009; DODONOV; MELLO, 2010). Assim, espera-se avaliar a adaptação de decisões de escalonamento à medida em que informações do ambiente são modificadas, tais como aquelas relativas ao comportamento de processos e recursos. É possível, também, avaliar o impacto de estratégias de coleta de informações relativas ao estado atual do sistema sobre a construção de estimativas de carga utilizadas para parametrizar o modelo proposto.

Com relação ao MHSA, novos estudos serão conduzidos de modo a melhorar sua razão de aproximação. Pode-se, por exemplo, considerar outras métricas na construção da árvore min-heap, de modo a obter soluções de escalonamento mais adequadas.

\subsection{Publicações}

Esta tese resultou nas seguintes publicações:

1. GABRIEL, P. H. R.; MELLO, R. F. de. Uma abordagem orientada a sistemas para otimização de escalonamento de processos em grades computacionais. In: SENGER, H.; AZEVEDO, R. J. de (Ed.). Escola Regional de Alto Desempenho de São Paulo, 1., 2010, São Paulo, Anais... São Paulo: Universidade Presbiteriana Mackenzie, 2010. p. $67-70$.

2. GABRIEL, P. H. R.; MELLO, R. F. de. Predição de comportamento de processos utilizando conceitos de sistemas dinâmicos. In: PANETTA, J. (Ed.). Escola Regional de Alto Desempenho de São Paulo, 2., 2011, São José dos Campos. São José dos Campos/SP: Departamento de Ciência e Tecnologia Aeroespacial, 2011.

3. GABRIEL, P. H. R.; MELLO, R. F. de. Scheduling based on process behavior analysis. In: MUSICANTE, M. A.; BATISTA, T. V. (Ed.). Congresso da Sociedade Brasileira de 
Computação, 31., 2011, Natal. Anais.... Porto Alegre: Sociedade Brasileira de Computação, 2011. p. 2033-2046.

4. GABRIEL, P. H. R.; MELLO, R. F. de. Modelo do comportamento de cargas de ambientes distribuídos. In: AZEVEDO, R. J. de (Ed.). Escola Regional de Alto Desempenho de São Paulo, 3., 2012, Campinas, Anais.... Campinas: Universidade Estadual de Campinas, 2012. p. 60-63.

5. GABRIEL, P. H. R.; MELLO, R. F. de. Modelling distributed computing workloads to support the study of scheduling decisions. International Journal of Computational Science and Engineering, 2013. No prelo.

O artigo "Formalization of the distributed process scheduling problem: An approach towards optimal bounds" foi submetido para o períodico internacional IEEE Transactions on Parallel and Distributed Systems. Nesse artigo, estão contidos os principais resultados desta tese: o modelo de otimização matemática e o algoritmo MHSA. Finalmente, dois outros trabalhos envolvendo os resultados experimentais apresentados no Capítulo 4 desta tese e a análise dos impactos causados por decisões de escalonamento em regiões de uma grade computacional estão em fase de elaboração. 
ARABNEJAD, $\mathrm{H}$. List based task scheduling algorithms on heterogeneous systems: An overview. In: OLIVEIRA, E.; SOUSA, A. A.; DAVID, G. (Ed.). Doctoral Symposium in Informatics Engineering. Porto: Faculdade de Engenharia da Universidade do Porto, 2012. p. 93-102.

ARABNEJAD, H.; BARBOSA, J. G. Performance evaluation of list based scheduling on heterogeneous systems. In: ALEXANDER, M.; D'AMBRA, P.; BELLOUM, A.; BOSILCA, G.; CANNATARO, M.; DANELUTTO, M.; MARTINO, B. D.; GERNDT, M.; JEANNOT, E.; NAMYST, R.; ROMAN, J.; SCOTT, S. L.; TRÄFF, J. L.; VALLÉE, G.; WEIDENDORFER, J. (Ed.). International Conference on Parallel Processing. Berlin Heidelberg: Springer-Verlag, 2011. (Lecture Notes in Computer Science, v. 7155), p. 440-449.

ARENAles, M.; ARMENTANO, V. A.; MORABITO, R.; YANASSE, H. H. Pesquisa operacional. Rio de Janeiro, RJ: Elsevier Editora Ltda., 2007. 524 p. (Coleção Campus-Abepro).

BENNETT, K. Intel Core i7-3960X - Sandy Bridge E Processor Review. 2011. Disponível em: hardocp.com/article/2011/11/14/intel_core_i73960x_sandy_bridge_e_ processor_review/. Acesso em: 20 Nov. 2012.

BERTSEKAS, D. P. Constrained Optimization and Lagrange Multiplier Methods. Belmont: Athena Scientific, 1996. 395 p.

BITTENCOURT, L.; SAKELLARIOU, R.; MADEIRA, E. DAG scheduling using a lookahead variant of the heterogeneous earliest finish time algorithm. In: DANELUTTO, M.; BOURGEOIS, J.; GROSS, T. (Ed.). Euromicro Conference on Parallel, Distributed and Network-based Processing. Washington: IEEE Computer Society, 2010. p. 27-34.

BLUM, C.; ROLI, A. Metaheuristics in combinatorial optimization: Overview and conceptual comparison. ACM Computing Surveys, v. 35, n. 3, p. 268-308, set. 2003. 
BOUGERET, M.; DUTOT, P.-F.; JANSEN, K.; OTTE, C.; TRYSTRAM, D. A fast 5/2approximation algorithm for hierarchical scheduling. In: D'AMBRA, P.; GUARRACINO, M. R.; TALIA, D. (Ed.). International Euro-Par Conference on Parallel processing: Part I. Berlin - Heidelberg: Springer-Verlag, 2010. (Lecture Notes in Computer Science, v. 6271), p. 157-167.

BOYD, S.; VANDENBERGHE, L. Convex Optimization. Cambridge: Cambridge University Press., 2004. 716 p. Disponível em: http://www. stanford.edu/ boyd/cvxbook/. Acesso em: 21 Mar. 2013.

BRAUN, T. D.; SIEGEL, H. J.; BECK, N.; BÖLÖNI, L. L.; MAHESWARAN, M.; REUTHER, A. I.; ROBERTSON, J. P.; THEYS, M. D.; YAO, B.; HENSGEN, D.; FREUND, R. F. A comparison of eleven static heuristics for mapping a class of independent tasks onto heterogeneous distributed computing systems. Journal of Parallel and Distributed Computing, v. 61, n. 6, p. 810-837, jun. 2001.

CARRETERO, J.; XHAFA, F.; ABRAHAM, A. Genetic algorithm based schedulers for grid computing systems. International Journal of Innovative Computing, Information and Control, v. 3, n. 5, p. 1053-1071, out. 2007.

CASAVANT, T. L.; KUHL, J. G. A taxonomy of scheduling in general-purpose distributed computing systems. IEEE Transactions on Software Engineering, v. 14, n. 2, p. 141-154, fev. 1988.

CHAPIN, S. J.; WEISSMAN, J. B. Distributed and multiprocessor scheduling. In: TRUCKER, A. B. (Ed.). Computer Science Handbook. 2. ed. Boston: CRC Press, 2004. cap. 88, p. 2752.

CHUNLIN, L.; LAYUAN, L. A system-centric scheduling policy for optimizing objectives of application and resource in grid computing. Computers and Industrial Engineering, v. 57, n. 3, p. 1052-1061, out. 2009.

COFFMAN JR., E. G.; GAREY, M. R.; JOHNSON, D. S. An application of bin-packing to multiprocessor scheduling. SIAM Journal on Computing, v. 7, n. 1, p. 1-17, fev. 1978.

CORMEN, T. H.; LEISERSON, C. E.; RIVEST, R. L.; STEIN, C. Introduction to Algorithms. 2. ed. Cambridge: The MIT Press, 2001. 1180 p.

DAVIDOVIĆ, T.; SELMIĆ, M.; TEODOROVIĆ, D.; RAMLJAK, D. Bee colony optimization for scheduling independent tasks to identical processors. Journal of Heuristics, v. 18, n. 4, p. 549-569, ago. 2012. 
DODONOV, E.; MELLO, R. F. de. A novel approach for distributed application scheduling based on prediction of communication events. Future Generation Computer Systems, v. 26, n. 5, p. 740-752, 2010.

DONG, F.; AKL, S. G. Scheduling Algorithms for Grid Computing: State of the Art and Open Problems. Kingston: School of Computing, Queen's University, jan. 2006. 55 p. (Relatório Técnico, 2006-504).

DONGARRA, J. J.; STEWART, G. LINPACK: A package for solving linear systems. In: COWELL, W. R. (Ed.). Sources and Development of Mathematical Software. New Jersey: Prentice-Hall, 1984. cap. 2, p. 20-48.

EAGER, D. L.; LAZOWSKA, E. D.; ZAHORJAN, J. Adaptive load sharing in homogeneous distributed systems. IEEE Trasactions on Software Engineering, v. 12, n. 5, p. 662-675, maio 1986.

EIBEN, A. E.; SMITH, J. E. Introduction to Evolutionary Computing. Berlin - Heidenberg: Sp, 2003. 299 p. (Natural Computing Series).

EVANS, M.; HASTINGS, N.; PEACOCK, B. Statistical Distributions. 3. ed. New York: Wiley-Interscience, 2000. 221 p. (Wiley Series in Probability and Statistics).

FALZON, G.; LI, M. Enhancing list scheduling heuristics for dependent job scheduling in grid computing environments. The Journal of Supercomputing, v. 59, n. 1, p. 104-130, jan. 2012.

FEITELSON, D. G.; RUDOLPH, L.; SCHWIEGELSHOHN, U.; SEVCIK, K. C.; WONG, P. Theory and practice in parallel job scheduling. In: Proceedings of the Job Scheduling Strategies for Parallel Processing. London: Springer-Verlag, 1997. p. 1-34.

FERNANDES, C. G.; MIYAZAWA, F. K.; CERIOLI, M.; FEOFILOFF, P. (Ed.). Uma introdução Sucinta a Algoritmos de Aproximação. Rio de Janeiro, RJ: Instituto Nacional de Matemática Pura e Aplicada, 2001. 157 p. (Publicações Matemáticas, 23o. Colóquio Brasileiro de Matemática). Disponível em: http: //www. impa.br/opencms/pt/biblioteca/cbm/23CBM/23_CBM_01_15.pdf. Acesso em: 19 Fev. 2013.

FIDANOVA, S.; DURCHOVA, M. Ant algorithm for grid scheduling problem. In: LIRKOV, I.; MARGENOV, S.; WAŚNIEWSKI, J. (Ed.). Large Scale Computing. Berlin - Heidelberg: Springer-Verlag, 2006. (Lecture Notes in Computer Science, v. 3743), p. 405-412.

FOSTER, I.; KESSELMAN, C. (Ed.). The Grid: Blueprint for a New Computing Infrastructure. San Francisco: Morgan Kaufmann Publishers Inc., 1998. 675 p. 
FOSTER, I.; ZHAO, Y.; RAICU, I.; LU, S. Cloud computing and grid computing 360-degree compared. In: Grid Computing Environments Workshop. Washington: IEEE Computer Society, 2008. p. 60-69.

FUJITA, S.; YAMASHITA, M. Approximation algorithms for multiprocessor scheduling problem. IEICE Transactions on Information and Systems, v. 83, p. 503-509, 2000.

GARA, A.; BLUMRICH, M.; CHEN, D.; CHIU, G.-T.; COTEUS, P.; GIAMPAPA, M.; HARING, R.; HEIDELBERGER, P.; HOENICKE, D.; KOPCSAY, G.; LIEBSCH, T. A.; OHMACHT, M.; STEINMACHER-BUROW, B. D.; TAKKEN, T.; VRANAS, P. Overview of the Blue Gene/L system architecture. IBM Journal of Research and Development, v. 49, n. 2.3, p. 195-212, mar. 2005.

GAREY, M. R.; GRAHAM, R. L.; JOHNSON, D. S. Performance guarantees for scheduling algorithms. Operations Research, v. 26, n. 1, p. 3-21, jan. 1978.

GAREY, M. R.; GRAHAM, R. L.; ULLMAN, J. D. Worst-case analysis of memory allocation algorithms. In: Annual ACM Symposium on Theory of computing. New York: ACM, 1972. p. $143-150$.

GAREY, M. R.; JOHNSON, D. S. Computers and Intractability: A Guide to the Theory of NP-Completeness. New York: W. H. Freeman \& Co., 1979. 338 p. (A Series of Books in the Mathematical Sciences).

GRAHAM, R. L. Bounds for certain multiprocessing anomalies. The Bell System Technical Journal, v. 45, n. 9, p. 1563-1581, nov. 1966.

. Bounds on multiprocessing timing anomalies. SIAM Journal on Applied Mathematics, v. 17, p. $416-426,1969$.

Bounds on multiprocessing anomalies and related packing algorithms. In: Spring Joint Computer Conference. New York: ACM, 1972. p. 205-217.

GUTIERREZ, S.; HJELM, N.; VENKATA, M.; GRAHAM, R. Performance evaluation of Open MPI on Cray XE/XK systems. In: Annual Symposium on High-Performance Interconnects. Washington: IEEE Computer Society, 2012. p. 40-47.

HAGRAS, T.; JANECEK, J. A simple scheduling heuristic for heterogeneous computing environments. In: International Symposium on Parallel and Distributed Computing. Washington: IEEE Computer Society, 2003. p. 104-110.

HALL, L. A. Approximation algorithms for scheduling. In: HOCHBAUM, D. S. (Ed.). Approximation Algorithms for NP-Hard Problems. Boston: PWS Publishing Company, 1997. cap. 1, p. 1-45. 
HAMSCHER, V.; SCHWIEGELSHOHN, U.; STREIT, A.; YAHYAPOUR, R. Evaluation of job-scheduling strategies for grid computing. In: BUYYA, R.; BAKER, M. (Ed.). International Workshop on Grid Computing. Berlin: Springer-Verlag, 2000. (Lecture Notes in Computer Sciences, 1971), p. 191-202.

HANEN, C.; MUNIER, A. An approximation algorithm for scheduling dependent tasks on $m$ processors with small communication delays. Discrete Applied Mathematics, v. 108, p. 239-257, 2001.

HWANG, J.-J.; CHOW, Y.-C.; ANGER, F. D.; LEE, C.-Y. Scheduling precedence graphs in systems with interprocessor communication times. SIAM Journal on Computing, v. 18, n. 2, p. 244-257, abr. 1989.

IBARRA, O. H.; KIM, C. E. Heuristic algorithms for scheduling independent tasks on nonidentical processors. Journal of ACM, v. 24, n. 2, p. 280-289, abr. 1977.

ILAVARASAN, E.; THAMBIDURAI, P.; MAHILMANNAN, R. High performance task scheduling algorithm for heterogeneous computing system. In: HOBBS, M.; GOSCINSKI, A. M.; ZHOU, W. (Ed.). Distributed and Parallel Computing. Berlin Heidelberg: Springer-Verlag, 2005. (Lecture Notes in Computer Science, v. 3719), p. 193-203.

JOHNSON, D. S. Approximation algorithms for combinatorial problems. Journal of Computer and System Sciences, v. 9, n. 3, p. 256-278, 1974.

KLEINROCK, L. Queueing Systems 1: Theory. New York: John Wiley \& Sons, Inc., 1975. $417 \mathrm{p}$.

KOUSALYA, K.; BALASUBRAMANIE, P. Ant algorithm for grid scheduling powered by local search. International Journal of Open Problems in Computer Science and Mathematics, v. 1, n. 3, p. 222-240, 2008.

LENSTRA, J.; KAN, A. R.; BRUCKER, P. Complexity of machine scheduling problems. Annals of Discrete Mathematics, v. 1, p. 343-362, 1977.

LUEKER, G. S. Two NP-complete problems in nonnegative integer programming. Princeton: Computer Science Laboratory, Princeton University, 1975. (Relatório Técnico, 178).

MA, T.; YAN, Q.; LIU, W.; GUAN, D.; LEE, S. Grid task scheduling: Algorithm review. IETE Technical Review, v. 28, n. 2, p. 158-167, mar./abr. 2011.

MAHESWARAN, M.; ALI, S.; SIEGEL, H. J.; HENSGEN, D.; FREUND, R. Dynamic matching and scheduling of a class of independent tasks onto heterogeneous 
computing systems. In: Heterogeneous Computing Workshop. Washington: IEEE Computer Society Press, 1999. p. 30-44.

MARTELLO, S.; TOTH, P. Knapsack problems: algorithms and computer implementations. New York: John Wiley \& Sons, Inc., 1990. 296 p.

MATTHEWS, P. C. Vector Calculus. 3. ed. Berlin - Heidelberg: Springer-Verlag, 2000. 200 p. (Springer Undergraduate Mathematics Series).

MELLO, R. F. de. Sistemas Dinâmicos e Técnicas Inteligentes para a Predição de Comportamento de Processos: Uma Abordagem para Otimização de Escalonamento em Grades Computacionais. Tese (Livre Docência) — Instituto de Ciências Matemáticas e de Computação, Universidade de São Paulo, São Carlos, SP, maio 2009.

MELLO, R. F. de; ANDRADE FILHO, J. A.; SENGER, L. J.; YANG, L. T. Grid job scheduling using route with genetic algorithm support. Telecommunication Systems, v. 38, n. 3-4, p. 147-160, 2008.

MELLO, R. F. de; SENGER, L. J.; YANG, L. T. Performance evaluation of route: A load balancing algorithm for grid computing. Revista de Informática Teórica e Aplicada, v. 13 , n. 1, p. $87-108,2006$.

MELLO, R. F. de; YANG, L. T. Prediction of dynamical, nonlinear, and unstable process behavior. The Journal of Supercomputing, v. 49, n. 1, p. 22-41, 2008.

MICHAEL, M.; MOREIRA, J.; SHILOACH, D.; WISNIEWSKI, R. Scale-up x scale-out: A case study using Nutch/Lucene. In: SAHOO, R. (Ed.). International Workshop on System Management Techniques, Processes, and Services. Washington: IEEE Computer Society, 2007.

MUNIER, A. Approximation algorithms for scheduling trees with general communication delays. Parallel Computing, v. 25, n. 1, p. 41-48, 1999.

NESMACHNOW, S.; CANCELA, H.; ALBA, E. Heterogeneous computing scheduling with evolutionary algorithms. Soft Computing, v. 15, p. 685-701, 2011.

NPB. NAS Parallel Benchmarks. 2012. Disponível em: http://www. nas.nasa.gov/ publications/npb.html.

OMARA, F. A.; ARAF, M. M. Genetic algorithms for task scheduling problem. Journal of Parallel and Distributed Computing, v. 70, p. 13-22, 2010. 
SCRUCCA, L. GA: A package for genetic algorithms in R. Journal of Statistical Software, v. 53, n. 4, p. 1-37, 2013. Disponível em: http://www.jstatsoft.org/v53/i04/. Acesso em: 22 Maio 2013.

SENGER, L. J.; MELLO, R. F.; SANTANA, M. J.; SANTANA, R. H. C. Aprendizado baseado em instâncias aplicado à predição de características de execução de aplicações paralelas. Revista de Informática Teórica e Aplicada, v. 14, p. 44-68, 2007.

SILBERSCHATZ, A.; GALVIN, P. B.; GAGNE, G. Operating System Concepts. 8. ed. EUA: John Wiley \& Sons, Inc., 2009. 972 p.

SOETAERT, K.; MEERSCHE, K. V. den; OEVELEN, D. van. limSolve: Solving Linear Inverse Models. [S.I.], 2009. R package 1.5.1.

STEFANO, A. D.; MORANA, G. A bio-inspired distributed algorithm to improve scheduling performance of multi-broker grids. Natural Computing, v. 11, p. 687-700, 2012.

STOCKINGER, H. Defining the grid: a snapshot on the current view. Journal of Supercomputing, v. 42, p. 3-17, 2007.

SUNDARAM, R. K. A First Course in Optimization Theory. Cambridge: Cambridge University Press, 1996. 357 p.

TOPCUOGLU, H.; HARIRI, S.; WU, M.-Y. Performance-effective and low-complexity task scheduling for heterogeneous computing. IEEE Transactions on Parallel and Distributed Systems, v. 13, n. 3, p. 260-274, mar. 2002.

WILLIAMSON, D. P.; SHMOYS, D. B. The Design of Approximation Algorithms. Cambridge: Cambridge University Press., 2010. 500 p.

XHAFA, F.; ABRAHAM, A. Computational models and heuristic methods for grid scheduling problems. Future Generation Computer Systems, v. 26, n. 4, p. 608-621, 2010.

XHAFA, F.; KOLODZIEJ, J.; DURAN, B.; BOGDANSKI, M.; BAROLLI, L. A comparison study on the performance of population-based meta-heuristics for independent batch scheduling in grid systems. In: International Conference on Complex, Intelligent and Software Intensive Systems. Washington: IEEE Computer Society, 2011. p. 123-130.

ZHOU, S.; FERRARI, D. An Experimental Study of Load Balancing Performance. Berkeley: EECS Department, University of California, jan. 1987. 27 p. (Número: UCB/CSD-87-336). 
Aglomerado Sistema computacional scale-out composto por computadores idênticos totalmente conectados entre si por uma rede de alto desempenho.

Algoritmo de aproximação Algoritmo que utiliza modelos formais de computação de modo a encontrar soluções cuja qualidade se aproxima do ótimo por um fator $\alpha$, denominado razão de aproximação.

Algoritmo de força-bruta Algoritmo que avalia todas as possíveis soluções para um determinado problema.

Algoritmo genético Algoritmo populacional inspirado nos mecanismos de seleção natural e evolução que, a partir de um conjunto de soluções candidatas, cria novas soluções por meio de operadores de reprodução: recombinação e mutação.

Algoritmo heurísticos Algoritmo que realizam buscas sistemáticas pelo espaço das possíveis soluções do problema, de modo a obter soluções adequadas para um problema de otimização em baixo tempo computacional.

Ambiente distribuído heterogêneo Sistema computacional scale-out composto por computadores com diferences capacidades em termo de processamento, interface de rede, etc.

Ambiente distribuído homogêneo Sistema computacional scale-out composto por computadores idênticos.

Aplicação Conjunto de processos que cooperam para resolver um problema individual.

Árvore heap Estrutura de dados que consiste em uma árvore binária balanceada com a seguinte propriedade: a chave de um nó tem uma determinada ordem em 
relação às chaves de seus dois filho. Caso a chave de $i$ seja menor que de seus filhos, a árvore é dita min-heap; caso contrário, tem-se uma max-heap.

Atraso total de execução Tempo em que os recursos mantém-se ocupados durante a execução de um conjunto de processos. $O$ atraso total leva em consideração 0 tempo gasto em processo e em operações de comunicação.

B

Bag-of-tasks Aplicação composta por processos que não se comunicam entre si.

C

Cluster O mesmo que aglomerado.

Completion time Tempo que um processo demanda para ser completamente executado.

Consumidor de recursos Processos de usuários ou do sistema que requerem determinados recursos computacionais para serem executados.

CPU-bound Aplicação com alta demanda de processamento, de modo que seu makespan depende exclusivamente da capacidade de CPU dos elementos de processamento.

$\mathbf{E}$

Elemento de processamento Unidade responsável pela execução de processos. Em ambientes scale-up, cada CPU é um elemento de processamento, enquanto que em ambientes scale-out cada computador do sistema é visto como um elemento de processamento.

Escalonamento de processos Método pelo qual processos e dados têm acesso a recursos computacionais (e.g., processadores, rede).

Escalonamento online Instância do problema de escalonamento de processos em que as informações sobre processos (número de instruções, grau de comunicação) não são conhecidas a priori, tornado-se disponíveis à medida que os processos chegam ao sistema.

Escalonamento orientado a aplicações Abordagem de escalonamento de processos cujo objetivo é reduzir o tempo de execução de aplicações de usuários. 
Escalonamento orientado a recursos Abordagem de escalonamento de processos cujo objetivo é aumentar a utilização de recursos (e.g., processadores, rede) computacionais.

Escalonamento orientado a sistemas Abordagem de escalonamento de processos cujo objetivo é, simultaneamente, reduzir o tempo de execução de aplicações e aumentar a utilização de recursos.

$\mathbf{F}$

Flowtime Soma dos tempos de execução de todos processos de uma aplicação.

G

Garantia de desempenho $O$ mesmo que razão de aproximação.

Grade Sistema computacional scale-out composto por computadores heterogêneos, geograficamente distribuídos, que compartilham recursos remotamente.

Grid $\quad$ mesmo que grade.

$\mathbf{L}$

linp Rotina que utiliza bibliotecas do LINPACK para resolução de problemas de programação linear e inteira.

LINPACK Biblioteca de programas para resolução de problemas de álgebra linear. É escrito em linguagem Fortran.

\section{$\mathbf{M}$}

Makespan Tempo de execução de uma aplicação, dado pelo tempo em que o último processo tem sua execução finalizada.

Meta-heurítica Método que busca, iterativamente, melhorar a qualidade de uma solução candidata respeitando medidas de qualidade. Considera pouca ou nenhuma informação sobre o domínio do problema e pode realizar buscas em grandes espaços de soluções.

Meta de escalonamento O mesmo que objetivo de escalonamento.

Mutação Operador de reprodução implementado em algoritmos genéticos para modificar aleatoriamente uma solução candidata, gerando novas soluções. 
$\mathbf{0}$

Objetivo de escalonamento Critério segundo o qual uma solução de escalonamento deve ser encontrada. Pode ser, por exemplo, a redução do makespan ou aumento da vazão do sistema.

$\mathbf{P}$

Política de escalonamento O mesmo que algoritmo de escalonamento.

Processo Unidade de computação em um sistema. Visto também como uma instância de um programa em execução.

Provedor de recursos Elemento de processamento que disponibiliza algum recurso computacional (processamento, memória, rede, disco rígido) para execução de processos.

$\mathbf{R}$

Random Algoritmo de escalonamento que escolhe aleatoriamente os computadores que receberão processos.

Razão de aproximação Razão entre a valor numérico solução gerada em relação à solução ótima.

Recombinação Operador de reprodução implementado em algoritmos genéticos para combinar características de duas ou mais soluções candidatas, gerando novas soluções.

Restrições temporais No contexto dessa tese, refere-se à busca por algoritmos que produzam soluções em tempo hábil.

Round-Robin Algoritmo de escalonamento que organiza os computadores do sistema distribuído em uma lista circular, atribuindo-lhes processos sequencialmente.

$\mathbf{S}$

Scale-out Ambiente de computação de alto desempenho cuja escalabilidade cresce de maneira horizontal, ou seja, pela adição de novos computadores ao sistema.

Scale-up Ambiente de computação de alto desempenho cuja escalabilidade cresce maneira vertical, ou seja, pela adição recursos (e.g., processadores, memória) a um único computador. 
Software Conjunto de instruções a serem seguidas e/ou executadas por um computador, na manipulação, redirecionamento ou modificação de um dado/informação ou acontecimento. Também chamado de programa.

\section{$\mathbf{T}$}

Tempo de execução de uma aplicação O mesmo que makespan.

Tempo de resposta de uma aplicação O mesmo que makespan.

\section{V}

Vazão Número de requisições processadas por um sistema computacional.

Vetor de computadores Estrutura de dados utilizada pelo MHSA para armazenar informações sobre computadores: identificador, capacidade e tempo de fila. 
Neste capítulo são apresentados os principais conceitos relacionados ao método dos multiplicadores de Lagrange, bem como sua interpretação geométrica e um exemplo prático. Esse capítulo se baseia principalmente em Boyd e Vandenberghe (2004).

\section{A.1 Conceitos}

Seja um problema de otimização apresentado em sua forma padrão (A.1):

$$
\begin{array}{ll}
\text { minimizar } & f_{0}(x) \\
\text { sujeito a } & f_{i}(x) \leq 0, \quad i=1, \ldots, m \\
& h_{i}(x)=0, \quad i=1, \ldots, p \\
& x \in X,
\end{array}
$$

sendo que $f_{0}$ é a função objetivo, ou seja, a função ser minimizada sujeita a dois tipos de restrição. A restrição $x \in X$ é dita restrição regional, pois delimita os valores da variável de decisão $x$ para os quais a solução do problema de otimização é válida. Por exemplo, pode-se ter $x \geq 0$. Por outro lado, as restrições $f_{i}(x) \leq 0$ e $h_{i}(x)=0$ são chamadas restrições funcionais, uma vez que os possíveis valores de $x$ estão limitados aos domínios dessas funções.

Supõe-se que o domínio da função $f_{0}(x)$, dado por $\mathcal{D}=\bigcap_{i=0}^{m} \operatorname{dom} f_{i} \cap \bigcap_{i=0}^{p} \operatorname{dom} h_{i}$, é não-vazio e a solução ótima do problema (A.1) é denotada por $f_{0}\left(x^{*}\right)$. É necessário que 
as funções $f_{0}, f_{i}$ e $h_{i}$ tenham primeira derivada contínua.

A ideia básica do método dos multiplicadores Lagrange é utilizar as restrições do problema para modificar a função objetivo, tornando-a uma soma ponderada. Assim, define-se a função de Lagrange (ou Langrangiana) $\Lambda: \mathbb{R}^{n} \times \mathbb{R}^{m} \times \mathbb{R}^{p} \rightarrow \mathbb{R}$ associado ao problema (A.1) da seguinte maneira:

$$
\Lambda(x, \lambda, \nu)=f_{0}(x)+\sum_{i=1}^{m} \lambda_{i} f_{i}(x)+\sum_{i=1}^{p} \nu_{i} h_{i}(x)
$$

cujo domínio é dado por $\operatorname{dom} \Lambda=\mathcal{D} \times \mathbb{R}^{m} \times \mathbb{R}^{p}$. Os vetores $\lambda$ e $\nu$ são denominados multiplicadores de Lagrange ou variáveis duais associadas ao problema (A.1). Pode-se, assim, resolver a função Lagrangiana sujeita apenas à restrição regional, tornando mais simples a solução do problema.

Define-se, também, a chamada função dual de Lagrange (ou simplesmente função dual) $g: \mathbb{R}^{m} \times \mathbb{R}^{p} \rightarrow \mathbb{R}$ como sendo o valor mínimo da Lagrangiana sobre $x$, ou seja:

$$
g(\lambda, \nu)=\inf _{x \in \mathcal{D}} \Lambda(x, \lambda, \nu)=\inf _{x \in \mathcal{D}}\left(f_{0}(x)+\sum_{x=1}^{m} \lambda_{i} f_{i}(x)+\sum_{i=1}^{p} \nu_{i} h_{i}(x)\right) .
$$

Uma importante propriedade da função dual, que justifica a adoção do método de Lagrange, é dada pelo seguinte resultado:

$$
g(\lambda, \nu) \leq f\left(x^{*}\right)
$$

ou seja, essa função produz limites inferiores para o valor ótimo $f\left(x^{*}\right)$ do problema (A.1), para $\lambda \geq 0$ e qualquer $\nu$ (BOYD; VANDENBERGHE, 2004).

Esse limitante inferior é ilustrado na Figura A.1, adaptada de Boyd e Vandenberghe (2004), para um problema com $x \in \mathbb{R}$ e apenas uma restrição de desigualdade. Nessa figura, a linha sólida mostra a função objetivo $f_{0}$ e a curva tracejada é a restrição $f_{1}$. O conjunto de soluções factíveis está no intervalo $[-0,46,0,46]$, indicado pelas duas linhas pontilhadas verticais. O valor ótimo é, portanto $f\left(x^{*}\right)=1,54$, quando $x^{*}=-0,46$. As curvas pontilhadas mostram a função Lagrangiana $\Lambda(x, \lambda)$ para $\lambda=0,1, \ldots, 1,0$. Cada uma dessas curvas tem mínimo menor que $f\left(x^{*}\right)$, uma vez que sobre o conjunto factível, para $\lambda \geq 0$, tem-se que $\Lambda(x, \lambda) \leq f_{0}(x)$.

Conclui-se, assim, que para cada par $(\lambda, \nu) \operatorname{com} \lambda \geq 0$, a função dual de Lagrange fornece um limitante inferior para o valor de $f_{0}\left(x^{*}\right)$ do problema de otimização (A.1). Basta, portanto, resolver o seguinte problema de maximização (A.4):

$$
\begin{array}{ll}
\text { maximizar } & g(\lambda, \nu) \\
\text { sujeito a } & \lambda \leq 0
\end{array}
$$




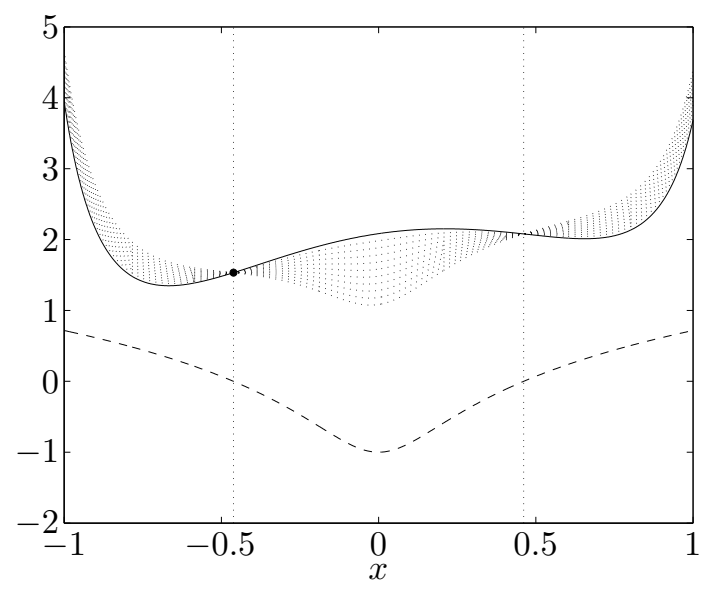

Figura A.1: Limitantes inferiores para um ponto dual factível, adaptado de Boyd e Vandenberghe (2004).

Esse problema é denominado problema dual de Lagrange, associado ao problema (A.1). Nesse contexto, o problema (A.1) é também chamado problema primal. É possível demonstrar que, mesmo quando o problema primal não é convexo, o problema dual será convexo (BOYD; VANDENBERGHE, 2004). Esse resultado é importante uma vez que, consequentemente, a solução ótima do problema (A.4) está contida em um conjunto convexo de soluções factíveis, simplificando a busca.

\section{A.2 Exemplo Numérico}

A fim ilustrar os conceitos apresentados na Seção A.1, seja o seguinte problema de maximização, adaptado de Sundaram (1996):

$$
\begin{array}{ll}
\text { maximizar } & x+y \\
\text { sujeito a } & x^{2}+y^{2}=1 \\
& x \in \mathbb{R}, y \in \mathbb{R} .
\end{array}
$$

Geometricamente, tem-se que as soluções factíveis formam um círculo de raio unitário em $\mathbb{R}^{3}$, sendo que o máximo ocorre no ponto $\left(x_{1}, y_{2}\right)=\left(\frac{\sqrt{2}}{2}, \frac{\sqrt{2}}{2}\right)$ e o mínimo é o ponto $\left(x_{2}, y_{2}\right)=\left(-\frac{\sqrt{2}}{2},-\frac{\sqrt{2}}{2}\right)$. Dessa maneira, $f(x, y)=x+y$ e $g(x, y)-b=x^{2}+y^{2}-1$. Consequentemente, aplicando-se o método dos multiplicadores de Lagrange, tem-se:

$$
\Lambda(x, y, \lambda)=f(x, y)+\lambda(g(x, y)-b)=x+y+\lambda\left(x^{2}+y^{2}-1\right) .
$$

A fim de resolver esse novo problema de otimização, calcula-se seu gradiente:

$$
\nabla_{x, y, \lambda} \Lambda(x, y, \lambda)=0
$$


resultando no seguinte sistema de equações:

$$
\begin{aligned}
& \frac{\partial \Lambda}{\partial x}=1+2 \lambda x=0 \\
& \frac{\partial \Lambda}{\partial y}=1+2 \lambda y=0 \\
& \frac{\partial \Lambda}{\partial \lambda}=x^{2}+y^{2}-1=0
\end{aligned}
$$

sendo que a última equação é a própria restrição. Resolvendo-se esse sistema, tem-se que, para $\lambda \neq 0, x=\frac{-1}{\sqrt{2} \lambda}$ e $y=\frac{-1}{\sqrt{2} \lambda}$, o que implica $\lambda= \pm \frac{1}{\sqrt{2}}$. Substituindo os valores de $\lambda$ nas demais equações, obtém-se dois pontos estacionários, ou seja: $\left(x_{1}, y_{2}\right)=\left(\frac{\sqrt{2}}{2}, \frac{\sqrt{2}}{2}\right)$ e $\left(x_{2}, y_{2}\right)=\left(-\frac{\sqrt{2}}{2},-\frac{\sqrt{2}}{2}\right)$.

Finalmente, avalia-se ambos pontos, o que resulta em $f\left(x_{1}, y_{1}\right)=\sqrt{2}$, que é o ponto de máximo, e $f\left(x_{2}, y_{2}\right)=-\sqrt{2}$, que é o mínimo. Logo, a solução para o problema de otimização (A.5) é $\left(x^{*}, y^{*}\right)=\left(\frac{\sqrt{2}}{2}, \frac{\sqrt{2}}{2}\right)$. 